University of Rhode Island

DigitalCommons@URI

Open Access Dissertations

1981

\title{
National Stereotypes and Their Relationship to Self-Perceptions in Irish, Italian, and American College Students
}

Caroline M. Salvatore

University of Rhode Island

Follow this and additional works at: https://digitalcommons.uri.edu/oa_diss

\section{Recommended Citation}

Salvatore, Caroline M., "National Stereotypes and Their Relationship to Self-Perceptions in Irish, Italian, and American College Students" (1981). Open Access Dissertations. Paper 1098.

https://digitalcommons.uri.edu/oa_diss/1098

This Dissertation is brought to you for free and open access by DigitalCommons@URI. It has been accepted for inclusion in Open Access Dissertations by an authorized administrator of DigitalCommons@URI. For more information, please contact digitalcommons-group@uri.edu. 
NATIONAL STEREOTYPES AND THEIR RELATIONSHIP TO SELF-PERCEPTIONS IN IRISH, ITALIAN, AND AMERICAN COLLEGE STUDENTS

BY

CAROLINE M. SALVATORE -

A DISSERTATION SUBMITTED IN PARTIAL FULFILLMENT OF REQUIREMENTS FOR THE DEGREE OF DOCTOR OF PHILOSOPHY

IN

PSYCHOLOGY

$$
8918019
$$

UNIVERSITY OF RHODE ISLAND 


\section{ABSTRACT}

This study examined self perceptions, and, their relationship to heterostereotypes and autostereotypes in three groups: Irish students from the University Colleges of Dublin, Galway, and St. Patrick's College in Dublin; Italian students from the-University of Palermo in Sicily; and American students at the Community College of Rhode Island, Bryant College, and the University of Rhode Island.

It was predicted that, as a reflection of greater cultural homogeneity, a higher degree of within-group similarity would be found in the self perceptions of both Italian and Irish students than in the self perceptions of American students. It was further predicted that differences would be found across the three groups in the saliency of certain self-perceived "traits". Finally, it was predicted that heterostereotypes would show a substantial degree of correspondence both with autostereotypes and self perceptions.

The samples consisted of 186 Irish students, 89 males and 97 females; 179 Italian students, 83 males and 96 females; and 190 American students, 90 males and 100 females.

Students in each group responded to two open-ended questions asking them to describe, in ten adjectives or fewer, their picture of the "typical" member of the other two groups. Ethnic stereotypes of Irish, Italians, and Americans thus elicited were then compared to each group's picture of its own "typical member" (autostereotype), and to the self perceptions of group members. 
Autostereotypes were measured by asking students to select, from the 81-word checklist of the Activity Vector Analysis (AVA) all those adjectives which best describe the "typical member" of their own cultural group.

Self perceptions were measured in two ways: the subjects responded to the AVA adjective checklist a second time by choosing all those adjectives which "best describe the person you really are". Subjects also completed the 126-item, forced-choice Myers-Briggs Type Indicator (MBTI). The AVA yields scores on four vectors: aggressiveness, sociability, emotional control and social adaptability. Ipsative scores on these four vectors combine in different ways to form 258 possible "personality profile" descriptions. The MBTI yields scores on four dichotomous preferences: introversion versus extraversion; sensing versus intuition; thinking versus feeling; and judging versus perceiving. A subject's preference within each dichotomy yields a four-letter "type description"; there are sixteen possible types.

Very little correspondence was found among heterostereotypes and either autostereotypes or self-perceptions, except for a few isolated traits. However, distributions of MBTI scores for both the Irish and Italian samples showed greater homogeneity than either the American sample or the normative U.S. sample of 3860 college students used for comparison purposes. The Irish sample was found to have a significantly greater proportion of "introverted, intuitive, feeling, perceptive" types while the Italian sample had a significantly greater proportion of "extraverted, sensing, thinking judging" types, than either the American sample or the normative U.S. sample. American students showed a 
greater-than-expected frequency of "sensing feeling" types than in the U.S. normative sample but overall the American sample was distributed more heterogeneous Ty across the MBTI types than the Irish and Italian samples. Tight clusters for the self-perceptions of students as measured by the AVA profiles were also found for the Italian students, with $84 \%$ of the sample clustered tightly around either one of two AVA pattern shapes. The AVA distributions of both Irish and American students were more heterogeneous, with approximately $65 \%$ of each sample found in three clusters on the AVA pattern universe. 


\section{ACKNOWLEDGMENTS}

This dissertation is dedicated, with the deepest gratitude, affection, and esteem, to my major professor, Dr. Peter F. Merenda. Words cannot adequately convey my thanks for his unfailing patience, wisdom, and support, not only during the progress of this research, but in the eight years it has been my privilege to be his student.

To each of the members of my committee, to Dr. Stanley Berger, Dr. Albert Lott, and Dr. Richard Purne11, for the time, effort, and excellent advice generously given during the successive phases of this research, I extend my deepest appreciation.

Research is always a cooperative effort, but the implementation of this particular study would have been impossible without the extraordinary measure of help received from colleagues in Ireland and Italy who obtained samples and collected data for me in those two countries. I offer very special thanks to Dr. Patricia Fontes, research scientist and lecturer at the Educational Research Centre, St. Patrick's College, Dublin; Dr. Christopher Sims, lecturer at the University College of Dublin; Ms. Pamela Merenda, lecturer at the University of Palermo, Sicily; and Ms. Rosalia Sparacino, lecturer at the University of Palermo, Sicily.

The translation into Italian of the test instruments used in this study was a crucial step in the research. For the time and painstaking care they generously devoted to this task, I am indebted to my husband, Dr. Santo Salvatore, and to Dr. Remo Trevelli, Professor of Italian in the Department of Languages, University of Rhode IsTand. 
I also extend my warmest thanks to Dr. William Pacitti, Ms. Jane Carey, Mr. Bob Heder, and Dr. Santo Salvatore for kindly allowing students in their classes at the Community College of Rhode Island and at Bryant College to participate in this research.

I particularly wish to thank Mr. Katchadoor N. Kazarian, President of WaTter V. Clarke Associates in Providence, Dr. Peter Merenda, and the office staff at Walter Clarke Associates for making available to me computer facilities for the scoring of the AVA.

To Dr. Charles Coliyer of the Psychology Department and Dr. Leo Carroll of the Sociology Department, University of Rhode Island, for generously giving their time to serve as additional outside mambers of my committee, and for their thoughtful comments on this dissertation, I give my thanks.

Finally, I would like to thank my husband, Dr. Santo Salvatore. The never-failing help and support he has given me throughout every phase of this research is truly beyond measure, as is my abiding love and gratitude. 


\section{TABLE OF CONTENTS}

CHAPTER

PAGE

Abstract...........................

Acknowledgements...................... vi

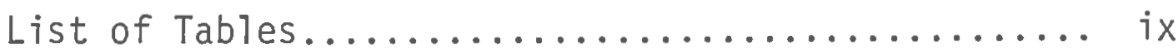

List of Figures........................

Introduction.......................

Statement of the Problem.............. 1

I Review of the Literature................... 3

II $\quad$ Method............................... 37

Subjects...................... 37

Instruments.................... 45

Procedure...........................63

III $\quad \operatorname{Results\ldots \ldots \ldots \ldots \ldots \ldots \ldots \ldots \ldots \ldots \ldots \ldots \ldots \ldots \ldots \ldots }$

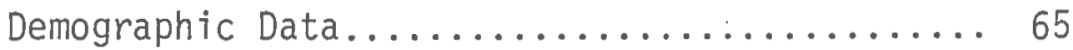

Heterostereotypes.................. 73

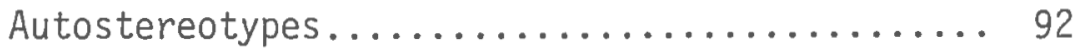

Self-Perceptions..................... 108

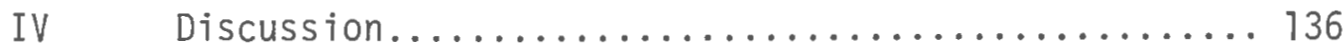

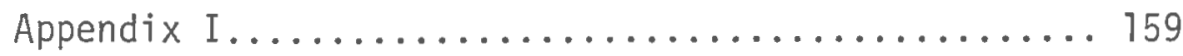

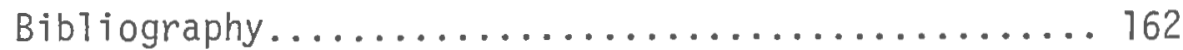




\section{LIST OF TABLES}

TABLE

PAGE

1 Description of Age, Sex, Country of Birth, Citizenship and Undergraduate Status of Subjects in Three Samples

2 Sample Items From the Myers-Briggs Type Indicator

3 MBTI Sixteen Personality Types

$59-62$

4 Percent of Responses in Categories of Marital Status, 68 Religious Affiliation and Church Attendance for Irish Italians and U.S.SS

5 Frequencies in 0ccupational Categories for Irish, Italian and U.S.A.

6 Comparison of the Mean Number of Adjectives Used by Irish, Italians, and Americans in Forming Heterostereotypes

7 Irish Heterostereotypes of Americans

8 Irish Heterostereotype of the Italians

9 Italian Stereotype of the Americans

10 Italian Stereotype of the Irish 88

11 American Stereotypes of the Irish 90

12 American Stereotype of the Italians 91

13 Mean Number of Adjectives Used in Autostereotype of Irish 94 Italians, and Americans (AVA Activity Level)

14 Irish Autostereotypes: Most Frequently and Least

Frequently Used AVA Adjectives

15 Italian Autostereotype: Most and Least Frequently Selected AVA Adjectives

16 American Autostereotype: Most and Least Frequent7y Selected AVA Adjectives

17 AVA Profile Clusters for the Irish, Italian, and American 103 Autostereotypes 
18 Comparison of the Irish, Italian, and American Modal AVA Self-Perceptions with Each Other and with a Normative U.S. Sample

19 Distribution of MBTI Types in a Normative U.S. Sample of 3676 Males and 184 Females Liberal Arts Students

20 Distribution of MBTI Types in the Irish Sample

21 Comparison of the Modal MBTI Types for the Three Samples with Each Other and with the Normative U.S. Sample

22 Distribution of MBTI Types in the Italian Sample

23 Distribution of American Sample on the MBTI Types

24 Correlations of AVA Autostereotypes with Basic Self-

25 Comparison of Modal AVA Autostereotypes with Modal AVA Self-Perceptions for Irish, Italian and American Students 


\section{LIST OF FIGURES}

FIGURE

PAGE

Example of Overlapping Semantic Clusters in

75

Analysis of Irish Heterostereotype Data

2

Irish Stereotype of the Americans Semantic

79 clusters

3

Irish Heterostereotype of the Italians: Semantic

82

clusters

$\cdot 4$

A Portion of the AVA Pattern Universe Showing

Clustering in a Distribution of Scores

101 
INTRODUCTION

\section{Statement of Problem}

Broadly viewed, the proposed study focuses on several questions which can be stated in a general way as follows:

In the face of increased communication, contact, and sophistication in contemporary society, do clear-cut ethnic stereotypes still exist? If so, are there differences in the willingness of particular groups to stereotype other groups? For example, are American college students less willing to stereotype Irish or Italians now than they have been in the past?

If members of a cultural group do hold clear-cut stereotypes of either their own or other national groups, are there sex-related differences in these stereotypes? For example, do Irish women have a sense of national identity which differs from that of Irish men? Do Italian men perceive the "typical" American differently from Italian women?

If individuals hold an ethnic as well as an individual identity, to what extent are these two perceptions congruent? That is, to what extent do individuals perceive themselves as being "typical" of their own culture? Further, are there cross-national differences in the degree of congruence of the "real self" with the national autostereotype? Are American college students, for example, more "alienated" from what they perceive as "typical" of their own culture than, say, Irish college students?

If individuals hold an ethnic as well as an individual identity, what is the effect of acculturation on this ethnic identity? For 
example, will Irish Americans of the third or fourth generation perceive the "typical" Irish person differently than the Irish national perceives himself?

If clear-cut national stereotypes do exist, to what extent do these stereotypes accurately reflect self-perceptions of group members?

The possibility that stereotypes may accurately reflect the selfperceptions of cultural group members carries with it the assumptions that there will be both within-group similarities and cross-group differences in such self-perceptions. This raises two further questions:

To what extent will members of the same cultural group show agreement or congruence in their self-perceptions? To what extent will the self-perceptions of one cultural group differ in nature from the selfperceptions of another cultural group? That is, will cultural groups differ from one another in the saliency of certain subjectively-perceived "characteristics" or "traits"?

(For the purposes of this study, the perception of the members of a national group of either their own or another national group will be referred to as a national stereotype. Consistent with the terminology used by previous researchers (Triandis, 1972; 0sgood, 1976) a group's perception of its own general characteristics is termed an autostereotype and a group's perception of the general characteristics of another national group is termed an heterostereotype.) 
CHAPTER I

\section{Review of the Literature}

While stereotypes held by one culture or ethnic group with respect to another have been rather frequently studies by social psychologists, the degree of accuracy of such stereotypes has less often been examined. This relative dearth of research interest is probably due, in part, to a bias on the part of social psychologists. As Middlebrook (1974) observes: "Until quite recently, the statement that all stereotypes are false and irrational has almost been a truism in social psychology. Some social psychologists have even defined the term as...an inaccurate, irrational over-generalization which, once formed, persists even in the face of contradictory evidence...[p. 122]."

This persisting tendency on the part of many social psychologists to view ethnic stereotypes as generally negative, inaccurate over-generalizations and to treat the term as almost synonymous with the term "prejudice" can be traced back historically to the earliest delineation of the concept by Lippmann in 1922 .

The noted newspaper commentator and author Walter Lippmann introduced and defined the concept of stereotype in his 1922 book, Public Opinion. Essentially, Lippmann characterized stereotyped thinking as rigid, factually incorrect over-generalizations applied to some aspect of the social environment and arrived at through faulty reasoning. Lippmann's theoretical framework set the stage for a long series of 
empirical investigations of stereotypes which used all or part of his definition of a stereotype as their point of departure.

In 1933, Katz and Braly carried out the pioneer empirical study of ethnic stereotypes and, in the process, established the methodological model or paradigm which has since been followed by the majority of workers in the field. In their now-classic study, Katz and Braly (1933) asked 100 Princeton students to describe 10 ethnic groups by selecting from a list of 84 traits "as many adjectives as you think are necessary to characterize these people adequately." Subjects were then asked to go back and star the five words in each list that "best described" the ethnic group in question. Only the starred words were used in the final analysis of data. Stereotypes of Blacks, Germans, Jews, Italians, EngTish, Irish, Americans, Japanese, Chinese and Turks were thus elicited from Princeton students who, according to Katz and Braly, showed "a very high degree of agreement on the assignment of traits to ethnic groups." This research procedure has, incidentaliy, been repeated at Princeton twice since, in the ensuing years, and provides an interesting measure of changes, both in the willingness of students to stereotype, and in the content of the stereotypes themselves.

Thus Gilbert, in 1950, found that Princeton students showed considerably less agreement in the assignment of traits to ethnic groups, and interpreted this as evidence for a "fading out" of the tendency to stereotype (Gilbert, 1951).

In 1969, Karlins, Coffman \& Walters, on the other hand, again using the identical original procedure used by Katz and Braly, found that Princeton students showed greater agreement in the attribution of traits 
to certain groups than Gilbert had found, but that students now assigned "new" traits which, in their opinion, indicated "more careful thinking about ethnic generalizations than their counterparts of the 1930's [p. 14]."

In addition to this trilogy, a considerable number of other studies have been carried out in the ensuing years which have tended to focus on stereotypes of minority groups and have adopted both the Katz and Braly methodology and their definition of a stereotype as a "fixed impression which conforms very little to the facts it tends to represent and results from our defining first and observing second [p. 81]."

More recently, however, Brigham (1971) has, in an extensive review of the concept of ethnic stereotypes, challenged this view. Among other objections, he feels that "characterizing something as invalid necessarily implies that a validity criterion is available. Yet, with reference to the actual distribution of traits within ethnic groups, empirical evidence is exceedingly scanty. Thus, in most cases, no criteria are available for assessing the factual validity of an ethnic generalization [p. 17]."

Brigham goes on to discuss the "kernel of truth" hypothesis which suggests that stereotypes are not necessarily either entirely false or entirely negative. While the evidence is incontrovertible that stereotypes can and in many cases do exist without any truth whatsoever, Brigham apparently agrees with Vinacke (1956) who stated: "It would be ridiculous to assert that groups of different national or cultural origin...do not have certain general characteristics which differentiate them from groups of different origin... In part wrong, superficial, and limited, they (national stereotypes) nevertheless generalize some actual 
traits $[p .285] . "$

The same point is made by the noted anthropologist Margaret Mead (1956) who, however, may have overstated the case somewhat when she remarked that "the elements which make up such stereotypes are accurate but incomplete descriptions of national character in particular crosscultural contexts [p. 222]."

In turning now to the few empirical studies which have actually compared heterostereotypes with autostereotypes or stereotypes with self-perceptions of a given group, some support for the "kernel of truth" hypothesis is found. For example, people from the Noahkali region of Pakistan were stereotyped by Pakistanis from other regions as more pious (among other traits), and their frequency of prayer was found to be higher than that of other Pakistani sub-groups (Shuman, 1966).

Triandis and Vassiliou (1967) studies the effect of frequency of contact on the autostereotypes and heterostereotypes of three groups of American subjects and three groups of Greek subjects. The groups were constituted on the basis of amount of contact with the other culture. The two maximum contact groups, for example, consisted of Americans working in Greece in jobs which brought them into frequent direct contact with Greeks, and Greek students studying in America. There were two medium contact groups and two minimum contact groups also. Triandis and Vassiliou found that contact between the two groups had a differential effect on the autostereotypes held by Americans, and on the heterostereotypes held by each group with respect to the other. Amount of contact had no effect on the autostereotype held by the Greeks about themselves all three groups showing essentially the same self-perception. 
Autostereotypes of Americans in the maximum-contact group, however, were generally more favorable than the autostereotypes of Americans in the other two contact groups. Apparently this was due to the positive feedback Americans received about themselves from Greeks with whom they were in a lot of contact. Further, the authors found substantial agreement between autostereotypes and heterostereotypes for both groups (one measure of validity). Finally, in an interesting finding, Greeks in maximum contact with Americans tended to hold more favorable stereotypes of them than either the moderate or minimum-contact Greeks. On the other hand, Americans in maximum contact with Greeks tended to hold less favorable stereotypes of Greeks than their moderate- and minimum-contact American counterparts. The authors conclude: "The present data suggest that there is a 'kernal of truth' in most stereotype when they are elicited from people who have first-hand knowledge of the group being stereotyped [p. 324]."

Another study which found "relatively high" agreement between autostereotypes and heterostereotypes was reportèd by Abate and Berrien (1967). They had two large groups of Japanese and American college students rate behavior descriptions drawn from the Edwards Personal Preference Schedule (EPPS) on the basis of "how well these descriptions fitted Japanese and Americans in general". In addition, Abate and Berrien attempted to assess the actual characteristics of smaller samples of students, drawn from the larger groups, by having them complete the EPPS on the basis of the perception of the "real self". Although they found relatively high, though differing, degrees of agreement between auto- and heterostereotypes for both groups, they found less agreement between 
stereotypes and vereotypes (actual characteristics), especially for the Japanese sample. Abate and Berrien interpret this discrepancy between national autostereotype and "actual characteristics" by suggesting the possibility that "respondents in both countries tended to give a stereotype of the socially accepted rather that the "typical" person of their own country [p. 437]." This explanation seems a little weak, especially in view of the rather large difference between discrepancies for the American group and discrepancies for the Japanese group. It is possible that Abate and Berrien failed to establish the validity of the Japanese translation of the EPPS.

Finally, Sue and Kitano (1973) found that American stereotypes of Asian Americans have changed quite dramatically over the years from the quite negative views held during the World War II period to the largely positive and, according to them, more valid views of the 1970's. They attribute this change in part to shifts in the "moods or conditions of society rather than [changes in] any real characteristics of the stereotyped group [p. 88]" but also state that the newer stereotypes are, in fact, more accurate. They cite numerous examples of agreement between the current stereotype of the Asian American as "industrious, quiet, loyal to family ties and courteous" and real behavioral and personality characteristics. They point, for example, to low rates of juvenile delinquency and high rates of college attendance among Asian Americans. They further remark that "studies tend to support current stereotypes in the following characteristics: introversion of Japanese males...; passivity of Japanese...; Chinese introversion and conformity...; and Japanese quietness...". 
The possibility that stereotypes may, in fact, have a certain degree of validity carries with it the assumption that ethnic or cultural groups actually do differ from one another in terms of certain identifiable characteristics. As it happens, this area of research interest lies at the intersection of several disciplines and thus forms an area of ground common to social sciences other than psychology, such as anthropology, sociology, political science and history. Thus a very substantial body of literature has accumulated, contributed to by scientists with a wide diversity of backgrounds and orientations. In particular, cultural character and ethnic differences have been studies quite extensively and from a rather different perspective, by cultural anthropologists, for whom the field of "culture and personality" constitutes a major subdivision of their science.

No attempt is made here to trace the historical development of this field because to do so, in the interest of providing background for the present study, would, even if traced in the broadest possible outline, take the reader too far afield. Excellent over-views were found, however, by the writer in both the psychological and the anthropological literature. In the psychological 7iterature, for example, the recently published six-volume Handbook of Cross-Cultural Psychology (edited by Triandis and Lambert, (1980) provides a comprehensive treatment of the different perspectives, methodologies, and substantive issues in the field of cross-cultural psychology. An excellent over-view, was found in an article on the topic of particular interest to the present study, "National Character: the Study of Modal Personality and Sociocultural Systems" by Inkeles and Levinson (in Chapter 34, Vol. 4, Lindzey and 
Aronson, editors). Reviews in the anthropological literature abound:

Culture and Personality (Wallace, 1970); Personality in'Culture

(Honigmann, 1967); and Culture and Personality (Barnouw, 1979), to mention only a bare few.

What is being done here is first, to briefly define the area of culture and personality - that is, the area where the interests of psychologists and anthropologists intersect; and second, (in what must necessarily be an oversimplification), to mention three major ways in which the perspectives of psychologists and anthropologists have generally differed somewhat from one another.

As Barnouw (1979) defines it, "culture and personality, or psychological anthropology, is an area of research where anthropology and psychology come together - more particularly, where the fields of cultural and social anthropology relate to the psychology of personality. Ethnologists, or cultural anthropologists, are students of culture - of the different ways of living that have developed in human societies in differing parts of the world, while psychiatrists and (at least some) psychologists are analysts of human personality whose work involves an effort to understand why and how individuals differ from one another as they do. Serving as a bridge between ethnology and psychology, the field of culture-and-personality is concerned with the ways in which the culture of a society influences the persons who grow up within it [p. 3]."

The perspectives of anthropologists and psychologists studying personality in culture appeal to differ from each other somewhat in at least three major areas: explanatory emphasis; theoretical orientation; 
and methodology.

In the first of these, explanatory emphasis, there are two prevalent emphases and these have been referred to as the "emic - etic" distinction. The terms "emic" and "etic" derive from the suffixes of the words "phonemics" and "phonetics". In linguistics, phonetics is a system for describing the units of sound found universally in all languages, whereas phonemics refers to specific sound units found only in particular languages. "In cross-cultural research, the emic approach seeks to explain phenomena in terms of categories deemed meaningful within a specific culture, whereas the etic approach emphasizes the development of explanatory constructs that are applicable to all cultures. In genera1, anthropological studies have used the emic approach, whereas psychologists have adopted an etic perspective [p. 1063-64, 01medo, 1979]." To state this a little differently (and, again, in a necessarily simplified fashion), anthropologists have tended to emphasize the similarities in personality types within a given culture and, at the same time, therefore, the differences in (moda1) personality types between one culture and another. Psychologists, on the other hand, have tended to emphasize both the greater variability of individual differences within a culture, and the universality of certain personality traits across cultures.

In fact, it was Freud's insistence on the universality of the Oedipal conflict that historically provided part of the impetus for the pioneer studies of anthropologists like Benedict (1934), Mead (1939), and Malinowski (1927) who went into the field to study the effects, in given cultures, of societal constraints on sexual behavior and repression. 
Incidentally - and ironically - the impetus given by Freudian psychoanalytic theory to anthropological field studies of personality also appears to have given rise to the second major difference in perspective between psychologists and anthropologists: that of theoretical orientation. Until quite recently, a great deal of the anthropological study of personality in a cultural context appears to have used Freudian psychoanalytic theory as a frame of reference and/or point of departure, whereas for psychologists the primary theoretical orientation in the understanding of personality has increasingly been behaviorism or learning theory. In fact, currently many psychologists are eschewing the concept of personality altogether when that construct is defined as "a set of relatively enduring inner traits" and are turning instead to encironmental determinants and situational specificity in the understanding and prediction of behavior.

Finally, psychologists and anthropologists have tended to differ in the methodology each utilizes, with psychologists stressing the use of objective experimental methods and psychometric techniques, often with relatively large numbers of subjects, while anthropologists often have used observational, clinical, and anecdotal methods (as well as the projective techniques) with relatively small numbers of subjects. In short, generally psychologists have engaged in extensive short-term studies while anthropologists have tended to engage in intensive, longterm studies.

The foregoing material has been presented in an attempt to sketch the background for the present study and to bring together the two major lines of research that converge on the topic at hand. 
In summary, then, a review of the rather scantly literature dealing with the issue of validity of stereotypes tends to lend some support to the "kernal of truth" hypothesis: That is, at least in more recent times, ethnic stereotypes have sometimes corresponded in part to a group's actual characteristics and/or its perception of its own characteristics.

Further, there appears to be a movement in contemporary psychology away from Lippmann's original conceptualization of the stereotype as a product solely of faulty or illogical thinking. Hilgard et. al (1979) typify this new and softer view when, after defining a stereotype as a "belief about a group of people that, even if not totally false, has been overgeneralized and applied too broadly to every member of the group", then go on to comment: "We emphasize again that the thinking process that gives rise to stereotypes is not in itself evil or pathological. Generalizing from a set of experiences and treating individuals as members of a group are common and necessary practices. It is simply not possible to deal with every new person as if he or she were unique, and the formation of 'working stereotypes' is inevitable until further experiences either refine or discredit them [p. 548]."

Finally, an extensive body of literature devoted to the study of personality in the context of culture forms an area of common interest to psychologists and anthropologists. This area has contributed strong and very extensive empirical support to the expectation that personality traits can and do reflect cultural influences.

These lines of research provide the theoretical background for the present study, which seeks to examine the degree to which autostereotypes of a given cultural group agree with heterostereotypes (that is, 
views held about that culture by other cultural groups), and to selfperceptions.

The current trends noted and the studies just reviewed provide, as has been stated, the background and theoretical framework for the present study and give rise to the following assumptions and working definitions:

1. Stereotypes are generalizations about the salient characteristics of a group of people. In line with Hilgard et al's thinking, generälizations are viewed as one type of basic cognitive activity or process (not too dissimilar, in fact, from Piaget's concept of assimilation), by which we seek to order and simplify, through generalizing or categorizing, what would otherwise be an overwhelmingly complex world.

2. It follows, therefore, that stereotypes are not necessarily "defensively held" in order to justify discriminatory behavior or prejudiciar attitudes, arthough there is no doubt that in some cases this is true.

3. Stereotypes are not necessarily negative views held by one group about another but can in fact be either neutral or even positive.

4. Stereotypes are not necessarily rigid and unchanging but can and probably are revised by most persons to reflect new experiences and information.

5. Although the operationalized stereotypes elicited from subjects in psychological experiments through the use of standard procedures such as that employed by Katz and Braly seem to reflect over-simplified and native generalizations, this "finding" may well be an artifact of the 
procedure used. The subject in the typical research study of stereotypes may be responding in part to the demand characteristics of the experimental situation. The subject, therefore, may not hold views which are isomorphic with the adjectives checked or produced in response to the experimenter's request. Most subjects, in fact, are probably fully cognizant that such generalized descriptions cannot possibly fit every member of a given group.

6. Stereotypes, although they are by definition overgeneralized descriptions which cannot possibly describe each and every member of a given group, are not necessarily, however, totally false. There is ample empirical evidence to suggest that some sociocultural systems especially closeknit, homogeneous, non-industrialized cultures - can be generally described in terms of one or a very few "modal personality types" which predominate within that cuiture.

7. Finally, it is assumed that the culture into which one is socialized exerts a profound effect upon the development of those relatively enduring attitudes, beliefs, perceptions and behavioral dispositions which constitute what is subsumed under the word "personality". If cultures differ from one another in the attitudes, beliefs and behavioral expectations that are transmitted from generation to generation, it follows that the personality "types" of members of one culture should differ from those of another.

The definition of culture being used in this study is the one provided by Barnouw (1979). "A culture is the way of life of a group of people, the configuration of all the more or less stereotyped patterns of learned behavior which are handed down from one generation to the 
next through the means of language and imitation [p. 5]."

"National character" refers to "the relatively enduring personality characteristics and patterns that are modal among the adult members of the society (p. 428 "Inkeles and Levinson in Lindzey and Aronson, 1969).

The attempt to measure personality traits or states, or what a person "really is" raises formidable theoretical and methodological problems. Since the interest of this research is a comparison of certain cultural stereotypes with personality descriptions of individual members of those cultures, it is necessary to operationally define the term "personality" or "real characteristics".

For the purposes of this study, it is assumed that whenever summary descriptions of the self or others are given in terms of a few basic "traits" or "states", it is likely that such descriptions are themselves stereotypes, to the extent that they act like statistical averages of trends or general tendencies, rather than predictions of the occurrences of specific behaviors in specific situations. As Triandis (1972) notes, "We cannot know what we call reality in a direct fashion" but act instead upon our subjective perception of reality. Thus even the perception of the self may qualify as a stereotype. To say: "I am a quiet person" implies that in general, or as a whole, "I tend to be quiet". Such a self description does not, thus, necessarily correspond with inherent, enduring "personality traits" (although it may). For the purposes of this research, then, "actual characteristics" or "personality traits" are terms operationalized as a self-description or self-perception. 
It is conceivable that such a self-description may even act as a constraint upon the individual, a constraint which is accepted, however, in the interest of retaining a consistent and coherent sense of identity.

It is likely that such self-perceptions arise in part from values internalized by the individual in the process of being socialized into a given family and cultural group. Finally, then, an ethnic or cultural group will be defined as Greeley \& McGready (1973) define it: "A large collectivity, based on presumed common origin, which is, at least on occasion, part of a self-definition of a person, and which also acts as a bearer of cultural traits [p. 210]."

In this study, it is hypothesized that national stereotypes are related to "actual characteristics", that is, to self-perceptions, of individual subjects in the national group. Accordingly, it is predicted that when cultural and/or ethnic groups are compared, there will be measurable differences between them in both national stereotypes and in self-perceptions.

The major groups that were studies are southern Irish, southern Italian, and American college students. The term "southern Irish" is used to highlight the geo-political and cultural distinctions between the now independent Republic of Ireland, and northern Ireland. Similarly, the term "southern Italian" is used to highlight the widely recognized geo-cultural distinction between the largely agricultural "Mezzogiorno" and the more industrialized region of northern Italy. In order to trace possible interactions between ethnicity and acculturation, the attempt has been made to subdivide the American sample into Italo-Americans and Irish-Americans. The criterion for determining ethnicity was that for 
the American sample three out of the four grandparents be identified by the subject as of either Irish, (in the case of the Irish-American sample), or Italian (in the case of the Italo-American sample.) This procedure depended, of course on the availability of sufficient numbers of subjects who met the ethnicity criterion.

Irish and Italians have been chosen as the groups to be studied for several reasons. The large scale emigration of Irish and Italians (especially from southern Ireland and southern Italy) to the United States during the late 1800's and early 1900's has made these two groups particularly salient in American culture. Both groups have thus figured prominently in the rapidly proliferating studies, over the last two decades, of ethnicity and related variables. A substantial body of anthropological and historical literature now exists which makes it possible to trace both the parallels and the differences in the history, traditions, and mores of the two groups. Such information is, of course, a necessary source for cross-cultural studies. Sufficient similarities in the history of tr:e two groups exist - for example, in the shared experiences of poverty, political oppression, subsistence economy and religious belief - to permit cross-cultural comparisons to be legitimately drawn. On the other hand, differences such as the contrast between the organization of Irish peasant life into isolated rural farms and the organization of Italian peasant life into small village communities; make it feasible to suggest that such differences might lead to differences in the traits and characteristics of the two groups. As Arensberg (1968) notes, a 1926 census of the Free State Government in Ireland found that "out of nearly three million inhabitants, one millon 
eight hundred thousand, or $63 \%$, live in rural areas, outside cities and towns... Fifty-one percent of all occupied persons, male and female, in southern Ireland work at agriculture, [p. 49]." Maraspini (1968) points out that, in contrast, "the phenomenon of the 'citta contadina' or city of peasants is characteristic of the southern Italian agricultural region." These tightly-knit and isolated villages or "cities of peasants" typically organized around the local church with its bell tower. The Italian word for bell tower is "campanile" and has given rise to the word "campanilismo", which is used to describe the villagers' feeling of belonging. "The sound of the bell was unique and familiar to each and every person in the village, and over the centuries the attachment the villagers felt for the bell metamorphosed into a sense of loyalty to the village itself and to one's neighbors. The sound of the bell defined the boundaries of the village (often quite literally); those who lived beyond were strangers not to be trusted... These village communities in their isolation developed manners and mores, nuances of language and dress, and human struggles and enmities that distinguished one village from another, regardless of geographical proximity (p. 63, Femminella \& Quadagno, in Mindel \& Habenstein, 1977)". One of the personality traits measured in this study was introversion versus extraversion. It is hypothesized on the basis of both theory and empirical findings that Italians may be more extraverted as a group than Irish. Such a difference, if it were to be found, may well be related to such historical differences in the organization of community life in the two societies.

A second reason for using these two groups also relates to the fact of the large-scale emigrations of Irish and Italians to this country 
in the nineteenth and twentieth centuries. The variable of ethnicity is a variable of interest in this study. Even if it were not possible to obtain sufficient numbers of subjects to form the two sub-groups of Irish-and Italo-Americans, it was felt that American subjects as a group would have had substantial contact with persons of Irish and Italian background. This contact should, therefore, affect the stereotypes held by Americans towards these two cultural groups. As previously noted, in the study by Triandis and Vassiliou (1967) frequency of contact should function to make these heterostereotypes more accurate.

It is of interest to note in this connection that the variable of ethnicity is frequently overlooked in psychological studies utilizing American subjects. One possible reason for the exclusion of this variable may be the persistence of the notion that America is indeed a "melting pot"; that ethnic identity with one's country of origin does not survive as an important influence past perhaps the second or third generation; and that the term "American" defines a unique and homogeneous cultural identification. If this is, in fact, the implicit assumption held by many social scientists, it might well explain the fact that a vast amount of research utilizing samples of American college students fails to isolate and control for ethnic variables. Yet this assumption has been sharply refuted by some social scientists. After years of studying ethnic groups in New York City, and their role, among other things, in the shift of political power in that city. Nathan Glazer and Daniel Moynihan (1970) write:

"Beyond the accidents of history, one suspects, is the reality that human groups endure, that they provide satisfaction to their members, and that the adoption of a totally new ethnic identity by dropping whatever one 
is to become simply American, is inhibited by strong elements in the social structure of the United States. It is inhibited by a subtle system of identifying which ranges from brutal discrimination and prejudice, to simply naming. It is inhibited by the simple unavailability of a simple "American identity". One is a New Englander or a Southerner or a mid-Westerner, and all of these things are too concrete for the ethnic to adopt completely, while excluding his ethnic identify. In any case, whatever the underlying fault lines in American society that seem to maintain or permit the maintenance of ethnic identity beyond the point of cultural assimilation, the fact is ethnic identity (remains)..."

$$
\text { [p. } x x x i i i]
$$

Since the researcher wished to examine not only cross-cultural differences, but also the possible effects of acculturation and frequency of contact on heterostereotypes, it was necessary to choose groups whose numbers would be sufficient in the Rhode Island population to make this possible. There is a sizeable population of both ItaloAmericans and Irish Americans in the Rhode Island area and this fact influenced the selection of groups to be studied as well.

Finally, the practical question of the availability of subjects in particular cultural groups also, by necessity, influenced the selection. It happened that contacts were made available to the researcher in both Ireland and Sicily that would make possible collection of data from college students in those two countries.

\section{Plan of the Study}

National autostereotypes of the cultural groups involved were obtained by having the subjects of each group select all those adjectives from the 81 adjectives of the Activity Vector Analysis (AVA) which best describe "the typical member" of their respective cultures. 
The AVA (Clarke, 1953) is an adjective check 1ist consisting of "81 non-derogatory self-referrent adjectives." It yields personality description in terms of a pattern consisting of four independent factors: sociability; aggressiveness; emotional control; and social adaptability. Since scores on each of these four factors can combine in many different ways to form different profiles, the AVA is an instrument which yields at least 258 interpretable profiles or personality types. Using the AVA to measure national autostereotypes makes it possible to describe the sense of cultural identity held by members of a given cultural group in two ways. First, the frequency with which each adjective was selected by subjects in a given national group was tallied. If a given adjective were selected by at least $55 \%$ of the subjects in a particular group, it was assumed that this adjective formed part of a rather definite autostereotype for the group in question. All those adjectives, then, which were selected by at least $55 \%$ of the group were considered as descriptive of the picture held by that group of its "general characteristics". (The use of 55\% was an arbitrary criterion used to ensure a clear majority.) Second, each subject's selection of adjectives were scored in the conventional manner to permit the determination of a profile or "personality type". (Scoring procedures will be detailed in the Methods section). These profiles were then plotted on the AVA pattern universe. The AVA pattern universe is a Mercator-type projection of the 258 personality types in two dimensional space. The distribution of types for a normative sample of 1199 Americans is available showing the very heterogeneous distribution of types for this normative sample. By definition, an autostereotype, if 
it is held by a substantial number of respondents for a given cultural group, should show rather tight clustering into one or a very few "modal" personality types. Thus, a second measure of the presence of a clear-cut national autostereotype should show rather tight clustering of the group into a very few groupings or types. If, on the other hand, no clear-cut autostereotype were to emerge, this distribution of personality types should show an heterogeneity of distribution approaching the American sample.

National heterostereotypes, on the other hand (the picture each group holds of the "typical" characteristics of the other two groups), were obtained by asking the three groups of subjects (Irish, Italian, and American) to describe, using ten adjectives or less, the "typical" member of the other two groups. For example, Irish students were asked to respond to this open-ended question by describing, in ten adjectives or less, their picture of the "typical" Italian, and then to describe their picture of the "typica1" American in the same fashion. (Earlier, the point was made that the Katz and Braly method of eliciting stereotypes through checking off adjectives from a pre-existing list tends to introduce a certain degree of bias into the procedure. It is felt that opne-ended questions are less likely to do so).

Individual self-perceptions ("personality" or "actual" characteristics) were measured using two instruments measuring a total of eight dimensions. A 126-item, forced-choice instrument, the Myers-Briggs Type Indicator (M-BTI), was administered and scores from this classified each subject into one of $] 6$ possible personality types. The MBTI is a personality measure of four dichotomous preferences conceived by the 
test authors to be rather basic dimensions of personality. (As Inkeles and Levinson note, "another important feature of the general definition of national character is that its components, whatever their specific nature, are relatively enduring personality characteristics... These are not phenotypic, behavior-descriptive terms. Rather, they are higherlevel abstractions that refer to stable, generalized dispositions or modes of functioning..." (in Lindzey and Aronson, 1969).

These four preferences are: introversion versus extroversion ( $I-E)$; sensing versus intuition $(S-N)$; thinking versus feeling (T-F); and judging versus perceiving (J-P). Introversion describes a preference for involvment with the inner world of ideas versus extroversion, which describes an orientation toward the outer world of people and things. Sensing versus intuition describes a preference for being matter-of-fact, practical, and conventional versus imaginative, creative, theoretical and unconventional. Thinking versus feeling describes a preference for making judgments based on logic, reason, and fact versus feeling, sentiment, and the affective rather than rational evaluation of situations. Finally, judging versus perceiving refers to the preference for being organized, decisive and systematic and making decisions based on a-priori values, versus being spontaneous, impulsive, adaptable and flexible and tending to make judgments on the spur of the moment based on the evaluation of the situation as it exists right now. Subjects are scored by determing both the letter of their preference (I versus $E, S$ versus $N$, etc.) and the numerical strength of the preference. The strength of the preference is determined by the number of items in the particular scale selected by the subject. Thus, a weak 
preference for the introverted orientation would be described by a score of, say, I3 (the subject selected three more I items than the total of the $E$ items selected). A strong preference for the introverted direction would be described by a score of, say, I46. Each subject is then described as one of the 16 personality types which form all possible combinations of the four basic preferences (e.g. INFP, ESTJ, ISTJ, etc.). Since this is one of the measures used in this study to measure self-perceptions of members of each cultural group, it is one of the measures used determine if there are recognizable and clear-cut differences between cultural groups in terms of subjectively perceived personality characteristics. As with the AVA, the distribution of personality types for a large normative sample of American subjects if known. Thus, significant differences in the distribution of personality types from that in the normative sample is one indication that culturally determined differences in personality types exist.

Finally, subjects again selected adjectives from the 81-word list of the AVA which they felt would best describe their "real" or "basic" self. As described previously, this instrument also yields personality profiles or types in terms of basic psychological dimensions. Thus this second, independent measure of self-perception, with dimensions which overlap those of the M-BTI, should yield personality descriptions which are supplementary to and somewhat congruent with, the results from the Myers-Briggs, thus providing an internal check on the validity of the measure of self-perceptions.

These measures of characteristics have been chosen for several reasons. First, stereotyped pictures of cultural groups are often given in 
terms of basic temperamental characteristics such as "warm", "friendly", "outgoing", "practical", etc. It was, therefore, necessary to choose measures of such basic traits, both to test hypotheses concerning the content of such stereotypes and a1so the hypothesis of "real differences" between the groups.

Second, both the AVA and the MBTI have highly satisfactory psychometric properties (reliability, validity, large normative samples, etc.) In addition, the AVA already had an existing form in Italian and had been used in cross-cultural research prior to this time. Finally, in order to make comparisons with previous empirical findings to be described shortly, it was necessary to choose comparable measures.

It will be recalled that subjects were to select adjectives from the AVA 1ist twice: once as a measure of the cultural autostereotype and once as a measure of the "real" self. Thus discrepancies between these two ratings, as measured by the correlation between the two profiles, would also provide a measure of the degree to which the subject does, in fact, hold an autostereotype of his culture which is distinct from his self-perception, and also the degree to which the individual subject feels congruent with or al ienated from, his own culture.

\section{Predictions and Related Empirical Studies}

In this study, the following specific predictions were made: With respect to within-group similarities, it was predicted that: (1) In the Irish and Italian samples, the distributions of selfperceptions, both on the MBTI measure and the AVA measure, would show greater homogeneity than in the American sample or in the U.S. normative 
samples used for comparative purposes. That is, there would be tighter clustering around fewer "types" for the Irish and Italian samples whereas the American sample distribution would be more heterogeneous.

With respect to between-group differences in self-perceptions, it was predicted that: (2a) Italian students, as a group, would show a greater frequency of "extraverted, sociable, "sensing" types than found in the Irish or American samples, or in the U.S. normative samples; (2b) Irish students, as a group, would show a greater frequency of "introverted, emotionally controlled, intuitive types" than found in the Italian or American samples, or in the U.S. normative samples; (2c) The distributions of AVA and MBTI self-perception scores of the American students would not differ significantly from the more heterogeneous distributions of the U.S. normative samples on these two measures.

With respect to the relationship between self-perceptions and national stereotypes, it was predicted that: (3a) Some elements in the heterostereotypes for these three groups would show correspondence with their autostereotypes; and that (3b) Some elements in both the heterostereotypes and autostereotypes would show correspondence with the self-perceptions of group members. In regard to this last prediction it should be noted, however, that the sampling limitations inherent in this study may well restrict the degree to which such correspondence is found. The degree to which heterostereotypes of the "average" or "typical" member of a national group will correspond either with the autostereotypes or self-perceptions of groups of college students is problematical. 
28.

The predictions made in this study were based on both theoretical considerations and on previous empirical findings. (Cf. Greeley and McCready, 1975; Merenda, Migliorino and Clarke, 1972; Abate and Berrien, 1967; et al.).

Historically, one of the broad tasks that the science of psychology early defined for itself was the attempt to measure and explain individual differences. While many of the pioneer workers in this field assumed that such differences were largely due to innate, genetic factor's, the prevailing theoretical bias has shifted. It is probably fair to say that the most widely accepted paradigm in contemporary American psychology has its philosophical roots in Lockean empiricism and its current expression in social learning theory.

Among other things, social learning theory is characterized by its emphasis on overt, measurable behaviors, rather than "intrapsychic conflicts, instincts, or dispositions...Further, social learning theory assumes that...personality is determined primarily through learning, which takes place in a social context." (Bourne and Ekstrand, 1976).

Elusive though the concept may be, the "culture" into which one is socialized must be counted as a vital and inextricable part of the social context or milieu in which learning takes place. The values, mores and traditions of a culture are, for the most part, immediately and proximally transmitted from generation to generation via the family. Frequentiy, the power structure within the family is in part dictated by the culture as wel1. It seems clear that, if cultures develop different traditions, power structures, and mores, then individuals socialized into that culture should differ in some ways from individuals 
socialized into another culture.

It appears, from even a cursory examination of the representative empirical evidence, that cultural differences do exist across a broad spectruc of variables, and that these differences have important implications.

Glazer and Moynihan (1970) cite a study, for example, which found different patterns of cognitive skills, apparently in part as a function of ethnicity. This study (Stodolsky and Lesser, 1967) selected four groups of school children - Chinese, Jewish, Puerto-Rican, and Black. Within each group, two sub-samples were formed of middle-class and lower-class children. Four tests of intellectual achievement verbal ability, reasoning, number facility, and space conceptualization were given. "The striking results were that, for each group, a distinctive profile of achievement emerged, which remained the same for middleclass and lower-class children. Though the middle-class children scored, in each case, better than the lower-class children, the profile remained intact. Chinese children scored highest on space conceptualization, Jewish children on verbal facility."

Turning to a quite different area, Opler and Singer (1956) reported finding distinct differences between two samples of Italian-American and Irish-American patients who had both been diagnosed as schizophrenics and were $a 11$ in-patients at a psychiatric facility. The original sample drawn included 40 Irish and 37 Italian male patients. Age, sex, religion, and provenience from New York City urban areas were controlled for both samples. The mean IQ, educational level, year of first hospitalization, and marital status for the two groups were closely equivalent. 
Prior to the onset of data collection, the author formulated specific hypotheses about cultural differences in both the normative and psychopathological behaviors for the two groups. To test these hypotheses, both groups were intensively studied and interviewed for a period of one year. By the end of the year, "chronicity and contraindications for testing yielded closely matched samples of 30 Irish and 30 Italian patients available for total psychiatric, anthropological, and psychological study, and an additional 10 Irish and seven Italians who could be studies by psychiatric and anthropological means alone."

Opler and Singer found ten areas in which there were significant differences between the two groups relating to their behavior and expression of psychopathology. Some of the most salient differences may be summarized as follows:

Irish patients much more often had problems centering on a "dominating, rejecting mother", while the fathers of Irish patients were generally perceived as weak or absent. Italian patients had conflicts of a less repressed kind centering instead on the father and male siblings. In addition, the Irish patients tended to exhibit greater degrees of repression and anxiety, while Italian patients were more overtly hostile and less repressed and anxious.

Irish patients appeared to utilize fantasy much more often and to appear quiet on the ward, while Italian patients were far more active and mobile. For example, 26 Irish patients showed no evidence of "acting-out" behavior on the ward, while 23 Italian patients "showed marked and "repeated evidences of acting out." 
Twenty-four Irish patients were rated by various ward personnel as generally compliant to authority, whereas almost the same number of Italians were rated as non-compliant.

Delusional fixity was extremely prevalent in the Irish, while exactly two-thirds of the Italian cases showed no fixity whatever, "and the remainder had slightly scattered and changeable delusions..."

In addition to the diagnosis of schizophrenia, alcoholism was present in 19 out of the 30 Irish patients while amongst Italian patients, only one out of the 30 had an alcoholism problem. (Interestingly, this finding has been corroborated again and again in many studies which have related alcoholism to ethnicity. Although Italians have a much higher rate of per capita consumption of alcoholic beverages, Irish and Irish Americans are groups which have been consistently rated as having one of the highest rates of alcoholism). In a further, and rather curious finding, there were no instances of overt homosexuality in the Irish patients, while 20 out of the 27 Italians were found to exhibit some degree of overt homosexuality. While, as has been noted, the findings with respect to alcoholism in the Irish group are substantiated in the literature as being present in the population, the findings with respect to homosexuality in the Italian group has no such parallel.

On the basis of these and other findings in their classic and wellcontrolled experiment, opler and Singer concluded: "If culture influences types of family organization and the social experience and role position of its carriers, its deepest reflection will occur on any and a11 biosocial levels as evidenced in norms of behavior and in types of psychopathology." With respect to the hypothesis of personality 
differences between members of different cultural groups, it is worth noting that some authorities feel that the kind of behavior expressed in psychopathology tends to be an intensification, or extreme, of the basic personality traits that exist in the normal personality. Thus, Opler and Singer's reported differences in the expression of psychopathology for Italian versus Irish patients may well reflect underlying normat personality differences in the two groups, carried to an extreme. It also, incidentally, points up the importance of understanding differences in normative behavior for different cultural groups since it is also possible that normal differences in behavior may be misperceived by some as indicative of psychopathology when such may not be the case.

The possibility that expressions of psychopathology may be normative behaviors carried to extremes, and that these behaviors may differ for different cultural groups, receives some support from a study by Merenda, Migliorino, and Clarke (1972). In this study, the AVA was administered to 395 Sicilian males at a public technical school in Palermo. As previously described, the AVA is an adjective check 1 ist of 81 words which yields a personality description in terms of profiles based on scores on the four dimensions measured by the instrument. The social perception and the perception of the real self of these Sicilian youths were compared to a normative sample of 7,732 Americans. It was found that, in contrast to the much more heterogeneous distribution of types in the American sample, the Sicilian sample clustered very tightly about two (somewhat similar) personality types or profiles. In general, the sample showed a split between "those who perceive themselves as 
friendly, warm, and socially-outgoing personalities, and those who see themselves as being somewhat ruthless, agressive, hard-hitting egotists." (The correlation between the two profiles is a moderately Tow $r=.31$ ). It is interesting to compare these findings with those of Opler and Singer for a sample of Italian male schizophrenics. It will be recalled that the Italians differed strikingly from the Irish in that the former were decidedly more extroverted, active, mobile and non-conforming - characteristics which, it can be inferred from the Merenda et al study, were shared to some extent by this Sicilian sample.

Finally, in 1975, Andrew Greeley and William McCready reported the results of a study of Irish and Italian Americans in which, of 75 a priori predictions of differences between the two groups across a wide spectrum of demographic, personality, and other variables, 52 statistically significant differences were actually obtained: 34 differences in the direction predicted, and 18 differences in the direction opposite to their a priori prediction.

Using the Greeley and McCready call "the substantial anthropological and sociological literature" on Irish Catholics and southern Italians, they derived a considerable "number of hypotheses about their respective differences from Anglo-American norms and from one another [p. 209]", (Greeley \& McCready, in Glazer \& Moynihan, editors, 1975).

These hypotheses covered a wide range of personality and behavioral and attitudinal variables. Italian- and Irish-Americans were, for example, compared on seven personality variables: trust, fatalism, authoritarianism, anxiety, conformity, tendency to be moralistic, and 
encouragement of independence in their children. They were also compared on such other broad behavioral and attitudinal dispositions as political participation, moral views, respect for the democratic process, and attitudes toward family structure.

With respect to the seven personality variables tested (and this is the aspect of the Greeley-McCready study of the greatest interest here), the authors found only one variable on which both "the Irish and the Italians were significantly higher than Anglo-Saxon Americans" and this variable was fatalism. Irish and Italian-American students were significantly more fatalistic than Anglo-Americans.

Irish-Americans differed significantly from Anglo-Americans on four variables. They were more trusting and more fatalistic than Americans, but less authoritarian and less anxious.

Italians differed significantly from anglo-Americans only on two variables. Italians were more fatalistic and less encouraging of independence in their children than Anglo-Americans.

Finally, in comparing Irish-American subjects with Italian-American subjects, they found Italians more authoritarian and more anxious than Irish, but less fatalistic, less conforming, less moralistic, and less inclined to encourage independence in their children. In fact, on the seven personality variables measured, Italians and Irish differed significantly from each other on six out of the seven.

It is interesting to note that the Greeley-McCready study found, in contrast to Opler and Singer, more anxiety in Italian-American than in Irish-American subjects. Although some of the differences, such as 
this one, found by Greeley and McCready are not consistent with previous findings (or, in fact, their own a priori predictions), the study is important in the principal finding that distinct differences were found as a function of membership in a particular ethnic group. It is felt that the particular measures of personality used in this study were not very refined. Apparently the personality instrument used by Greeley and McCready was a seven-factor instrument "which emerged from a battery of 57 items. We (used) items which had factor loadings of over .200 for each scale." An item loading .20 on a factor is a very weak item. Another disturbing aspect of the study is the absence of data on the subjects and sampling procedures. It is possible that methodological problems weaken the validity of the results.

\section{Justification}

It seems clear that there are both theoretical and practical reasons for pursuing the study of cross-cultural differences in stereotypes and self-perceptions, if these exist. As Rohner (1977) points out, knowledge gleaned from cross-cultural research helps to edit and extend" man's image of himself and to correct myths and stereotypes. Even the clarification of existing stereotypes has important implications. Recent world events make it compellingly evident that individual nations can no longer pursue their interests in isolation from other nations. Leaders of nations must, as a matter of survival, negotiate with and make decisions regarding other nations. It is clear that such negotiations and decisions are based upon the mutual perceptions of the aims and national character of the countries involved. 
Research which helps to clarify what these mutual perceptions are and the extent to shich they are or are not based on real characteristics, makes a small contribution to this important area.

Finally, as Inkeles and Levinson note (Ed. Lindzey and Aronson, 1969) "If it is shown that national character does not exist, social science will have dealt a severe blow against popular stereotypes and ethnocentric thinking about nations; and if modal personality structures are found, the way will be opened for the development of new insights into the relations between individuals and society [p. 428]." 


\section{CHAPTER 2}

\section{METHOD}

\section{Subjects}

The Three Samples as a Whole $(N=555)$

The subjects for this study were drawn from populations of college students, $78.7 \%$ of them freshman and sophomores, enrolled on a fulltime basis in for the most part public liberal arts educational institutions in their respective countries.

The total number of subjects across the three national samples consisted of 555 students, 293 (or 53\%) of whom were females and 262 (or $47 \%$ ) of whom were males.

The three samples were quite comparable to each other in age, sex ratio, marital status, citizenship, and most of the other demographic variables for which measures were obtained.

The overwhelming majority (approximately 96\%) of the subjects were between the ages of 17 and 25 , with a modal age for the samples as a whole of 19 years. Almost all of the subjects (95\%) were born in, and were citizens of, their respective countries. Ninety-four percent were single, and most (75\%) stated that their religious affiliation was Roman Catholic.

Based on the income level, education, and occupation of their parents as reported by these students, the sample can be described somewhat loosely as "middle class". 
The "typical subject" in this study, then, was a native-born, 19-year old single Catholic freshman or sophomore enrolled in a public liberal arts college in his or her respective country of birth. The subjects fell into one of three samples: the Irish sample $(N=186)$; the Italian sample $(N=179)$; and the American sample $(N=190)$. Each of these samples will be described individually. (See Table 1 for a summary description of subjects).

\section{The Irish Sample $\quad(N=186)$}

The Irish sample was obtained largely through the gracious personal help of Dr. Patricia Fontes, an American research scientist and lecturer presently affiliated with the Educational Research Centre at St. Patrick's College in Dublin, Ireland.

The Irish sample consists of a total of 186 students, 89 males (48\%) and 97 females (52\%).

The sample was obtained from three sources: the University College at Dublin (112 subjects), the University College at Galway (43 subjects) and St. Patrick's College in Dublin (31 subjects, all males).

The Universities at Dublin and Galway are two of the three universities associated with the National University of Ireland. (The third is the University College at Cork). St. Patrick's College is also part of the National University of Ireland but it is a college for the education of primary school teachers. Because it was not possible to obtain a sufficient number of male students from the two universities, additional male students for the sample were obtained 
Table 1

Description of Age, Sex, Country of Birth, Citizenship and Undergraduate Status of Subjects in Three Samples
IRELAND
ITALY
U.S.A.

Number of

m $f$ total $m$ I total $m$ to total

Subjects:

$89 \quad 97 \quad 186$

$\begin{array}{lll}83 & 96 & 179\end{array}$

$90 \quad 100 \quad 190$

Age:

$\begin{array}{rrrrrrrrrr}17-19 & 65 & 79 & 144 & 27 & 24 & 51 & 26 & 49 & 75 \\ 20-22 & 15 & 11 & 26 & 48 & 58 & 106 & 51 & 34 & 85 \\ 23-25 & 5 & 3 & 8 & 5 & 12 & 17 & 7 & 13 & 20 \\ 26- & 4 & 4 & 8 & 2 & 2 & 4 & 6 & 4 & 10\end{array}$

Country of

Birth:

$\begin{array}{lrrrrrrrrr}\text { Native: } & 87 & 84 & 171 & 67 & 95 & 162 & 85 & 95 & 180 \\ \text { Other: } & 2 & 13 & 15 & 1 & 1 & 2 & 4 & 5 & 9 \\ \text { No Ans. } & & & & 15 & 0 & 15 & 1 & 0 & 1\end{array}$

Citizen of:

$\begin{array}{lrrrrrrrrr}\text { Native } & 89 & 95 & 184 & 62 & 93 & 155 & 88 & 96 & 184 \\ \text { Other: } & 0 & 2 & 2 & 0 & 0 & 0 & 2 & 3 & 5 \\ \text { No Ans. } & & & & 21 & 3 & 24 & 0 & 1 & 1\end{array}$

Undergraduate:

$\begin{array}{llllllllll}\text { Freshman } & 89 & 97 & 186 & 59 & 43 & 102 & 57 & 92 & 149\end{array}$

Sophomore

$\begin{array}{llllllllll}\text { Junior } & 0 & 0 & 0 & 19 & 52 & 71 & 27 & 3 & 30\end{array}$

Senion

Other

$\begin{array}{llllll}1 & 0 & 1 & 4 & 5 & 9\end{array}$

No Ans.

$\begin{array}{llllll}4 & 1 & 5 & 2 & 0 & 2\end{array}$


from St. Patrick's College. No significant differences were found among the three sub-samples on any important variables and they were combined to form the total Irish sample of 186 subjects.

The Irish sample was the most homogeneous of the three national samples. One hundred percent of the students were freshman and sophomores at the time data were collected in the Spring of 1980. Ninetysix percent were between the ages of 17 and 25 . The mean age for the females was 18.85 years and for the males it was 20.00 years. Most of the students were born in Ireland and are citizens of Ireland. Of the very small percentage ( $8 \%$ ) who were born out of the country, threefourths of these were born in Great Britain (England or Northern Ireland) and the remainder (one each) in the U.S.A., China, and Belgium.

Ninety-nine percent of the sample were Irish citizens (one subject claimed dual U.S./Irish citizenship, and one was a citizen of Hong Kong). Ninety-seven percent of the sample was single. Ninety percent stated their religious affiliation was Roman Catholic.

The overwhelming percentage of the parents of these students ( $92 \%$ of the mothers and $96 \%$ of the fathers) were also born in Ireland. of the few who were not, most were born in one of the other parts of the British Isles.

Combining the reported education, income level, and occupation of parents as reported by students into a rough estimate of socioeconomic status (SES), it appears that the Irish students are sons and daughters of middle- to upper-middle class families. Details of the demographic data for these students will be reported in greater detail in Chapter 3 (Resu7ts). 
The Italian Sample $\quad(N=179)$

The Italian sample was obtained through the generous personal assistance of Ms. Pamela Merenda and Ms. Rosalia Sparacino, both of whom are lecturers at the University of Palermo in Sicily.

The Italian sample consisted of a total of 179 students, 83 males (46\%) and 96 females (54\%). A11 were students at the University of Palermo and were enrolled in Introductory Psychology classes and English language classes at the time data were collected in the Fall of 1981 .

The University of Palermo in Sicily is a national university, part of the highly centralized Italian educational system which includes at least 28 other universities located at centers throughout Italy.

Though the majority of students indicated they were freshman and sophomores $(57 \%)$, a substantial proportion (especially of females) reported they were juniors and seniors. It should be pointed out, however, that this fourfold classification of students is not as meaningful for Italian as it is for American and Irish colleges, since the system of higher education in Italy is somewhat different. Students typically proceed more independently, studying until they are ready to present themselves for series of qualifying examinations and usually taking between four and six years to do so.

Ninety-seven percent of the students were between the ages of 17 and 25 with a modal age for the sample as a whole of 22 years. The mean age for females was 27.0 years, and for males, 20.52 years. 
Ninety percent of the sample stated that they were born in Italy. However - in a pattern typical especially of the males in the Italian sample - a fair number of students failed to respond.to this (and other) questions. Since, however, only two subjects specifically gave birthplaces other than Italy, it is assumed that the true percentage of native birth probably approaches $99 \%$.

The same reasoning may be applied to the question of citizenship. Although $86 \%$ of the sample stated they were Italian citizens, it is felt that the remaining $74 \%$ who failed to answer the question probably are citizens as well, especially since no student reported citizenship in any other country. This means that the sample is very likely $99 \%$ to $100 \%$ Italian citizenship.

Ninety-three percent of the Italian students stated they were single and sixty-five percent declared their religious affiliation to be Roman Catholic, with a significant difference here between the $46 \%$ of the male subjects versus the $82 \%$ of the female subjects who stated they were Catholic.

It is likely that almost all of the parents of these students were also born in Italy, though on $7 y$ 75\% of the subjects specifically stated this. The remaining $24 \%$ did not respond to the question although no subject reported any other country of birth for either parent. The majority of students (83\%) reported that the income level of their parents was average or above average and though the educational attainment and occupational status reported for their parents by the subjects was somewhat lower than for the Irish and American samples, the students can probably fairly be described as of middle or "working class". 
The American Sample $(N=190)$

The American sample was obtained by the researcher through the kind cooperation of instructors at the Community College of Rhode Island, the University of Rhode Island, and Bryant College in Smithfield, Rhode Island, who permitted students in their introductory Psychology classes to take part in the research.

The American sample consists of 190 students, 90 males (47\%) and 100 females (53\%). Data were initially collected from 256 students in an attempt to form sub-samples of sufficient numbers of IrishAmerican and Italo-American students to include ethnicity as a variable. When it became apparent that this would not be feasible, due to the great diversity of ethnic backgrounds of the American students and some inherent weaknesses in the measure used to determine ethnicity, the American sample was formed by matching the Irish and Italian samples as closely as possible on the basis of age and sex ratios and discarding data from the remaining 66 subjects. Except for matching on the basis of age and sex, selection of subjects for the American sample was carried out on a strictly random basis and, of course, prior to any analysis of the data. A11 100 female subjects were students at the Community College of Rhode Island at the time data were collected in the Spring of 1981. Interestingly, the same difficulty in obtaining a sufficient number of male subjects in the classes made available to the researcher was encountered in the American sample as in the Irish and Italian samples. For this reason, it was necessary to obtain relatively small numbers of male subjects from the University of Rhode Island ( 13 subjects) and Bryant College ( 21 subjects), to augment the 
56 subjects obtained from the Community college. These subjects were a17 enrolled in introductory Psychology classes at the time data were collected in Fa11, 1981. No significant differences were found on any important variables and the three groups were combined to form the male sample of 90 subjects.

Seventy-eight percent of the subjects stated they were freshman or sophomores. Ninety-five percent of the students were between the ages of 17 and 25 years, with a modal age for the sample as a whole of 19 years. The mean age for female subjects was 20.84 years and for males, 21.30 years.

Ninety-five percent of the subjects reported they were born in the United States and ninety-seven percent stated they were U.S. citizens.

Ninety-one percent of the sample stated they were single. Seventytwo percent - $80 \%$ of the females and $62 \%$ of the males - gave Roman Catholicism as their religious affiliation. Ninety-one percent of the parents of these students were born in the United States.

The educational attainment, income level, and occupational status of parents as reported by these students fell between the slighter lower levels for the Italian sample and the slightiy higher levels for the Irish sample. Combining these three variables into an informal estimate of SES, the American sample can probably also be fairly described as. "middle" or "working class" in background. 
Instruments

The "Test Booklet"

Each subject in this research received a "test booklet" consisting of materials to be completed in the following order. Part I: A single sheet requesting demographic information. Part II: A folded sheet consisting of three open-ended questions on the facing page eliciting heterostereotypes of the other two national groups and the amount of contact subject estimated $\mathrm{s} / \mathrm{he}$ had with each; and, on the inside pages, a list of the 81 adjectives of the Activity Vector Analysis (AVA) repeated twice: once as a measure of the subject's autostereotype and once as a measure of the "real" or "basic" self. Part III: the MyersBriggs Type Indicator (MBTI) and accompanying answer sheet. Each measure will be discussed individually in the order in which subjects completed them.

\section{Demographic Variables}

For the Irish and Italian samples, the Demographic sheet consisted of the same set of questions, identical except that an Italian language version was provided for the latter group.

For the American sample, the Demographic sheet was identical except for the addition of a question used to determine ethnicity of the subject.

The demographic information requested from all three groups included: age, sex, country of birth, citizenship, year of undergraduate study presently being completed, marital status, religious affiliation, church attendance, parents' country of birth, parents' education (in 
years of formal schooling completed), parents' occupation, and approximate level of income of parents.

For the American sample only, an additional question asked for the country of birth and "nationality" of each of the four grandparents.

Most of the questions were open-ended to allow the subject maximum freedom in responding, but the following four questions, along with the response categories provided, were exceptions:

Year of Undergraduate Study Presently Being Completed: Fresh$\operatorname{man}$ ; Sophomore ; Junior ; Senior ; Other

Martial Status: Single ; Married ; Widowed ; Divorced Separated

Church Attendance: Daily ; Week1y ; Monthly ; Several Times a Year ; Never

Approximate Income Level of Parents: Much Below Average Below Average ; Average ; Above Average ; Much Above Average

Questions requesting information on education, occupation, and country of birth of the parents were completed for both mother and father individualiy. (See Appendix I for sample of the American form of the Test Instruments).

\section{National Heterostereotypes}

These were measured through two open-ended questions, identical in wording except for the national groups specified. The instructions for all groups were the same: "Most people have a national or cultural identity, as well as an individuat identity, even though we know that such identities are very generalized descriptions and most certainly 
not true of every member of a given group. Though we recognize that such descriptions are necessarily very general, can you describe your picture of the national groups listed below?".

Each subject was then asked to respond to two open-ended questions phrased as follows: "Using ten adjectives or less, please try to give your picture of the 'average' or 'typical' .$"$ (Irish/Italian/American). Each National group responded to this question twice: once each for the other two national groups. Thus, Americans stereotyped Irish and Italians; Irish students stereotyped Americans and Italians; and Italian students stereotyped Americans and Irish. A third question, also open-ended, asked subjects to: "please indicate very briefly how much contact you personaliy have had with members of these two groups".

The Activity Vector Analysis (AVA): Measures of the National Autostereotype and of the "Real" or "Basic" Self

In this study, the national autostereotype was measured by instructing the subject to: "Place an ' $X$ ' before every word given below that you believe describes (your own) people as a whole or in general. I believe the 'typical' (member of my own national group) is...".

The list of words following these instructions were the 81 adjectives of the AVA:

In the same fashion, perception of the "real" or "basic" self was measured by instructing the subject to: "Now place an ' $X$ ' before every word which you honestly believe is descriptive of you." The 81 adjectives of the AVA were again Tisted below these instructions. 
The AVA was originally constructed by Walter V. Clarke (1956) as a personality test for use in industrial selection - that is, for the purposes of enhancing job placement by determining the degree to which an individual's temperament and behavioral tendencies are compatible with the demands of a particular job. Since its original development in the late 1940's, the use of the AVA has been expanded to include a considerable number of applications beyond this.

The conventional form of the AVA consists of a list of 81 adjectives, repeated twice. The subject is asked first to check "every word that has ever been used by anyone in describing you"; and then to select, from the second list of the same 81 adjectives, every work "you honestly believe is descriptive of you". In this way, two profiles are obtained: the "social self" or self the subject believes is perceived by others; and the basic or "real" self: the self the subject believes himself to "real1y" be. A third profile, the resultant of these two, is termed the "composite self" - or "how the person is apt to be in fact perceived by others" (Merenda and Clarke, 1965). These instructions may be altered to obtain other profiles - for example, profile of the "ideal self", profile of a public figure, or, as in the case of this research, profile of the "typical" member of a given group.

These profiles yield personality descriptions that are based on the integration of the scores on four factors or vectors measured by the AVA: aggressiveness ( $V-1)$; sociability $(V-2)$; emotional control $(V-3)$; and social adaptability $(V-4)$. A fifth variable, activity leve1, determined by the total number of words checked, though not 
directly involved in determining the profile, is postulated to indicate the individual's energy level. and therefore to contribute psychologically significant information.

A profile shape (PS) is designated by a four-digit number which represents the subject's ipsative position on each of the four vectors. A raw score on a given vector is determined by the number of adjectives checked by the subject which "belong to" that vector. Each vector of the AVA has approximately 20 words empirically determined, through factor analytic techniques, to be associated with its core meaning, (Merenda and Clarke, 1959).

Vector 1, or aggressiveness, has been determined, for example, to have a core meaning embodied in the AVA adjectives: stubborn, selfcentered, dominant, argumentative, opinionated, and impulsive. The more words of this type checked by a subject, the higher his score on vector one, or aggressiveness.

Similarly, $V-2$, or sociability, has a meaning embodied in the core words: Charming, appealing, admirable, smooth, and attractive.

Emotional control, or $V-3$, is signified by the subject's selection of words like: stable, calm, relaxed, quiet and patient.

Social adaptability, or $V-4$, is embodied by the core words: anxious, hesitant, submissive, tense, and dependent.

Raw scores on each vector are converted to standard scores having a mean of 50 and standard deviation of 10. An individual's profile is then determined ipsatively by assigning a value to each vector of from one (1) to nine (9), based on the deviation of the subject's score on 
that vector from his own mean. As an example, a subject's raw scores on vectors one through four, of: $26,12,18$, and 8 respectively, when converted to standard scores, become: $V-1=58 ; V-2=48 ; V=3=46$; and $V-4=46$. The subject's own mean would thus become the sum of these four scores divided by four, or 50 .

Pattern shapes are then derived by transforming standard scores to a nine-point scale, with one (1) representing the minimum value on a vector and nine (9) the maximum value. There are two constraints imposed on deriving the profile pattern: the four numbers of the profile must add up to 20; and at least one of the numbers must be either a 1 or a 9, depending on whether the outstanding vector deviates from the mean in a negative (1) or positive (9) direction. For the illustration given above, since vector $1=58$, it receives a value of 9 . Based on the relative deviations of the other vector scores from $\mathrm{V}-1$, the profile designation in this case becomes: PS 9434. Scoring is thus ipsative and yields a four-digit number or pattern shape which is associated with a unique personality type. The AVA yields 258 profile or pattern shapes.

It should be emphasized that the personality type or profile derived in this manner is not simply a linear composite of the four vectors involved but, rather, a complex integration of four behavioral tendencies.

Clarke hypothesized that the observed behavioral tendency of an individual is the result of a complex interplay of psychological forces or variables acting upon or within the individual. He went on to postulate that an adequate, although not, of course, exhaustive, 
description of an individual's behavioral tendency could be derived by taking into account the interplay of the four independent vectors of aggressiveness, sociability, emotional control, and social adaptability.

It was Clarke's belief that underlying these four variables are two basic kinds of responses (approach versus avoidance) to two basic kinds of social situations (favorable versus unfavorable).

Thus, aggressiveness $(V-1)$ is conceived of as approach behavior in an unfavorable or antagonistic situation - or, in other words, the tendency on the part of an individual to meet difficulties head on.

Sociability $(V-2)$ is conceived of as an approach behavior in a favorable situation - or the tendency of an individual to respond in an active, positive way to friendiy situations.

Emotional control $(\mathrm{V}-3)$, on the other hand, is a basic tendency on the part of the individual to withdraw or retreat from a friendly or favorable situation and may be conceived of as similar to (though not identical with) traits like introversion and field independence or the tendency to maintain a certain distance from the social environment.

Finally, social adaptability $(V-4)$ is the tendency to withdraw or shrink from unfriendly or antagonistic social situations.

It will be recalled that the profile or pattern which results from the subject's scores on these four variables represents a unique personality type. It will further be recalled that, though in theory the number is infinite, contraints imposed by the mathematical model underlying the AVA limit the actual number of discrete profiles to 258. 
These types taken together can be conceived of as a universe or sphere, containing 258 possible behavioral tendencies having both direction and magnitude. The resolution of the four vectors or variables into a single behavioral tendency (that is, its placement as one of the radii within this sphere) can be conceived of in mathematical terms as the problem of expression four independent forces of differing directions and magnitudes as a single resultant vector. Mathematically, this problem reduces to an application of the parallelogram law, performed twice over. Thus, if $V-1$ and $V-2$ are conceived of as two independent forces of differing strengths and magnitudes, they may be resolved into a single resultant, vector 12 . Vectors 3 and 4 can similarly be resolved

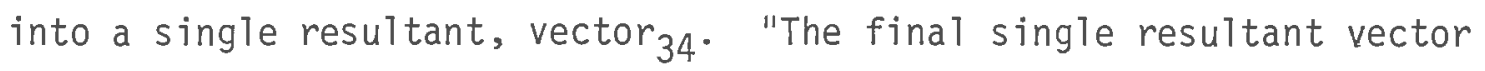
can now be obtained by combining or adding these two vectors by means of the parallelogram rule [p. 7]". (Clarke Inc., 1958).

It is now possible to conceptualize the universe of behavioral tendencies or possible profiles as a three-dimensional sphere, with a core or center, from which 258 radii project outward toward the surface in all possible directions. (The four reference vectors, $V-1$, $V-2, V-3$, and $V-4$ lie within this sphere mutually equidistant from each other and separated by an angle of $110^{\circ}(r=-.34)$.) Each of these 258 radii represents a uniquely determined behavioral tendency or pattern shape (that is, "the final single resultant vector" discussed above).

One of the outstanding advantages of this mathematical conceptualization, is that it permits the spatial representation of each type and allows relationships between types to be visualized in terms of 
angular separation between radii. "Since the cosine of the angular difference in direction between two pattern shapes is the coefficient of correlation" it further permits determination of the degree of Pearsonian relationship between any two types.

A method of projecting the three-dimensional space of this sphere onto a two-dimensional "map" known as the AVA Pattern Universe, has been accomplished through use of a Mercator-type projection technique.

This, in turn, permits the plotting on this universe of the distribution of profiles shapes in samples derived from various populations, a fact pertinent to the present research.

In summary, the AVA is a free-response list of 81 adjectives descriptive of human behavior which, although relatively simple and efficient to administer, nevertheless rests upon a psychologically sound theory and a sophisticated mathematical model. The subject's scores on four vectors provide the basis for determination of the profile. The psychometric properties of the test reflect its meticulous development and refinement that has been carried out over close to four decades. The reliabilities of the word choices themselves, the vector scores and the profiles have been investigated extensively and found to be quite high. The validity of the test has been repeatedly demonstrated utilizing a wide variety of methods and samples. Construct validity has been established through, among other methods, factor analytic techniques of a measure of the social self (Merenda \& Clarke, 1959a) and comparisons of AVA profile patterns with narrative self-descriptions of advanced graduate students (Merenda \& Clarke, 1965). 
The predictive validity of the AVA has similarly been well-established by demonstrating, for example, that distinctive AVA profiles exist for successful versus unsuccessful life insurance agents (Merenda \& Clarke, 1959b); management personnel versus line workers (Merenda and Clarke, $1959 \mathrm{C}$ ); and self-made company presidents (Merenda \& Clarke, 1959 d).

Finally, the 81 adjectives of the AVA have been shown to be almost entirely free of sex bias (Hasler and Merenda, 1978) or a social desirability factor.

The Myers-Briggs Type Indicator (MBTI): A Second Measure of the "Basic" $\underline{\text { Self }}$

Buros (1978) calls the MBTI "A major effort to capture Jungian personality typology in a psychometric instrument."

Development of the test rests upon the fundamental assumption that "much apparently random variation in human behavior is actually quite orderly and consistent, being caused by certain basic differences in mental functioning (Myers, 1962, p. 51).

There "basic differences", according to Carl Jung, arise in four areas of human functioning" perception, judgment, orientation with respect to the environment, and characteristic method of dealing with the environment.

Within each of these four basic areas there are, in turn, "two distinct and sharply contrasting modes of functioning." (Test Manual)

Thus Jung hypothesizes two kinds of preference in perceiving the world: (1) "sensing", or reliance solely upon the direct evidence of the five senses; versus (2) "intuition" or "indirect perception" in which additional ideas or associations are "unconsciousiy tacked on to" 
the perceptions coming in from the external senses, thus leading to "hunches", "intuitions" or "insights" which go beyond the immediate evidence.

A similar dichotomy of preferences exists in the use of judgment (defined as the process of "coming to conclusions about what has been perceived.") One preference in the use of judgment is the thinking approach, in which conclusions are based on a rational and impersonal weighing of the "facts", or on a true/not true basis. The other preference is the feeling approach, in which decisions are based on an affective evaluation of the situation, or on a like/dislike basis.

Jung is probably most famous for the third dichotomy, his postulation of two basically different orientations toward the environment, introversion versus extraversion. Jung, who introduced both the concept and the terms, theorizes that introverts are mainly interested in, and direct their attention upon, "the inner world of concepts and ideas" while extraverts are mainly interested in and direct their attention upon, "the outer world of people and things".

One last dichotomy of preferences is in the characteristic attitude toward, or way of dealing with, the environment, the judging mode versus the perceptive mode. As the Test Manual succinctly states it, "judging people run their lives while perceptive people live them." The judgmental person operates in a deliberate, planned and orderly way, imposing on situations a pre-determined way of dealing with them, while the perceptive person operates more flexibly, spontaneously changing his approach to situations as the situation and his whims dictate. (The judging versus perceiving preference is also theorized 
to determine the individua7.'s dominant process but this will not be discussed here. It rests on shaky empirical evidence and is not relevant to the present research.)

These four dichotomies should give rise theoretically to different "personality types" based on the direction of the person's preference on each of the four dimensions. It is this rationale on which the MBTI is based.

The MBTI has undergone continuous revision and refinement since work was first begun on its development in 1942. There are currently two forms in use, the older and longer Form F (166 items) and the shorter and more recent Form $G$ (126 items). Form $G$ was used in the present research.

The format of the test is forced-choice and the test yields measures on eight scales (four dichotomies): Introversion versus Extraversion (I-E); Sensing versus Intuition $(S-N)$; Thinking versus Feeling $(T-F)$; and Judging versus Perceiving $(J-P)$.

The numerically higher score on each dichotomy provides the direction of the person's basic preference. The strength of the preference is calculated by subtracting the score on the less preferred dimension from the score on the more preferred dimension to obtain what is called a difference score; and then converting, through use of a simple formula designed to eliminate zero scores, to the final preference score.

For example, a subject receiving a raw score of 17 on the $E$ scale and 6 on the I scale will have a difference score of Ell, and a preference score of 2D - 1, or E21. A subject's score on the MBTI, then, 
consists of the four letters indicating his preferential modes of functioning, and the strength associated with each preference: for example, I $35 ; \mathrm{N} \mathrm{46;} \mathrm{F} \mathrm{16;} \mathrm{P} 5$. In practice, unless special use is to be made of the strength, the type is usually simply designated by letters only or, for example, INFP.

In addition to items, the MBTI also contains some simple word pairs in which the subject must choose the preferred word. Some typical items from each of the four dichotomous scales of the MBTI, along with the scales on which they are scored, will be found in Table 2.

Sixteen possible personality types can be formed through the various combinations of the basic preferences. The Test Manual provides a qualitatively rich narrative description for each of the sixteen personality types. See Table 3 for the sixteen types.

These personality descriptions have apparently been developed, not only on the basis of theory, but also through the extensive empirical work that has been done correlating the various scales of the MBTI with a wide variety of other psychological measures. Scales of the MBTI have been shown to correlate substantially and in accordance with apriori predictions, with scales on such instruments as the Strong Vocational Interest Blank, the Allport-Vernon Study of Values, and the Edwards Personal Preference Schedule. Correlations have also been demonstrated with non-test variables, notably between the $\mathrm{S}-\mathrm{N}$ scale and scholastic performance.

The Test Manual reports respectable split-half reliabilities for the type categories (tetrachoric correlation coefficients were utilized with a Spearman-Brown correction). It is surprising, however, in a test 
Table 2

Sample Items from the Myers-Briggs Type Indicator

I-E Scale: Introversion vs Extraversion

When you are with a group of people, would you usually rather

$E$ (a) join in the talk of the group, or

I (b) talk with one person at a time.

Which word in each pair appeals to you more?

I (a) reserved

\section{S-N Scale: Sensing vs Intuition}

If you were a teacher, would you rather teach

$S$ (a) fact courses, or

$N$ (b) courses involving theory

Which word in each pair appeals to you more?

$S$ (a) foundation

$\mathrm{N}$ (b) spire

T-F Scale: Thinking vs Feeling

Is it a higher compliment to be called

$F$ (a) a person of real feeling, or

$T$ (b) a consistently reasonable person

Which word in each pair appeals to you more?

$T$ (a) justice

$F$ (b) mercy

J-P Scale: Judging vs Perception

Does following a schedule

$J$ (a) appeal to you, or

P (b) cramp you?

Which word in each pair appeals to you?

$\begin{array}{ll}\text { J } & \text { (a) punctual } \\ \text { P } & \text { (b) Teisurely }\end{array}$ 
Table 3

MBTI Sixteen Personality Types

Characteristics Frequently Associated with each Type Among Young People

Sensing Types - Introverts

I S T J

Serious, quiet, earn success by concentration and thoroughness. Practical, orderly matter-of-fact, logical, rea 1istic and dependable. See to it that everything is well organized. Take responsibility. Make up their own minds as to what should be accomplished and work toward it steadily, regardless of protests or distractions.

\section{S F J}

Quiet, friendly, responsible and conscientious. Work devotedly to meet their obligations and serve their friends and school. Thorough, painstaking, accurate. May need time to master technical subjects, as their interests are usually not technical. Patient with detail and routine. Loyal, considerate, concerned with how other people feel.

\section{S T P}

Cool onlookers - quiet, reserved, observing and analyzing life with detached curiosity and unexpected flashes of original humor. Usually interested in impersonal principles, cause and effect, how and why mechanical things work. Exert themselves no more than they think necessary, because any waste of energy would be inefficient.

\section{S F P}

Retiring, quietly friendly, sensitive, kind, modest about their abilities. Shun disagreements, do not force their opinions or values on others. Usually do not care to lead but are often loyal followers. often relaxed about getting things done, because they enjoy the present moment and do not want to spoil it by undue haste or exertion. 
Table 3 (cont'd)

MBTI Sixteen Personality Types

Characteristics Frequently Associated with each Type Among Young People Sensing Types - Extraverts

\section{E S T P}

Matter-of-fact. do not worry or hurry, enjoy whatever comes along. Tend to like mechanical things and sports, with friends on the side. May be a bit blunt or insentive. Can do math or science when they see the need. Dislike long explanations. Are best with real things that can be worked, handled, taken apart or put together.
ESFP

Outgoing, easygoing, accepting, friendly, enjoy everything and make things more fun for others by their enjoyment. Like sports and making things. Know what's going on and join in eagerly. Find remembering facts easier than mastering theories. Are best in situations that need sound common sense and practical ability with people as well as with things.

\section{ES F J}

\section{E S T J}

Practical, realistic, matter-offact, with a natural head for business or mechanics. Not interested in subjects they see no use for, but can apply themselves with necessary. Like to organize and run activities. May make good administrators, especially if they remember to consider others' feelings and points of view.
Warm-hearted, talkative, popular, conscientious, born cooperators, active committee members. Need harmony and may be good at creating it. Always doing something nice for someone. Work best with encouragement and praise. Little interest in abstract thinking or technical subjects. Main interest is in things that directly and visibly affect people's lives 
Table 3 (cont'd)

MBTI Sixteen Personality Types

Characteristics Frequently Associated with each Type Among Young People Intuitive Types, - Introverts

I NF J

Succeed by perseverance, originality and desire to do whatever is needed or wanted. Put their best efforts into their work. Quietly forceful, conscientious concerned for others. Respected for their firm principles. Likely to be honored and followed for their clear convictions as to how best to serve the common good.
I $N$ T J

Usually have original minds and great drive for their own ideas and purposes. In fields that appeal to them, they have a fine power to organize a job and carry it through with or without help. Skeptical, critical, independent, determined, often stubborn. Must learn to yield less important points in order to win the most important.

\section{N F P}

Full of enthusiasms and loyalties but seldom talk of these until they know you well. Care about learning, ideas, language, and independent projects of their own. Tend to undertake too much, then somehow get it done. Friendly, but often too absorbed in what they are doing to be sociable. Little concerned with possessions or physical surroundings.

\section{N T P}

Quiet, reserved, brilliant in exams, especially in theoretical or scientific subjects. Logical to the point of hair-splitting. Usually interested mainly in ideas, with little liking for parties or small talk. Tend to have sharply defined interests. Need to choose careers where some strong interest can be used and usefuT. 
Table 3 (cont'd)

MBTI Sixteen Personality Types

Characteristics Frequently Associated with each Type Among Young People Intuitive Types - Extraverts

ENFP

Warmly enthusiastic, highspirited, ingenious, imaginative. Able to do almost anything that interests them. Quick with a solution for any difficulty and ready to help anyone with a problem. Often rely on their ability to improvise instead of preparing in advance. Can usually find compelling reasons for whatever they want.

\section{E NF J}

Responsive and responsible. Generally feel real concern for what others think or want, and try to handle things with due regard for other people's feelings. Can present a proposal or lead a group discussion with ease and tact. Sociable, popular, active in school affairs, but put time enough on their studies to do good work.
EN T P

Quick, ingenious, good at many things. Stimulating company, alert and outspoken. May argue for fun on either side of a question. Resourceful in solving new and challenging problems, but may neglect routine assignments. Apt to turn to one new interest after another. Skillful in finding logical reasons for what they want

\section{ENT J}

Hearty, frank, able in studies, leaders in activities. Usually good in anything that requires reasoning and intelligent talk, such as public speaking. Are usually well-informed and enjoy adding to their fund of knowledge. May sometimes be more positive and confident than their experience in an area warrants. 
which has undergone such extensive development and refinement, to find that the Manual does not report test-retest coefficients.

After noting that there are some problems with the test, especially the rather high intercorrelation of the J-P scales with the S-N scales, Buros nevertheless concludes: "...A substantial body of empirical data gathered on the MBTI... from a variety of occupational and academic groups... are broadly supportive of the construct validity of the scales."

\section{Italian Language Translations of the Instruments}

An Italian Language version of the AVA had already been developed and used extensively prior to this study and was therefore available for use in the present research. The Demographic Variables sheet and the Myers-Briggs had to be translated into Italian especially for this study. The first translation was made by Dr. Santo Salvatore. It was checked and refined by Dr. Remo Trevelli of the Language Department at the University of Rhode Island. It was "back-translated" with the assistance of Dr. Peter Merenda, Ms. Pamela Merenda, and Ms. Rosalia Sparacino. The translation was judged to be adequate.

\section{Procedure}

The instruments discussed in the preceding section were combined into a "test booklet" which was distributed to subjects during a 50minute lecture period. After briefly explaining that this was a crosscultural study, subjects were instructed to begin by filling out the demographic sheet and then proceeding at their own pace through the 
rest of the test material. Printed instructions were provided so as to make the instrument virtually self-administering.

The researcher administered the instrument to the American sample. As previously noted, Dr. Patricia Fontes and Dr. Christopher Sims administered the instrument in Ireland; and Ms. Pamela Merenda and Ms. Rosalia Sparadino in Italy. Almost all of the subjects completed the inventories in the fifty minute period. Of the very few who did not, most were close enough to completion so that the data were useable. The MBTI, which was the last to be administered, can be scored if the subject completes at least 50 items. This was the case for virtually a)1 the subjects. 
65.

\section{Chapter 3}

\section{RESULTS}

Demographic Variables

Brief descriptions of the three samples in terms of age, sex ratios, undergraduate status, country of birth, and citizenship have a]ready been presented in Chapter 2. This section will compare the martial status, religious affiliation, and church attendance of students in the three samples, and the educational attainment, occupation, and approximate income levels of their parents.

Though the vast majority of students in a 11 three groups were single, the slight differences in marital status that were found appear to reflect underlying differences in the populations from which the samples were drawn.

The Irish students had the highest proportion of single students, $96 \%$, with only three subjects who stated they were married, and five who did not respond to the question.

The Italian sample had the second highest proportion of single students, 93\%, with seven students reporting they were married, and five who did not respond to the question.

The American sample had the lowest proportion of single students, $91 \%$, with six married students, one widowed student, eight divorced students, and two who did not respond.

Though the majority of students in all three samples reported their religious affiliation as Roman Catholic, there were some 
unexpected differences in the proportions doing so.

The proportion of Irish students who stated they were Catholic was $88 \%$. This falls somewhat short of the official census figures for the Irish population ( $94 \%$ as of 1978) but was still the highest proportion for the three groups, as was to be expected. Two students reported they were Protestants, 14 said they had no religious affiliation, and five did not answer.

The proportion of Italian students, $65 \%$, giving Catholicism as their religion was, however, not only considerably lower than might be expected on the basis of the population parameter $(97.5 \%$ as of 1978) but was actually lower than that of the American sample. In addition, there was a significant sex difference, with only $46 \%$ of the males as opposed to $82 \%$ of the females, stating that they were Catholics. (On the basis of approximately equal expected frequencies, the difference is significant at the .001 alpha level.) The sex difference is almost entirely accounted for by the males (22\%) who explicitely stated they were agnostics, atheists, or "nessuna" (nothing), and the males (22\%) who did not respond, as contrasted with the $5 \%$ each of Italian females whose responses fell into these two categories. There were two Protestants in the total sample, no Jews, and 14 subjects who reported affiliations in the category of "other", e.g. "Christian", "ecumenical", etc.

Seventy-two percent of the American sample, $62 \%$ of the males and $80 \%$ of the females, stated they were Catholic. Though high for the U.S. as a whole, these percentages show neither a significant difference between the sexes nor a significant difference (for either sex) 
between the sample values and the population parameter for the state of Rhode Island. Based on figures provided by the Diocese of Providence, the percent of Catholics in Rhode Island as of 1980 was $65 \%$, the highest of any state in the union. In the remaining American sample, there were 20 Protestants, two Jews, two agnostics, no atheists, 13 who claimed no religious affiliation, seven who did not answer the question, and ten in the category of "other" - e.g. Muslim, Christian, etc.

Responses across the three samples to the question regarding church attendance follow in general the same lines, and show, again, somewhat unexpected differences between Italian and American students.

Irish students report the highest proportion of regular church attendance: $69 \%$ claiming to attend daily or week $7 y, 16 \%$ occasionally (monthly to several times a year); $11 \%$ "never"; and 4\% not responding.

In contrast, only $28 \%$ of the total Italian sample claim regular attendance: $18 \%$ of the males and $36 \%$ of the females. Occasional attendance is reported by $32 \%$ of the females and $18 \%$ of the males. Forty-four percent of the males and $25 \%$ of the females claim they "never attend". Twenty-two subjects did not respond to the question.

Somewhat unexpected7y, a higher proportion, 34\%, of American versus Italian students, report regular attendance. Thirty percent of the males and $37 \%$ of the females, state they attend weekly; occasional attendance is reported by $43 \%$, and $20 \%$ state they never attend. Only four subjects did not respond to the question.

These data are summarized in Table 4. 
68.

Table 4

Percent*of Responses in Categories of Marital Status, Religious Affiliation and Church Attendance for Irish, Italians and U.S.Ss

Nationa 1 Group:

VARIABLE : IRISH $=186 \quad$ ITALIANS $=179 \quad$ AMERICANS $=190$

Marital Status: $\underline{m} \underline{f}$ total $m \underline{f}$ total $m \underline{f}$ total

$\begin{array}{llllllllll}\text { Single: } & 99 \% & 96 \% & 97.3 \% & 91 \% & 95 \% & 93 \% & 90 \% & 92 \% & 91 \%\end{array}$

$\begin{array}{llllllllll}\text { Married: } & 1 \% & 2 \% & 1 \% & 4 \% & 4 \% & 4 \% & 4 \% & 2 \% & 3 \%\end{array}$

$\begin{array}{llllllllll}\text { Widowed: } & 0 & 0 & 0 & 0 & 0 & 0 & 0 & 7 \% & .5 \%\end{array}$

$\begin{array}{llllllllll}\text { Divorced: } & 0 & 0 & 0 & 0 & 0 & 0 & 3 \% & 5 \% & 4\end{array}$

No Answer: $\quad \begin{array}{lllllllll}0 & 2 \% & 1 \% & 5 \% & 1 \% & 3 & 2 \% & 0 & 1\end{array}$

Religion:

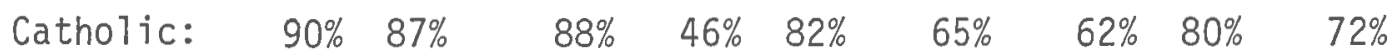

$\begin{array}{llllllllll}\text { Protest.: } & 0 & 2 \% & 7 \% & 7 \% & 7 \% & 7 \% & 12 \% & 9 \% & 10\end{array}$

$\begin{array}{llllllllll}\text { Jewish: } & 0 & 0 & 0 & 0 & 0 & 0 & 2 \% & 0 & 1.0\end{array}$

$\begin{array}{llllllllll}\text { Other: } & 0 & 1 & .5 \% & 10 \% & 6 & 8 & 7 & 4 & 5\end{array}$

$\begin{array}{llllllllll}\text { Agnostic: } & 0 & 0 & 0 & 8 & 4 & 6 & 2 & 0 & 1\end{array}$

None: $\quad \begin{array}{lllllllll}7 \% & 8 & 7.5 & 13 & 1 & 7 & 9 & 5 & 7\end{array}$

No Answer: $\quad$\begin{tabular}{llllllllll}
$3 \%$ & 2 & 3 & 22 & 5 & 13 & 5.5 & 2 & 4 \\
\hline
\end{tabular}

Church Attendance:

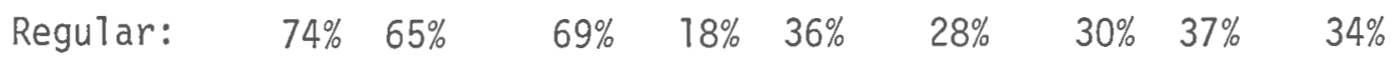

$\begin{array}{llllllllll}\text { Occasional: } & 9 & 23 & 16 & 18 & 32 & 26 & 40 & 47 & 44\end{array}$

$\begin{array}{llllllllll}\text { Never: } & 12 \% & 9 & 11 & 45 & 25 & 34 & 27 & 15 & 20\end{array}$

$\begin{array}{llllllllll}\text { No Answer: } & 4 \% & 3 \% & 4 \% & 19 & 6 & 12 & 3 & 1 & 2\end{array}$

*Percents rounded off 
Turning now to the data on parents of these students, the ethnicity of the American sample, and the education, income and occupation of parents of students in all three samples, will be discussed.

It is, first, not surprising to note that though the overwhelming majority of parents of students in all three countries were born in their respective countries, a slightly higher number of U.S. students' parents were born elsewhere. There seems little question that for both the Irish and Italian samples, almost all of the parents (and probably, grandparents, great-grandparents, and so on) were native born. (For the Irish sample, most of the very small number of parents not born in Ireland were born elsewhere in the British Isles.)

This was not true, however, for the American sample. Although $91 \%$ of the fathers and $92 \%$ of the mothers were born in this country, the percentage drops sharply for the grandparents. Thus, $56 \%$ of the materna1 grandmothers, 59\% of the maternal grandfathers, 55\% of the paternal grandmothers, and $59 \%$ of the paternal grandfathers were born in this country. Furthermore, American students come from extremely diverse ethnic backgrounds. A partial list of the countries from which the grandparents come, roughly in order of descending frequency, includes: Italy, Canada, Ireland, Portugal, England, Poland, Russia, Germany, Turkey, Finland, Sweden, Norway, Nigeria, Syria, Austria, Scotland, Czechoslovakia, and the Dominican Republic. The ethnic variable was dropped from this research in large part because this great diversity resulted in too few students who could meet the ethnicity criterion that three out of the four grandparents be either Irish or Italian. 
A rough index of the socioeconomic status of the three groups was obtained by examining the data on educational attainment, occupational status, and approximate income level of parents.

Differences in the legal requirements, and in the structures, of the educational systems in the three countries involved makes difficult strict comparisons of parents' education in number of years of formal schooling. Thus, conclusions based on this data are offered cautiously.

On this measure it does appear, however, that the parents of the Irish students are the most highly educated, with $35 \%$ of the mothers and $43 \%$ of the fathers reported as having gone beyond 12 years of formal schooling, or what in the U.S. would be called a high school education.

This compares to $23 \%$ of the mothers and $32 \%$ of the fathers in the Italian sample, and $28 \%$ of the mothers and $39 \%$ of the fathers in the American sample who had more than 12 years of formal schooling.

In terms of occupation, the same order appears to hold. Irish students claim the greatest proportion of professional parents, $20 \%$, followed by Americans, 14\%, and Italians, 13\%. Interesting1y, Irish students had both the highest proportion of mothers whose sole occupation was listed as "housewife/mother", and also the highest proportion of professional mothers. Sixty-three percent of the Irish mothers as opposed to $51 \%$ of Italian mothers and $26 \%$ of American mothers are fulltime housewives.

While the percentage of unskilled laborers among parents in the Irish sample was negligible, it rises to $7 \%$ in the Italian sample and $13 \%$ in the American sample. 
The modal occupational categories for fathers in each of the three countries are: Ireland - professional (followed closely by business, managerial level); Italy - clerical (followed not at all closely by business); and U.S.A. - business, managerial level (followed closely by skilled labor). See Table 5 for a list of the occupational categories used and the frequencies in each for the three countries.

In terms of approximate income level, the majority of students in a11 three countries report at least average income for their parents, but once again, the Irish report the highest percentage of "above" or "much above" average; $36.5 \%$ as opposed to $12 \%$ of Italians and $30 \%$ of Americans in these categories.

On the basis of these data, it is felt that the Irish students can be fairly described as sons and daughters of "middle" to, perhaps, "upper middle class" parents, while Italian and American students in these samples can be described as of "middle" or "working class" backgrounds.

Again, however, these conclusions are offered with the caution that the data derive from self-reports, not objective measures, and may well reflect response biases (e.g. exaggeration, understatement, etc.) as we11. Furthermore, differences in the economic and educational systems in the three countries make strict comparisons impossible. 
Table 5

Frequencies in Occupational Categories for Irish, Italian and U.S.A.

Students' Parents

\begin{tabular}{|c|c|c|c|c|c|c|}
\hline \multirow[b]{2}{*}{ Occupation: } & \multicolumn{2}{|c|}{ IRELAND } & \multicolumn{2}{|c|}{ ITALY } & \multirow{2}{*}{\multicolumn{2}{|c|}{$\begin{array}{l}\text { U.S.A. } \\
\text { mothers fathers }\end{array}$}} \\
\hline & mothers & fathers & mothers & fathers & & \\
\hline Housewife & 118 & 1 & 92 & 0 & 50 & 2 \\
\hline $\begin{array}{l}\text { Professional } \\
\text { (M.D. law, etc.) }\end{array}$ & 23 & 51 & 7 & 16 & 5 & 22 \\
\hline $\begin{array}{l}\text { Semi-Prof. } \\
\text { (Teachers, etc.) }\end{array}$ & 10 & 1 & 20 & 6 & 33 & 15 \\
\hline Clerk/Clerical & 10 & 4 & 14 & 47 & 48 & 5 \\
\hline $\begin{array}{l}\text { Business } \\
\text { (Managers) }\end{array}$ & 0 & 47 & 1 & 19 & 9 & 49 \\
\hline $\begin{array}{l}\text { Government } \\
\text { (Military, etc.) }\end{array}$ & 2 & 23 & 0 & 3 & 1 & 12 \\
\hline $\begin{array}{l}\text { Shopkeepers } \\
\text { (Owners sma11 } \\
\text { businesses) }\end{array}$ & 3 & 12 & 2 & 1 & 1 & 5 \\
\hline $\begin{array}{l}\text { Skilled Labor } \\
\text { (Craftsman, etc) }\end{array}$ & 2 & 12 & 1 & 14 & 11 & 36 \\
\hline $\begin{array}{l}\text { Unskilled } \\
\text { (factory, etc.) }\end{array}$ & 0 & 2 & 1 & 11 & 11 & 14 \\
\hline $\begin{array}{l}\text { Farmers/ } \\
\text { Fishermen }\end{array}$ & 0 & 16 & 0 & 2 & 0 & 1 \\
\hline Deceased & 5 & 4 & 0 & 4 & 4 & 9 \\
\hline No Answer & 13 & 6 & 31 & 26 & 7 & 9 \\
\hline $\begin{array}{l}\text { Retired/ } \\
\text { Disabled }\end{array}$ & 0 & 7 & 8 & 28 & 8 & 19 \\
\hline
\end{tabular}




\section{Heterostereotypes}

It will be recalled that heterostereotypes were measured in this study by having the students in each of the three groups respond to two open-ended questions asking them to describe in "ten adjectives or less their picture of the "typical" or average member of the other two groups. A third, open-ended question asked each subject to estimate the amoung of personal contact with members of those groups.

The data were analyzed by compiling a list for each sample of al1 the words generated by the subjects in that sample, alphabetizing the words, and then tallying responses to each word. Three lists of varying lengths were obtained: the Irish students generated a list of approximately 525 words or word phrases; the Italian students a list of 417 words or word phrases; and the American students a list of 440 words or word phrases.

Once tallying was completed and response frequencies determined for each word, "frequently used" words were compiled into a shorter list and synonyms were combined into semantic categories - that is, clusters of two or more words conveying substantially the same meaning. Response frequencies within clusters were then summed.

Given the open-ended nature of the question, no a priori criterion was set for how frequently a given word would have to be used in order to qualify it as part of a group stereotype.

However, in the actual analysis of the data, it was found that almost any word used by even as few as four or five subjects almost always has synonyms in the 7 ist which also had appreciable response frequencies associated with them. This was particularly true in the Irish data. 
As an example, the word "conceited" was used by only three Irish subjects in describing Americans. Certainly a word used by less than $2 \%$ of the total sample would hardly qualify it as an element in a group stereotype. However, when response frequencies (given in parentheses in the list that follows) to semantically similar words are summed, a stereotype does indeed emerge: "big-headed" (6); boastful (24); confident (28); egotistical (4); self-confident (3). A total of 90 subjects, or very nearly one half the sample, produced highly similar words in describing Americans, words which appear to convey the same meaning as the word "conceited".

The problem that arose in this approach to the data was deciding which words should be assigned to a given cluster. It may be argued, for example, that the word "confident" is not strictly synonymous with the word "conceited". The assignment to the word "confident" of the connotation "conceited" and its placement in the cluster of words just given is made on the basis of its relationship to other overlapping semantic clusters that were found to exist - that is, the connotation assigned to any word is influenced by the over-all context of which it is a part. Figure 1 should help make clearer the way in which the data were analyzed and interpreted.

In Figure 7, words falling within the intersection of two circles take on or derive their connotation on the basis of their relationship to the clusters on either side. Thus, in the results to be presented, heterostereotypes have been defined in terms of clusters comprised of semantically similar items having appreciable response frequencies associated with them. Any given word was, of course, assigned to only 
75.

Figure 1. Example of Overlapping Semantic Clusters in Analysis of Irish Heterostereotype Data

Cluster I. Conceited Cluster II. Dominating

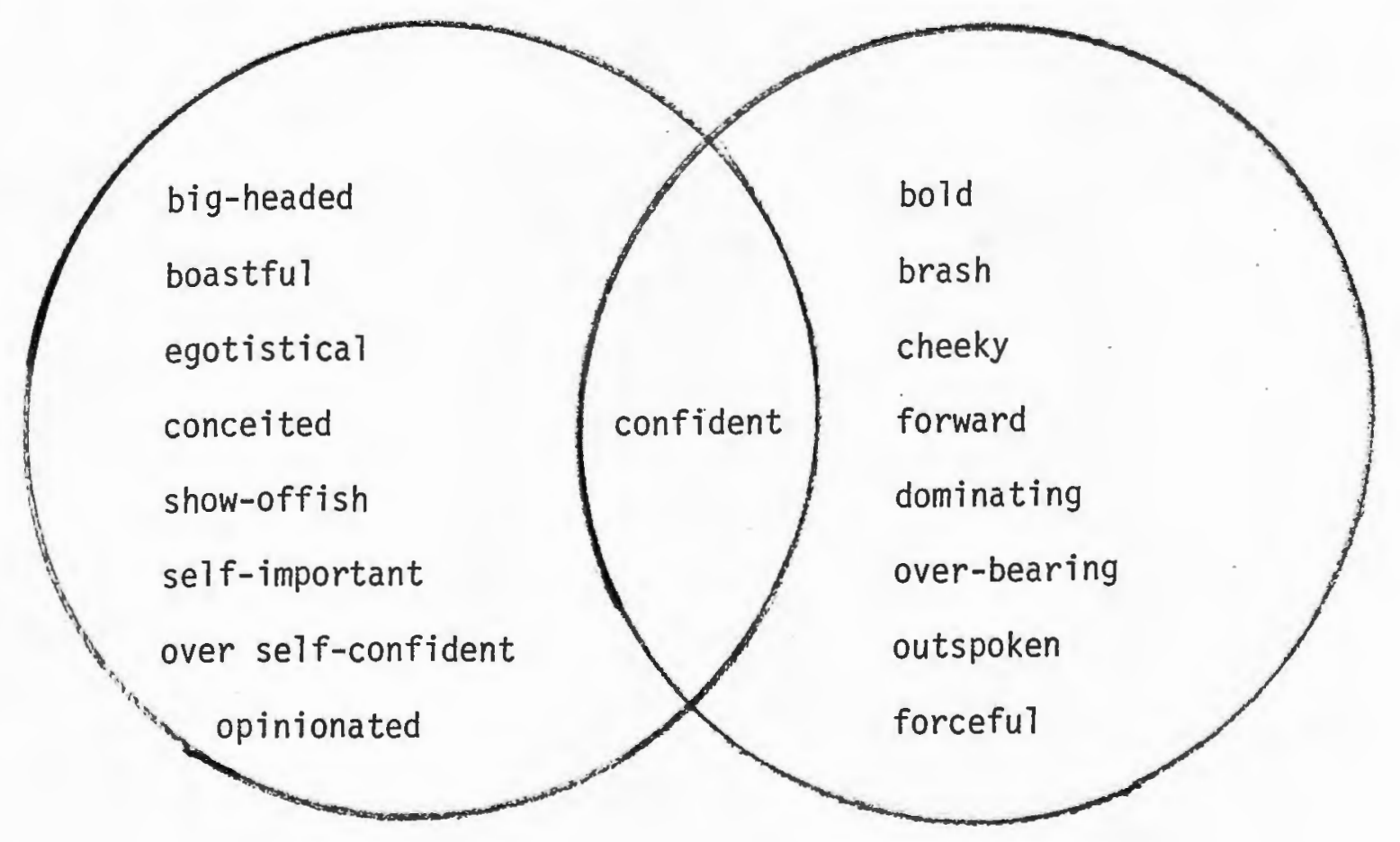


one cluster. These clusters may be thought of as analogous to factors. In the data to be presented it will be seen that such "factors" are often highly related to each other in such a way that a coherent heterostereotype based upon their interrelationships does emerge.

\section{A. The Irish Heterostereotypes}

The Irish, it will be recalled, produced the longest list of words or word phrases. In a11, they used close to 525 adjectives. However, in contrast to both the Italians and the Americans, this list contained many synonyms. This finding is of interest in and of itself since both the number of words used and the words themselves reveal to a striking degree of fluency of the Irish students. Furthermore, most of the words produced were adjectives descriptive of psychological traits - in contrast, for example, to American subjects who tended to focus on physical attributes, and Italian subjects who, in a rather diffident way, tended to describe superficial social traits.

More importantly, this finding is of interest because the presence of a great many synonyms in the list accounts for the fact that even though the Irish produced 100 or so more adjectives than either of the other samples, the strongest and clearest stereotypes of both Italians and Americans emerge from these data.

Irish males and females used a mean number of approximately seven adjectives in describing Americans and a mean number of approximately five to six adjectives in describing Italians. Inspection of Table 6 reveals that there were no significant differences between the sexes in the number of adjectives used, and, on the average, slightly more adjectives were used in describing Americans than in describing Italians. 
Table 6

Comparison of the Mean Number of Adjectives used by Irish, Italians, and Americans in Forming Heterostereotypes

1. Irish Stereotypes of Americans and Italians

Males $\quad \underline{\text { Females }}$

Americans:

6.67

7.41

Italians:

5.35

5.75

2. Italian Stereotypes of Irish and Americans
Males
Females

Irish:

3.54

4.10

Americans:

6.24

6.61

3. American Stereotypes of Irish and Italians

Males .. Females

Irish:

5.07

5.17

Italians:

4.73

5.27 
Irish students used a higher mean number of adjectives, in almost all cases, than used by the other two samples. Irish students as a group also reported more contact with Americans than with Italians, although many subjects spontaneously gave television and tourists as the source of this contact.

In the Irish stereotypes of Americans, five highly related clusters of synonyms reveal a picture of the typical American as loud, selfconfident, competitive, aggressive, and over-bearing. A sixth cluster, sociability, also emerges as a somewhat unrelated, or separate, "factor", in which Americans are, in addition, pictured as friendly, extraverted and outgoing.

Four words having the highest response frequencies (ranging between 33 and 79) were used repeatedly by the Irish about Americans. Of these four words, three of them appear to be unrelated to any of the clusters. The word "loud" had the highest frequency, being used in exactly that form by 79 subjects. This word, together with other highly related words like boisterous, articulate, vocal and vociferous, forms one of the clusters found in the data. Three other words, however, do not appear to relate to any of the clusters and, therefore, stand alone. These words are: "rich" (used 43 times); "fat" (used 36 times) and "talkative" (used 33 times).

The overall picture of the Irish stereotype of the Americans is presented in Figure 2. Inspection of this figure reveals the presence of a strong, clear stereotype of Americans. These clusters, if each is represented by a single descriptive word, were used by from $22 \%$ to $57 \%$ of the sample. The high degree of relationship between the word clusters 
Figure 2. Irish Stereotype of the Americans: Semantic Clusters

1. LOUD (79)

Boisterous (7)

Articulate (2)

Argumentative (4)

Opinionated (16)

Voluble (2)

Vociferous (2)
Brash (10)

Vocal (2)

2. CONFIDENT

Confident (28)

Self-confident (7)

Boastful (24)

Haughty (18)

Self-important (11)

Egotistical (4)

Pompous, pretentious ( 8 )

Arrogant, proud (17)

Vain (5)

Patronizing (4)

Conceited (3)

4. $\overline{\text { AGGRESSIVE }}$

Aggressive (14)

Forceful, forward

Busy, active (6)

Bold, adventurous

Energetic (4)

Brave (2)

Ambitious (11)

Direct, dynamic (9)

$\overline{32 \%}$

FAT $(19 \%)$
5. COMPETITIVE

Competitive (21)

Determined (13)

Enterprising (7)

(7) - Hard-working (12)

Industrious (9) $\overline{33 \%}$
3. DOMINANT

Dominating, Domineering (19)

Overbearing (8)

Overpowering (11)

Forceful (9)

Bossy, assertive (5)

Independent (7)

$\overline{32 \%}$
6. $\overline{\text { SOCIABLE }}$

Sociable (18)

Friendiy (34)

Extraverted (14)

Good mixer (2)

Outgoing (9)

Gregarious (1)

$\overline{42 \%}$

$\mathrm{RICH}(22 \%)$ 
suggests that if these data were described in terms of a single "higher order factor", the single word most descriptive of the Irish picture of Americans would be the word "dynamic" or "aggressive", although with a somewhat negative coloring. The single words used most frequently by Irish students about Americans are presented in Table 7.

Turning now to the Irish stereotype of the Italians, the same tendency to use a high number of synonyms, leading to clusters, is also found, but to a less striking degree. The Irish stereotype of the Italians is weaker and less clear. This may reflect, in part, the fact that the Irish, according to their own subjective estimate, have less contact with Italians. While nearly half the Irish sample (48\%) report "some" or "a 1ot" of contact with Americans, only $17 \%$ report the same amount of contact with Italians. Amount of contact by itself, however, does not appear to account for all of this difference.

In the Irish stereotype of the Italians, presented in Figure 3, more "clusters" appear, they have smaller frequencies associated with them, and they are less closely related to each other. However, as in the stereotype of the Americans, a coherent picture emerges.

The Italians are also seen as dynamic or active, but in a quite different way. The single word that probabiy best describes the emergent picture is "volatile" or emotionally expressive. This, in association with other clusters, gives a picture of a people who are warm and emotional rather than aggressive and competitive. Many of the clusters which are shown in Figure 3 do not have very large response frequencies associated with them, but they are included because, taken together, they form a coherent picture of the Irish stereotype of the 
Table 7

Irish Heterostereotypes of Americans

Most Often Used Words

(Number in parentheses is how often used)

LOUD (71)

RICH (42)

FAT (36)

FRIENDLY (34)

TALKATIVE (33)
CONFIDENT (28)

BOASTFUL (24)

GENEROUS (21)

COMPETITIVE (21)

DOMINANT (21)
SOCIABLE (18)

OPINIONATED (16)

MATERIALISTIC (16)

SHOW-OFFISH (15)

EASY-GOING (15)

Less Often Used Words

EXTRAVERTED (14)

AGGRESSIVE (14)

DETERMINED (13)

PROUD (13)

HARDWORKING (12)
PATRIOTIC (12)

AMBITIOUS (11)

INTELLIGENT (11)

AMUSING (10)

BRASH (10)
TALL (10)

LAZY (10)

OVERBEARING (9)

SELFISH (9)

SELF-CENTERED (9)

FUSSY, FICKLE (7)

HEALTH (7)

INDEPENDENT (7)

ATTRACTIVE (7) 
Figure 3. Irish Heterostereotype of the Italians: Semantic Clusters

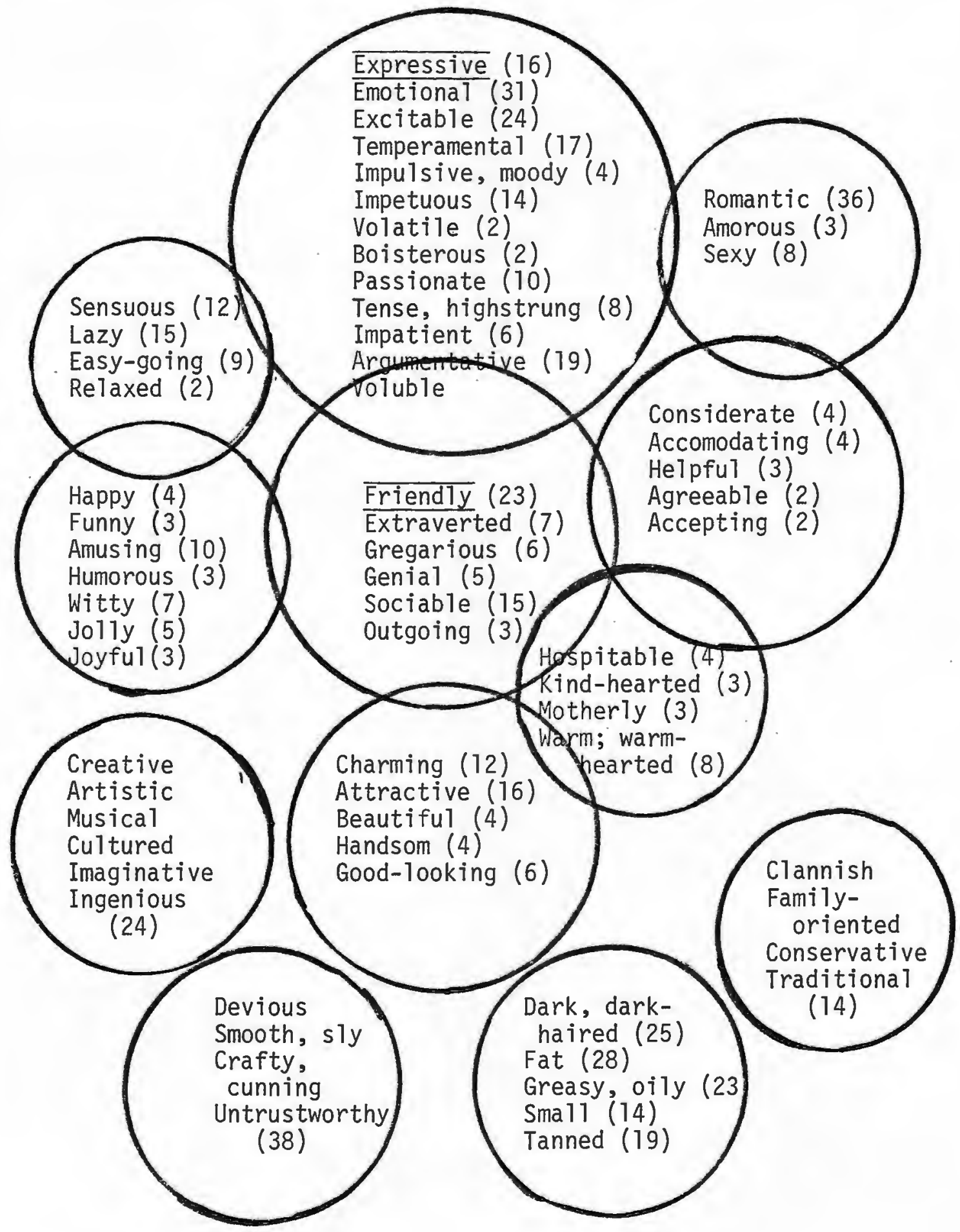


Italians. The single words used most frequently by Irish students about Italians are presented in Table 8.

\section{B. Italian Heterostereotypes}

In sharp contrast to the Irish data, no strong or clear heterostereotype of either Americans or Irish were produced by Italian subjects. The Italian students were the most diffident of the three groups in their approach to this task. They produced the shortest list of adjectives (417); used, on the whole, fewer words per subject; and had the highest proportion of failure to respond to the question. (Thirty-three percent of the males, for example, and $12 \%$ of the females failed to produce a stereotype of the Irish).

Italian students reported much more contact with Americans than with the Irish (many of them spontaneousiy indicating television, tourists, and American students as the nature of this contact) and they used, on the average, more adjectives in describing them. Forty percent of the Italian sample reported "some" to a "lot" of contact with Americans as opposed to only six percent reporting the same amount of contact with Irish. There were no significant sex differences in the number of adjectives used in describing a given group, but overall females used one or two more adjectives than males, and both groups used more adjectives in describing Americans. (See Table 6.)

The Italian stereotype of the Americans does not include strong, interlocking word clusters as did the Irish data. Neither the few clusters that appear, nor the individual words used, have very high response frequencies associated with them. 
Table 8

Irish Heterostereotype of the Italians

Most Frequently Used Words

(Frequency of use of word in parentheses)

ROMANTIC (36)

EMOTIONAL (31)

FAT (28)

HOT-TEMPERED (25)

EXCITABLE (24)

FRIENDLY (23)

DARK (22)

GREASY (20)

ARGUMENTATIVE (19)

RELIGIOUS (19)

PASSIONATE (10)

NATIONALISTIC (9)

LOUD (9)

HARD-WORKING (9)

GENEROUS (9)

INDUSTRIOUS (8)

SEXY (8)

HOT-HEADED (8)

WELL-DRESSED (8)

TENSE, HIGH STRUNG (8)

FORCEFUL (7)
TEMPERAMENTAL (17)

EXPRESSIVE (16)

ATTRACTIVE (16)

SOCIABLE (15)

LAZY (15)

SMALL (14)

TALKATIVE (14)

AGGRESSIVE (13)

CHARMING (12)

IMPULSIVE (11)

WELL-INTENTIONED (7)

EXTRAVERTED (7)

BOLD (6)

ACTIVE (6)

GOOD LOOKING (6)

BOLD (6)

GREGARIOUS (6)

IMPATIENT (6)

FAMILY-ORIENTED (6)

WARM (6)

FOOD-LOVERS (6) 
The only words with appreciable frequencies are largely unrelated; "Allegro" (happy, cheerful), used by $24 \%$ of the sample is the most frequently used word, followed by "simpatico" (attractive, charming, genial), 20\%; "pratico" (practical, experiences), 16\%; "spendaccione" or "stravagante" (spendthrift, extravagant), 24\%; and "megalomane" (mega1omaniac or grandiose), 13\%. The data are presented in Table 9.

Italian students appear to hold a rather weak stereotype of Americans. Integrating the words that were used in an attempt to form a coherent picture, these Italian students appear to see Americans as friendly and sociable, but in a lighthearted, frivolous, somewhat superficial way. The only real point of correspondence between the Irish and Italian stereotypes of Americans is agreement that Americans tend to have a somewhat pompous and inflated notion of their importance.

The Italian stereotypes of the Irish are even weaker. There are only four words or word clusters used with any appreciable frequency and then by only $11 \%$ to $18 \%$ of the sample. Previous researchers using the open-ended format to measure heterostereotypes have used a criterion of about $25 \%$ (Shuman, 1966) in defining the presence of a sterotype. These data, then, are only weakly suggestive, at best, of the presence of any real consensus among Italians about the "typical" Irish person.

The four words or word groups produced give a picture of the Irish as Catholic or religious (13\%), irascible or quarrelsome (18\%); drinkers $(12 \%)$; and conservative or traditional $(12 \%)$. The only other words used suggest a somewhat negative picture (cold, introverted, unsociable, serious, stingy or miserly, and nationalistic) held by a very small percentage of the group. 
Table 9

Italian Stereotype of the Americans

Most Frequently Used Words

(Frequency of occurence of word in parentheses)

HAPPY, CHEERFUL (43) allegro

COMPETITIVE (9)

HANDSOME, ATTRACTIVE (36) simpatico

CONSUMER (9)

SOCIABLE (31) socievole

ENTERPRISING (9)

SPENDTHRIFT (28) spendaccione

NOISY (9)

PRACTICAL (28) pratico

OPEN (9)

SPORTY (25) sportivi

EXPANSIVE (8)

MEGOLAMANIAC (23) megelomane

SIMPLE (9)

SELF-ASSURED (17) sicuro di se

POOR DRESSER (9)

INGENIOUS (16) ingenuoso

INDUSTRIOUS (9)

EXTRAVAGANT (16) stravante

WORKERS (8)

RICH (15) ricchi

GENEROUS (8)

SUPERFICIAL (15) superficiale

AMUSING (7)

CORDIAL, HEARTY (14) cordiali

BLONDE (7)

EASY GOING (14) facilone

EXHIBITIONIST (6)

CAPRICIOUS (14) estroso

AFFECTIONATE (4) 
Finally, the Italian description of the Irish is notable for what it does not convey. There is a rather striking lack of words suggesting the trait of extraversion or sociability. The word "sociable" was used by Italians in describing Americans 23 times and only six times in describing the Irish. The word "extraverted" was used 14 times in reference to Americans and not at all in reference to the Irish. Table 10 presents the words most frequently used by the Italians about the Irish. Because of the low frequencies of these words, they cannot be called a valid stereotype. (See Table 10.)

\section{American Heterostereotypes}

Americans used 440 words or word phrases in describing Italians and Irish, including a fair number of non-adjectives such as "St. Patrick's Day", "IRA", "Irish pub", "wine", "pasta", and "Mafia". (One subject asked the researcher, during the administration of the instrument, to define an adjective for her). Not surprisingly, Americans report approximately equal amounts of moderate to frequent contact with both groups. Forty-four percent of the total sample report "a lot" of contact with both Irish and Italians whereas only between three to seven percent report "no contact" with Irish and Italians, respectively.

Americans used approximately the same number of adjectives, on the average, in describing both Irish and Italians (refer to Table 6). American stereotypes of both groups focused heavily on physical characteristics, somewhat more so in describing Italians than in describing the Irish. The strongest (highest frequency) words for both 
Table 10

Italian Stereotype of the Irish

Most Frequently Used Words

(Frequency of use in parentheses)

RELIGIOUS (24)

CONSERVATIVE (20)

CATHOLIC (14)

TRADITIONAL (14)

STINGY, MISERLY (14)

COLD (13)

NATIONALISTIC (9)

STUBBORN (9)

INTROVERTED (8)

SERIOUS (8)

WORKERS (6)
DRUNKARD (ubbriacone) (18)

ALCOHOLIC (7)

DRINKER (10)

IRASCIBLE (12) irascible

LITIGIOUS (10) litigioso

QUARRELSOME (5) rissoso

WAR LIKE (guerriere) (5)

STRONG (6)

PROUD (6)

SOCIABLE (6)

ATTRACTIVE (6) 
groups are those containing physically descriptive words such as dark, blonde, freckled, brown-eyed, etc.

In addition, clusters of synonyms appear to a greater extent than in the Italian data but less dramatically than in the Irish data, and the clusters are more independent of each other.

The American stereotype of the Irish, in addition to the predominating description of physical characteristics, emphasized their goodnatured and almost boisterous sociability, drinking habits, Catholicism, stubborness, and quick temper. See Table 11 for a summary of the data.

The American stereotype of the Italians emphasizes physical characteristics even more strongly, with $74 \%$ of the sample using words 1 ike "short", "stocky", "good-looking", and dark complexioned". Other, less frequently used words or clusters, describe Italians as aggressive, forceful, virile, emotional, hard-working, romantic, conservative and family-oriented. Results are presented in Table 12.

Summarizing the data on heterostereotypes across a11 three samples, the clearest heterostereotypes were produced by the Irish students who focused on personality characteristics in describing Italians and Americans. Americans produced descriptions of Irish and Italians most strongly in terms of physical characteristics, with less frequently used words giving an overall more superficial picture. In terms of a criterion used by some previous researchers that a word or synonym be used by at least $25 \%$ of the sample, no clear stereotype of either Americans or the Irish were produced by Italian students.

Americans appear to be a more salient group for both Irish and Italian students than either of these latter groups are for each other. 
Table 17

American Stereotypes of the Irish

Most Frequently Used Words

DRINKERS (47)
HAPPY (28)
FRIENDLY (27)
STUBBORN (27)
HOT-TEMPERED (25)
RELIGIOUS (22)
RED-HAIRED (22)
HARD WORKING (27)

FRECKLED (16)

EASY GOING (15)

LIGHT-SKINNED (14)

GREEN (14)

JOLLY (11)

LOUD (10)

FAIR-SKINNED (9)

AGGRESSIVE (9)

PROUD (8)

TALL (6)

"TEMPER" (8)

OPINIONATED (6)

FUNNY (8)

THICK-HEADED (6)

CATHOLIC (7)

LUCKY (6)

FAMILY ORIENTED (7)

BRAVE (6)

JOVIAL (7)

BOISTEROUS (6)

GOOD-NATURED (6)

ATTRACTIVE (6)

ACCOMODATING (6)

FUN-LOVING (6) 
Table 12

American Stereotype of the Italians

Most Frequentiy Used Words

DARK-SKINNED (34)

DARK EYES (23)

FAT (22)

LOUD (19)

HARD WORKING (18)

FAMILY ORIENTED (16)

AGGRESSIVE (16)

ROMANTIC (76)

FOOD-LOVERS (15)

DARK (13)

RELIGIOUS (13)

DOMINANT (12)

STUBBORN (12)

WITTY (6)
ATTRACTIVE (11)

CONSERVATIVE (10)

FRIENDLY (9)

"MACHO" (9)

PROUD (9)

PASTA LOVER (9)

WINE DRINKER (8)

OPINIONATED (7)

EMOTIONAL (6)

TALKATIVE (6)

MAFIA (6)

GOOD COOKS (5)

BOLD (5)

BOSSY (5) 
Italian and Irish students report much more contact with Americans, use more adjectives in describing them, and present a clearer, more coherent picture of them than they do of each other.

Irish and Italian students show little agreement in their respective pictures of the "typical" American except that both groups perceive the Americans as somewhat boastful and self-aggrandizing. Americans are seen as aggressive and competitive by Irish students but as almost frivolous and outgoing by the Italian students.

Irish are perceived by both American and Italian students as drinkers, devout Catholics, traditional, and quick-tempered or irascible. While the Irish are seen as jovial and friendly by a substantial proportion of the American sample, a much smaller proportion of the Italian sample sees them as emotionally cold, introverted, and serious, and almost none of the Italian sample perceives them as extraverted.

Irish and American students agree in perceiving Italians as emotionally expressive and volatile, conservative, and family-oriented. But the American sample perceived Italians as aggressive, forceful, and dominant, whereas the Irish sample perceived them as warm, gregarious, and genial.

\section{Autostereotypes}

Autostereotypes were measured by having subjects select those adjectives from the 81 word-AVA checklist which best describe the "typical" member of their own national group. It was possible to set a much more rigorous criterion for the existence of a clear stereotype than in the case of the open-ended measure of the heterostereotypes. 
The existence of an autostereotype was defined in two ways. The frequency of selection of each word in the AVA list was tallied for the three groups and any word used by more than $55 \%$ of the sample was considered to be a significant element of their group self-description. Second, the profile or personality "type" derived from scores on the four vectors of the AVA were plotted on the AVA pattern universe. The existence of distinct clusters, rather than a heterogeneous distribution, provided further evidence that an autostereotype existed. Further, this autostereotype could now be described in terms of an integrative profile rather than in discrete words. An American normative sample of over 1,199 subjects was used as the reference group in defining departure from heterogeneity.

The results of the word frequency tabulations will be presented for each group first, and then the clustering (or lack of it) of personality types within each sample will be reported.

As will be seen in Table 13, American and Irish students used approximately the same number of adjectives in describing their autostereotypes. Italian students used significantly fewer adjectives than either of the other two groups. There were no within-group sex differences in the number of adjectives used for any of the samples. There were also almost no within-group differences in the content of the autostereotypes themselves, either in terms of the most frequently chosen words or in terms of the least frequently chosen words.

Males and females agree strongly with each other in perceiving the typical Irish person as socially graceful - relaxed, friendly, easygoing, witty and amusing. Nine words were chosen by $55 \%$ or more of the 
Table 13

Mean Number of Adjectives used in Autosteretotypes of Irish, Italians, and Americans (AVA Activity Level)

\begin{tabular}{|c|c|c|c|}
\hline & Males & Females & $\begin{array}{l}\text { t-test between } \\
\text { the sexes }\end{array}$ \\
\hline Irish: & $\begin{array}{l}\text { mode }=22.00 \\
\text { mdn. }=22.53 \\
\bar{X}=23.12 \\
s=11.63\end{array}$ & $\begin{array}{l}\text { mode }=17.00 \\
\text { mdn. }=20.28 \\
\bar{X}=22.05 \\
s=9.05\end{array}$ & $\begin{array}{l}t=0.67, \text { df } 184, \\
\text { n.s. }\end{array}$ \\
\hline Italians: & $\begin{array}{l}\text { mode }=12.00 \\
\text { mdn. }=13.85 \\
\bar{X}=16.75 \\
s=9.35\end{array}$ & $\begin{array}{l}\text { mode }=17.00 \\
\mathrm{mdn}=17.45 \\
\bar{X}=18.75 \\
s=10.00\end{array}$ & $\begin{array}{l}t=1.38, \text { df } 175 \\
\text { n.s. }\end{array}$ \\
\hline Americans: & $\begin{array}{l}\text { mode }=17.00 \\
\text { mdn. }=19.25 \\
\bar{X}=23.00 \\
s=11.45\end{array}$ & $\begin{array}{l}\text { mode }=22.00 \\
\text { mdn. }=22.75 \\
\bar{X}=25.35 \\
s=12.17\end{array}$ & $\begin{array}{l}t=1.57, \text { df } 188 \\
\text { n.s. }\end{array}$ \\
\hline
\end{tabular}

t-test for Italian versus U.S. males:

$$
t=3.78, d . f .159, p<.001
$$

t-test for Italian versus Irish females:

$$
t=2.41, d . f .191, p<.05
$$


Irish females and eight words by $55 \%$ or more of the Irish males, and seven of these words were selected by both groups. The most frequently used word, "sociable" was selected by exactly $81 \%$ of both males and females. In addition to words like witty, amusing, etc. which reveal a perception of the typical Irish person as socially graceful, both Irish men and women perceive the "typical" member of their own group as "argumentative". The same high degree of agreement between Irish males and females is seen in the words which are not chosen. Less than 4\% of either sex described the Irish people as polished, punctilious, graceful, smooth, or decisive. Results of the Irish autostereotype in terms of the most frequently selected adjectives, are presented in Table 14.

Italian males and females also show a high degree of agreement in their picture of the "typical" Italian, except that eight words were chosen by $55 \%$ or more of the Italian females whereas four words were chosen by $55 \%$ or more of the males. Both males and females perceive the "typical" member of their own group as a" "good mixer", "amusing", "ingenious", and "romantic". Females, in addition, perceived Italians as sociable, magnetic, theatrical, and witty. Both males and females agree that the typical Italian is not relaxed or stable. Results are presented in Table 15.

American males and females agreed in their picture of the "typical" American, as wel1. Fifty-five percent or more of each group selected 12 adjectives from the AVA 1ist, ten of which were the same for both groups. The "top three" (for both groups) were; "competitive", "aggressive", and "sociable". The least frequently selected adjective 
Table 14

Irish Autostereotypes: Most Frequently and Least Frequently Used AVA Adjectives

\section{Irish Are:}

MaTes

Sociable........81\%

Witty...........75\%

Easy-going......71\%

Amusing........6.69\%

Good mixer......66\%

Argumentative....59\%

Self-conscious....58\%

(Leisurety.......54\%)*

(Relaxed.......47\%)*
Females

Sociable........81\%

Easy-going......81\%

Amusing.........73\%

Leisure $y . . . . . .772 \%$

Relaxed..........71\%

Self-conscious...66\%

Good mixer......66\%

Witty.........62\%

Argumentative....55\%

Irish Are Not:

Polished.......... $7 \%$

Punctilious........2\%

Poised...........2\%

Gracefut.........3\%

Decisive.........3\%

Smooth...........4\%

Serene...........4\%
Rolished......... 1\%

Punctilious........ $1 \%$

Gracefut.........3\%

Smooth............3\%

Decisive.........4\%

Dominant..........4\%

*These words form part of the autostereotype of females but not males. The percentage for males is given for comparison. 
Table 75

Italian Autostereotype: Most and Least Frequently Selected AVA Adjectives*

Italians Are:

Males

Good mixer.....58\%

Amusing.......58\%

Ingenious......57\%

Romantic.......55\%

(Witty.......50\%)

(Sociable.....37\%)

(Magnetic.....28\%)

Italians Are Not:

Analytical...... 1\%

Leisurely......4\%

Stable......... 1\%

Relaxed........2\%

Composed.......2\%

Quiet........... 3\%

CaIm...........4\%

Solemn.........4\%

*Words in parentheses were used by $55 \%$ or more of the opposite sex. Their frequencies in the sex not selecting them this often is given for the sake of comparison. 
for both groups was "serene". In addition to the ten words selected in common by both groups, $59 \%$ of the females saw Americans as "bold" and "interesting", whereas 59\% of the males described the "typical" American as "skeptical" and "enterprising". Results of the American autostereotypes are shown in Table 16.

AVA Profiles: Second Measure of the Autostereotype

The second way in which the presence of an autostereotype was defined in this research was by deriving the patterns from the AVA vectors and then inspecting the distribution of these patterns for the presence of clustering. When profiles are plotted on the AVA pattern universe, highly similar profiles lie adjacent or nearly adjacent to each other. As discussed earlier, correlations between profiles are equivalent to correlations between resultant vectors. A Table of Correlations has been developed (Walter Clarke Associates, 1958) which provides these correlations between each profile and every other profile in the pattern universe. Profiles which correlate .69 or greater with each other are considered to be highly similar.

In addition, when profiles are plotted, clustering can be determined visually by inspecting the pattern universe for areas of especical1y dense distributions. A portion of the AVA pattern universe is reproduced in Figure 4 to illustrate the presence of clustering or a high degree of homogeneity in a distribution of scores. These data are taken from the actual distribution of American female autostereotypes on the AVA pattern universe, and show $72 \%$ of the total sample clustered in about 15\% of the area of the pattern universe. 
Table 16

American Autostereotype: Most and Least Frequently Selected AVA Adjectives

Americans Are:

Males

Competitive.......81\%

Aggressive.......71\%

Sociable........65\%

Opinionated......6.61\%

Determined.......60\%

Anxious.........60\%

Skeptical........59\%

Argumentative.....59\%

Defensive........57\%

Enterprising......57\%

Industrious.......56\%

Self-conscious.....55\%

(Bold...........49\%)

(Interesting......42.5\%)
Females

Competitive.......88\%

Sociable.........82\%

Aggressive.......75\%

Industrious......71\%

Argumentative.....66\%

Anxious.........66\%

Determined.......65\%

Opinionated......65\%

Bold............59\%

Interesting......59\%

Self-conscious.....57\%

Defensive.........55\%

(Skeptica1.......52\%)

(Enterprising.....44\%)

Americans Are Not:

Serene...........4\%

Solemn............3\%

Submissive........3\% 
Once clustering has been determined, a single profile is chosen from within the cluster to represent what is called the Group Centroid of that cluster. The group centroid is defined as the profile with which every other profile in the cluster will correlate .69 or greater, and may be considered to represent the "central tendency" of scores within the cluster. Thus, the personality description associated with the group centroid typifies all the persons falling within that cluster. The selection of the group centroid is analogous to "the line of best fit" or the "line of least squares" in a scattergram. It is the selection of the profile or pattern that minimizes the distance between it and every other pattern in the cluster in terms of the correlation between them.

In the distribution illustrated in Figure 4 , the group centroid is PS 7616, identified with an asterik in the diagram.

This discussion should help make clear the second way in which both the presence and nature of autostereotypes were defined in this research.

Presence of an autostereotype was defined as the presence of clustering within the distribution, or the departure from heterogeneity. The nature of the autostereotype - that is, the personality characteristics associated with it - was defined in terms of the profile description associated with the group centroid of a given cluster. With this approach to the data in mind, the autostereotypes of each of the three samples will now be discussed. 
Figure 4. A Portion of the AVA Pattern Universe Showing Clustering in a Distribution of Scores

* Each number represents a pattern or ․:- Profile **Each dot represents an Individual sub: $\cong c t ' s$ score (about 15\% of the Pattern Universe)

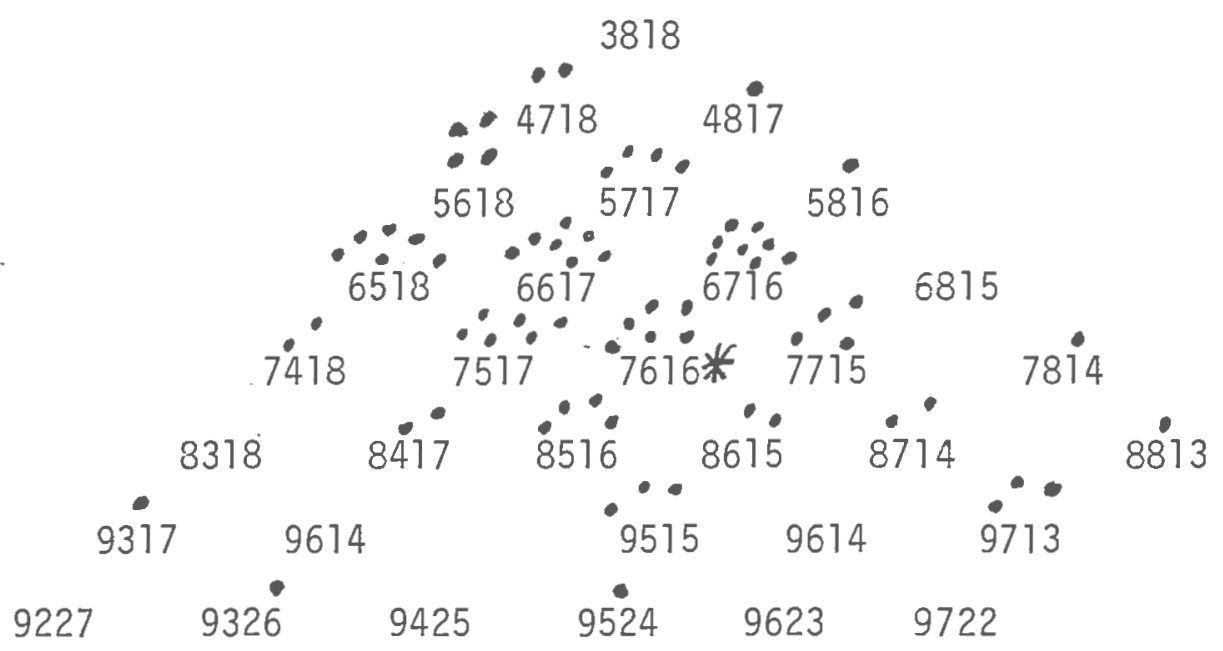

72 out of the 100 American female subjects: AVA autostereotypes 
Irish Autostereotypes

The least amount of agreement as to what constitutes a "typical" member of one's own national group was found in the Irish sample. Three distinct clusters were formed, centering around AVA patterns 3539,5717 , and 3944 .

Inspection of Table 17 shows that, while $84 \%$ of the total Irish sample can be accounted for by membership in one of these clusters, no one cluster includes more than $37 \%$ of the total sample.

Furthermore, there are significant sex differences in the proportions of membership in two of the three clusters. The largest proportion of Irish females clustered around PS 3944, which drew a significantly smaller proportion of Irish males (17\%). The largest proportion of males, 37\%, clustered around PS 5717, which drew a significant7y emaller proportion of females - 23\%. The two profiles, 5717 and 3944 , correlate .44 with each other so the two perceptions they represent, though different, are somewhat related.

The person described by PS 3944 is sociable, active, friendly, and helpful to others. According to the description provided by a certified AVA analyst, "this person is well at ease in social situations and in initiating personal contacts. S/he is attracted to a wide variety of people... is a joiner of clubs and social groups... and rises quickly to leadership positions. This person is also quite politically astute and has the ability, through charm and persuasive manner to influence others." This was the autostereotype held by the majority of Irish females and the minority of Irish males. 
Table 17

AVA Profile Clusters for the Irish, Italian, and American Autostereotypes

Irish Sample

\begin{tabular}{ccccc}
$\begin{array}{l}\text { AVA Profile } \\
\text { (Group Centroid): } \\
\text { Description: }\end{array}$ & $\begin{array}{c}\% \text { of } \\
\text { Males }\end{array}$ & $\begin{array}{c}\% \text { of } \\
\text { Females }\end{array}$ & $\begin{array}{c}\% \text { of } \\
\text { Total }\end{array}$ & $\begin{array}{c}\text { significant } \\
\text { sex differ. }\end{array}$ \\
\hline 3539 - dutiful, humble & $29 \%$ & $28 \%$ & $28.5 \%$ & n.s. \\
5717 - demanding, active & $37 \%$ & $23 \%$ & $29.5 \%$ & p<.01 \\
3944 - sociable, friendly & $17 \%$ & $34 \%$ & $25.8 \%$ & p<.01 \\
\hline of total sample: & $83 \%$ & $85 \%$ & $83.8 \%$ & \\
\hline
\end{tabular}

Italian Sample

AVA Profile:

$\begin{array}{llrrr}5915 \text { - masterful } & 73 \% & 85 \% & 79.32 \% & p<.05 \\ 5519 \text { - anxious } & 26 \% & 12.5 \% & 18.43 \% & \text { p<.01 } \\ \begin{array}{l}\text { \% of total sample } \\ \text { accounted for: }\end{array} & 99 \% & 97.5 \% & 97.75 \% & \end{array}$

American Sample

AVA Profile

Centroid:

\begin{tabular}{lllll}
$\begin{array}{l}7616 \text { - high-powered } \\
4439-\text { humble, "yes-man" }\end{array}$ & $66 \%$ & $72 \%$ & $69 \%$ & n.s. \\
\hline $\begin{array}{l}\% \text { of total sample } \\
\text { accounted for: }\end{array}$ & $97 \%$ & $97 \%$ & $91 \%$ & n.s. \\
\hline
\end{tabular}


The autostereotype favored by the majority of the males and the minority of the females was AVA pattern 5717. The person of this type is similar in some respects to the one just described. Both types are active "doers" who prefer action to inaction, are socially outgoing, and possess the enthusiasm, poise, and optimism that win friends easily. However, the person described by PS 5717 has more intellectual drive and inner tension. "S/he is sensitive and basically discontented, due to a desire for perfection, seeks and demands logical answers to...the problems that confront him/her... has the intellectual tenacity to keep. arguing and probing for answers, and is nervous and tense beneth the facade of outward social poise. This person is slow and deliberate in formulating decisions and, driven by the desire for perfection may vacillate in doing so."

The third cluster in the Irish data, chosen by an equal proportion of males and females (28\%) formed around profile 3539. This profile shows no correlation at all with the one chosen by the majority of females (PS 3944) and is only slightly correlated with PS 5717 $(r=.09$ and .33 respectively).

The person described by this profile is "humble...usually quiet, unassuming in manner and highly dependent on others. This is a rather meek, obliging person, highly conscientious, motivated by a strict sense of duty and loyalty, and meticulous in carrying out tasks."

Although the distribution of profile types for the Irish do form distinct clusters, the fact that there are three clusters, each drawing approximately equal proportions of the sample, prevents the emergence of a clear and widely-held Irish autostereotype. Though the 
majority of males and females perceive the "typical Irish person" as active, outgoing, and socially graceful, sex differences do emerge, and the sample is distinctly split in its perceptions.

\section{Italian Autostereotypes}

Italian males and females showed an extremely high degree of agreement in describing the "typical" member of their own culture. The autostereotype profiles for both sexes form a tight cluster around AVA pattern 5915 , and $82 \%$ of al1 the females and $73 \%$ of al1 the males fall into this single cluster. A second, much smaller and more widely dispersed cluster around profile 5519 picks up almost al1 the remaining members in both sample groups. Thus membership in two overlapping clusters $(r=.50)$ accounts for $98 \%$ of the entire sample. (Refer back to Table 17 for a summary of these findings.) The distinctive nature of this very tight clustering reveals the high degree of consensus among Italian males and females about the "typical" member of their own culture.

The personality description associated "with PS 5915 (held by $79 \%$ of the total sample) is that of a person who has acquired a sure sense of mastery over the social environment and is skillful at manipulating it, both in carrying out his/her own interests and promoting the interests of others. According to the description provided, this person "is constantly eager to seek out people and build an extensive network of personal contacts and social acquaintances which s/he accomplishes through the energetic use of social skills." This is a person with good ability to mobilize others in the environment and to use situations to practical advantage. 
Although this is the autostereotype held by the majority of Italian students, a small part of the sample clustered, rather widely, around PS 5519. Their perception is of a person who lacks the confidence and sure mastery over the environment of the type just described but tends, instead, to be a worrier who anxiously regulates his/her life style, and goes to extremes to avoid trouble "or the perceived danger of such". This person "exudes nervous tension; appears always to be "on the go", usually to service the desires of others; and is generally perceived as a very anxious type of person."

American Autostereotypes

Although not quite as dramatic as in the case of the Italian students, the American students also show a fairly high degree of consensus in describing their autostereotype. As can be seen in Table $17,72 \%$ of the females and $66 \%$ of the males clustered rather tightiy around PS 7616. A much smaller cluster, accounting for $22 \%$ of the total sample, formed around PS 5339. The two profiles correlate .44. Onty five males fell outside of these two clusters and their profiles were widely dispersed over the rest of the pattern universe. Eight females fell outside of these two clusters and all eight formed a loose cluster around a third centroid, PS 4952.

Pattern 7616 describes a tense, active, "high powered" person who is constantly "on the go". "S/he is a rather high-strung individual who approaches most demanding life situations with zeal, but invariably take on much more than s/he can handle..." This person is prone to be irritable and impatient and tends to be impulsive in making decisions. 
A very different picture of the "typical" American is held by a minority of males and females in the sample who clustered around PS 5339. An almost identical profile also emerged as one of the autostereotypes held by the Irish (PS 3539, which correlates .83 with PS 5339).

Once again, this is the highly dependent person who "is more comfortable doing the bidding of others than in assuming a leadership role in any major enterprise in life - a humble, quiet, unassuming, 'yes' type of person." (It is possible that this description, found in both the Irish and American autostereotypes, is a projection of the "real" self.)

The findings just described indicate that fairly clear autosterotypes, agreed upon by a substantial majority of the students in each of the two samples, are held by Italian and American students. Irish students, on the other hand, split into three groups in describing their differing perceptions of the "typical" Irish person.

An integration of the findings just reported with respect to the most frequentiy selected AVA adjectives, yields the following "thumbnail" sketches of the autostereotypes held by each group.

The Irish generally perceive themselves as a socially graceful people, charming and persuasive in manner, and relaxed and at ease with the social environment. Two of the adjectives chosen most frequently by both Irish males and females in describing their autostereotype were "sociable" and "easy going". For Irish males, however, and to a lesser extent for Irish females, this social ease and grace masks an inner tension and intellectual drive. (Recall that whereas Irish 
females described their autostereotype with the words "leisurely" and "relaxed", many fewer Irish males did so.)

The Italian autostereotype held by the majority of both males and females emphasizes a dynamic control or mastery over the social environment, a mastery which enables them to put it to good advantage in carrying out their aims and interests. This is typified by the adjectives chosen most often by both males and females, "good mixer" and "ingenious", for example, and is underscored by the profile of a type "constantly eager to seek out people and build up an extensive network of personal contacts."

American males and females agreed for the most part in the selection of adjectives like "competitive" "social" and "aggressive" in describing the "typical" member of their own culture, and this description was also reflected in the profile description of the tense, highpowered person who relates somewhat aggressively to the social environment chosen by $69 \%$ of the sample.

\section{Self-Perceptions}

In this study it was hypothesized that the process of being socialized into a given culture should give rise to a certain degree of within-group similarity in self-perceptions; and that, further, certain self-perceived "traits" would prove to be more salient in one cultural group than in another. The term "personality trait" was earlier defined in this study as the perception held by an individual of his/her "real" or "basic" self. The final portion of this section wi11 present the results of the two measures used to determine this 
self-perception, the AVA "self" profile, and the Myers-Briggs Type Indicator. It will focus on the degree to which consensus was found to exist in the self-perceptions of members of the three groups studied, and the differences across the three groups with respect to the saliency of certain subjectively perceived "traits".

\section{Irish Self-Perceptions}

With respect to the AVA profiles of the "real" or "basic" self, approximately $53 \%$ of the Irish sample fell into two clusters on the AVA 258-pattern universe, with exactly the same number of subjects $(N=49)$ in each. The proportion of an American normative sample of $\mathrm{N}=1199$ cases, drawn from the general adult population, found in these two areas of the AVA pattern universe is, by contrast, $28.1 \%$, or a little more than one half that of the Irish sample. (This U.S. normative sample will be used as the reference sample in defining significant differences in distribution between the U.S. and the samples in this study. For a description of this normative sample see Clark (1973).

The chi-square test for the significance of the difference between the observed frequency in the Irish sample and the expected frequency (based on the U.S. normative sample) indicates significantly greater homogeneity in the distribution for the Irish sample on the AVA pattern universe.

Whereas $17.76 \%$ of the U.S. normative sample is distributed in the area of the pattern universe around PS $3449,26.48 \%$ of the Irish sample fell into that area. The chi-square for the difference based on these two proportions is 7.75 , (d.f. 1), p <. 01 . 
For the second area, that around PS 5717, the difference between the observed frequency in the Irish sample and the expected frequency (derived from the normative U.S. sample) is equal to 47.37 , (d.f. 1), $p<.01$. (See Table 18 for a comparison of the modal AVA self-perceptions for the three samples.)

The clustering of the Irish sample was rather tight, with all the profiles correlating between .72 and .97 with their respective group centroids. No significant sex differences were found in group membership in either of these two clusters.

The remaining $47 \%$ of the Irish sample fel1, for the most part, into two weaker clusters, within which the pattern types are dispersed more widely (.69 to .96 with their centroids). Only $10 \%$ of the sample was found outside of these four clusters. The proportions of membership in these two latter and weaker clusters did not differ significantly from that found in the normative U.S. sample.

On this basis, it appears that there is a greater consensus in the self-perceptions of these Irish college students than among the general adult population of Americans whose patterns are distributed much more heterogeneously throughout the pattern universe.

AVA pattern shape 5717 was previously described as one of the autostereotypes held by these Irish students, particularly the males, about themselves. This is the "optimistic and socialty outgoing person... who possesses the enthusiasm and social poise that win friends easily..." but who, behind this facade has an intellectual drive for perfection and truth that can never quite be satisfied." 
Table 18

Comparison of the Irish, Italian, and American Modal AVA Self-Perceptions with Each Other and with a Normative U.S. Sample

Irish Sample

\begin{tabular}{cccc}
$\begin{array}{c}\text { AVA Pattern } \\
\text { Number: }\end{array}$ & $\begin{array}{c}\% \text { of total } \\
\text { sample: }\end{array}$ & $\begin{array}{c}\% \text { of U.S. } \\
\text { normative }\end{array}$ & $\begin{array}{c}\text { Chi-square for } \\
\text { the difference }\end{array}$ \\
\hline 3449 & $26.48 \%$ & $17.76 \%$ & 7.75, (df 1), <.01 \\
5717 & $26.48 \%$ & $10.34 \%$ & 47.37, (df 1), <. 001 \\
5942 & $13.50 \%$ & $11.84 \%$ & 3.00, n.s. \\
\hline
\end{tabular}

$\%$ of total sample accounted for:

$66.46 \%$

$39.94 \%$

Italian Sample

\begin{tabular}{cccc} 
AVA Pattern & $\%$ Italian & $\%$ U.S. norm & Chi-square \\
\hline 5717 & $56 \%$ & $11.42 \%$ & $320.00,<.001$ \\
3539 & $28 \%$ & $14.84 \%$ & $20.35,<.001$ \\
1667 & $8 \%$ & $10.51 \%$ & .235, n.s.
\end{tabular}

$\%$ of total sample accounted for:

$92 \%$

$48.19 \%$

American Sample

\begin{tabular}{cccc} 
AVA Pattern & $\%$ Americans & $\%$ U.S. norm & Chi-square \\
\hline 3539 & $35 \%$ & $17.26 \%$ & $33.03,<.001$ \\
6716 & $16 \%$ & $9.42 \%$ & $8.47,<.001$ \\
3944 & $14 \%$ & $6.00 \%$ & $17.82,<.001$ \\
1676 & $15 \%$ & $9.00 \%$ & $36.00,<.001$
\end{tabular}


AVA pattern 3449 is nearly identical to pattern 3539, which was also previousty described as one of the three autostereotypes the Irish sample held about their "typical" countryman. This is the quiet, humble, unassuming person "driven by a strict sense of loyalty" and almost compulsively conscientious in carrying out tasks. This person tends to be dependent on others for direction.

A third, weaker cluster, representing eight females and seventeen males, formed around AVA pattern 5942 and the proportion in this cluster did not differ significantly from the normative U.S. sample. This pattern, again, was also very close to one of the three Irish autosterotypes, PS $3944(r=.88)$. This is the socially graceful, helpful, and facilitative individual always ready to promote ideas and projects, either their own or others...a politically astute person with considerable charm and persuasive ability able to "influence others to go along with his/her point of view."

In the distribution of AVA profiles of the perceived "real self", then, $66 \%$ of the Irish sample fell into three clusters, each of which can fairly be represented by a single personality description or "group centroid".

The Myers-Briggs Type Indicator, was the second instrument used in this study to measure the self-perception. This instrument yields 76 personality types. (Refer back to Table 3.)

The distributions of these sixteen types in normative samples drawn from various U.S. populations - e.g. high school students, liberal arts college students, business students, engineering students, etc. - are reported in the MBTI Test Manual (1962). Thus, cross-group comparisons 
can be made in the case of the MBTI, as well as the AVA.

The selection of a suitable normative sample, however, proved to be difficult because of the fact that the normative samples reported in the Test Manual are either exclusively male or exclusively female. This problem was handled by averaging the percentages reported for two liberal arts normative samples, one male and one female, using a formula which weights the averages to take into account their differing N's.

The two normative samples selected for combination into a single reference sample were 3,676 male liberal arts college students drawn from Dartmough, Brown, Amherst, Stanford, Wesleyan Universities; and 184 Long Island University female liberal arts students. The sample sizes in this case are so vastly different that this solution is regarded as far from ideal. In addition, it should be pointed out that the colleges from which the normative sample is drawn are "ivy league" and probably quite atypical of the educational institutions from which the American sample in this study was drawn.

The procedure used in "averaging" the male and female normative samples was an application of the formula for obtaining weighted averages, applied to each of the sixteen cells of the MBTI type table. For example, for ISTJ types,

Sample 1. Male Liberal arts
Total $\mathrm{N}$ of sample: 3676

$$
\begin{aligned}
\% \text { of ISTJ types } & =7.32 \% \\
\text {. } & \text { N of ISTJ types }=269
\end{aligned}
$$

Sample 2.

Female Liberal arts Total $\mathrm{N}$ of sample: 184

$$
\% \text { of ISTJ types }=3.3 \%
$$$$
\text { . } \mathrm{N} \text { of ISTJ types }=6
$$ 


$$
\bar{X}=\frac{E X_{1}+E X_{2}}{N_{1}+N_{2}}=\frac{269+6}{3676+184}=\frac{275}{3860}=7.12 \%
$$

The normative U.S. sample distribution on the sixteen MBTI types is reported in Table 19. These normative samples are described in the MBTI Test Manual (1962).

Irish Self-Perceptions: MBTI types

The distribution of MBTI types in the Irish sample is reported in Table 20. To facilitate comparison with the U.S. normative sample, which is also shown in Table 19, the percent of that type found in the U.S. sample will be shown in parentheses below the percentage of those types in the Irish sample.

Three cells of MBTI types, INFP, INTP, and ENFP, appeared to draw proportionately large percentages of the Irish sample, and the three together account for $43 \%$ of the total sample.

As seen in Table 21, which compares the modal MBTI types in al1 three samples with each other and with the U.S. normative sample, the frequencies of these three types differs significantly from that found in the normative U.S. sample. In addition, as will be noted in the Table showing the Irish distribution, the frequency of ESTJ types is significantly less than it is the normative U.S. Sample (Chi-square equals 6.36 , d.f. $1, p$.05). This is a finding of special interest since the ESTJ type is the polar opposite of the INFP type, the type which appears to be "modal" for the Irish sample. Thus, it appears 
Table 19

Distribution of MBTI Types in a Normative U.S. Sample of 3676 Males and 184 females Liberal Arts Students

SENSING TYPES

INTUITIVE TYPES

with THINKING with FEELING with FEELING with THINKING

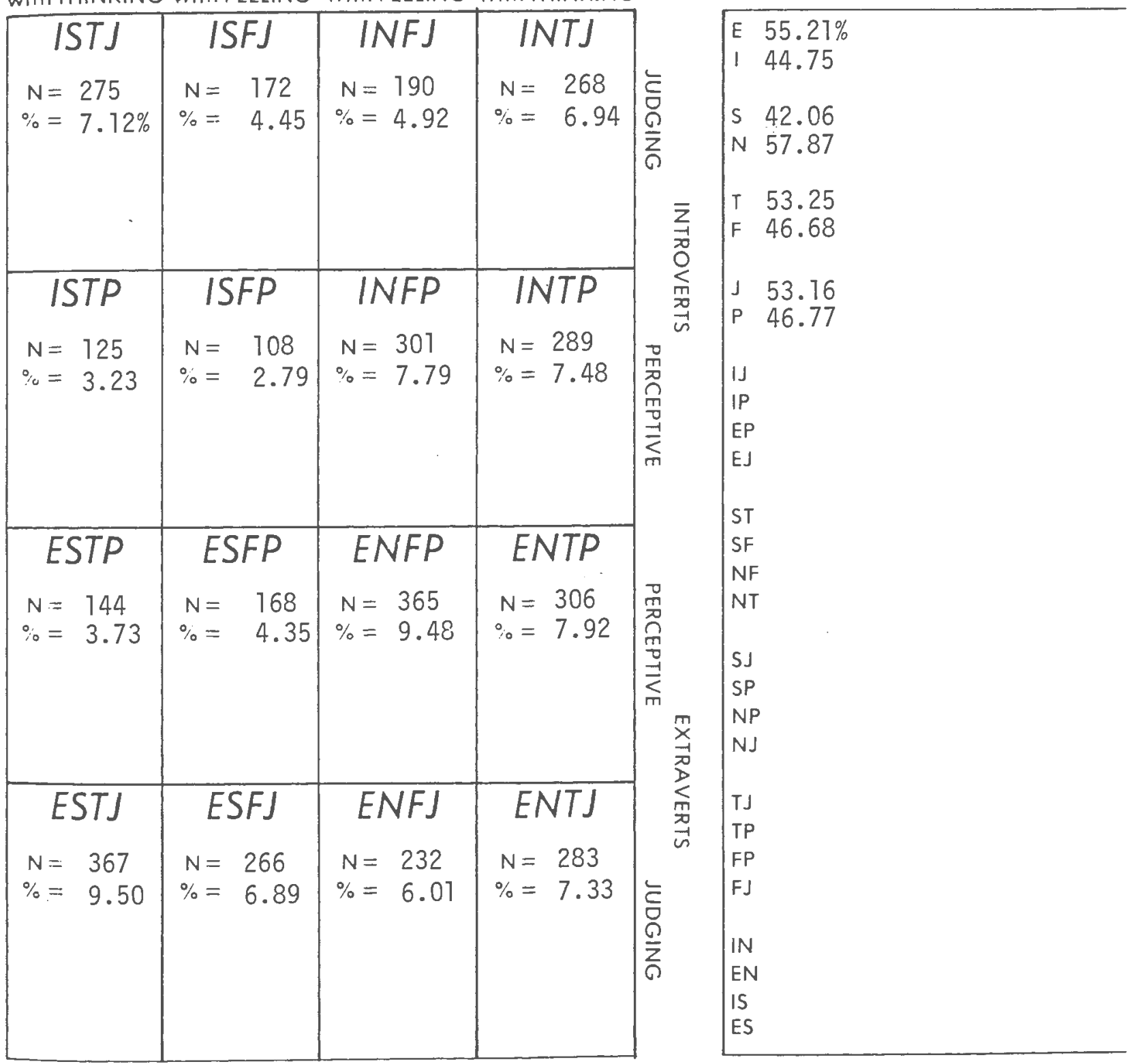

NOTES: 
Table 20

Distribution of MBTI Types in the Irish Sample

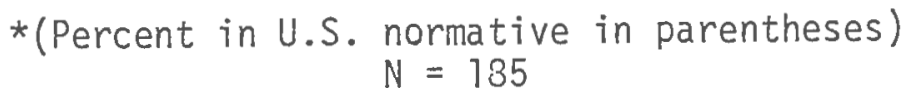

SENSING TYPES

INTUITIVE TYPES

with THINKING with FEELING with FEELING with THINKING

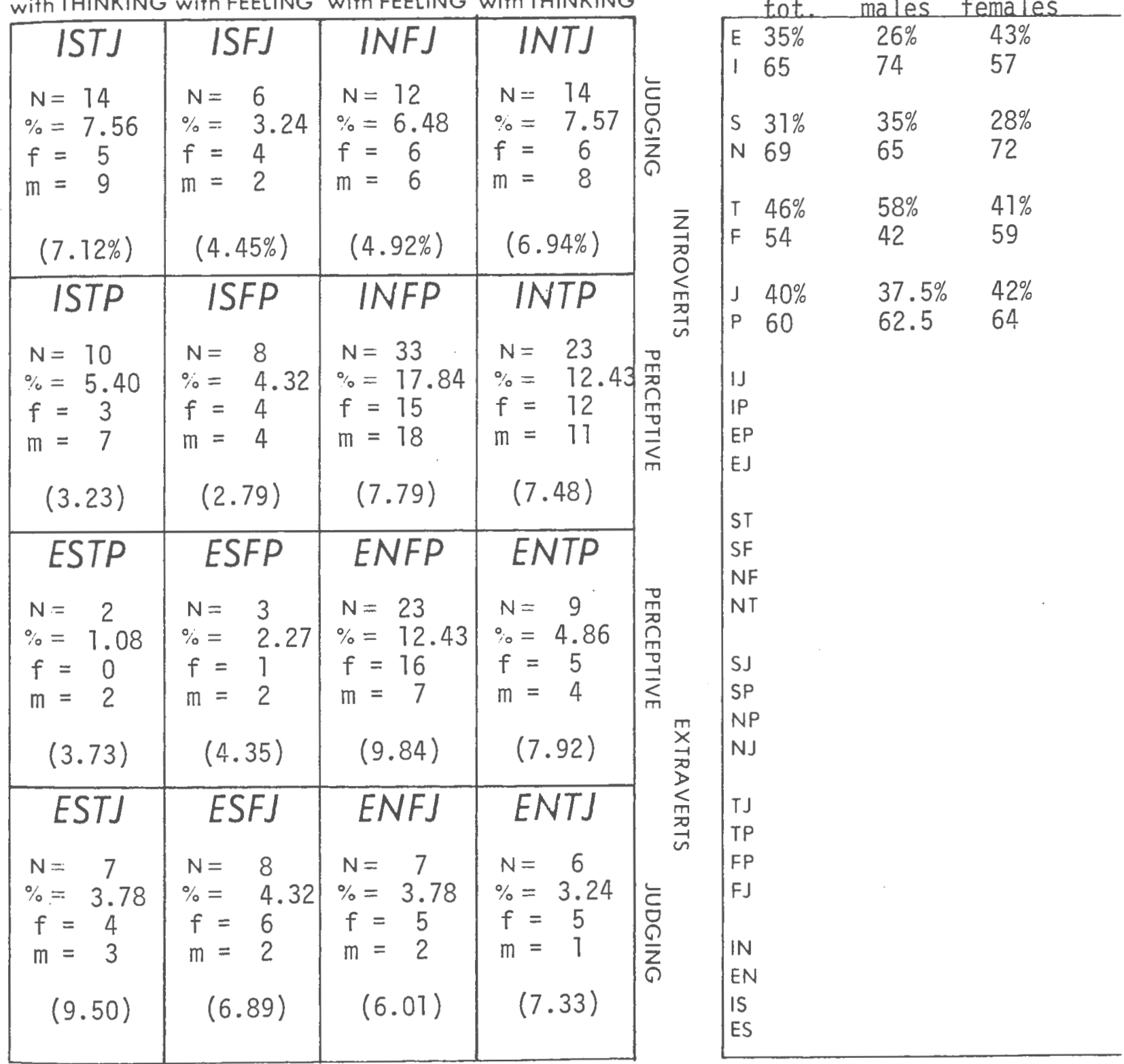

NOTES: 
Table 21

Comparison of the Modal MBTI Types for the Three Samples with Each Other and with the Normative U.S. Sample

Irish

\begin{tabular}{lccc} 
MBTI type: & $\begin{array}{c}\% \text { of total } \\
\text { Irish Sample }\end{array}$ & $\begin{array}{c}\% \text { of U.S. } \\
\text { normative }\end{array}$ & $\begin{array}{c}\text { Chi-square for } \\
\text { the difference } \\
\text { (d.f. }=1)\end{array}$ \\
\hline INFP & 17.84 & 7.79 & $25.78,6.001$ \\
INTP & 12.43 & 7.48 & $5.78,6.05$ \\
ENFP & 12.43 & 9.84 & 1.39, n.s.
\end{tabular}

$\%$ of total

accounted for

42.70

25.11

Italians

\begin{tabular}{cccc} 
MBTI type: & $\begin{array}{c}\% \text { of total } \\
\text { Italian Sample }\end{array}$ & $\begin{array}{c}\% \text { of U.S. } \\
\text { Normative }\end{array}$ & $\begin{array}{c}\text { Chi-square for } \\
\text { the difference } \\
(\text { d.f. }=1)\end{array}$ \\
\hline ISTJ & 19 & 7.12 & $33.92,<.001$ \\
ESTJ & 17.5 & 9.50 & $11.53,<.001$ \\
ESTP & 15.8 & 3.73 & $63.00,<.001$ \\
ISTP & 11.29 & 3.23 & $24.14,<.001$
\end{tabular}

$\%$ of total

accounted for

\begin{tabular}{l}
$63.59 \quad 24.08$ \\
\hline
\end{tabular}

Americans

\begin{tabular}{cccc} 
MBTI type: & $\begin{array}{c}\% \text { of total } \\
\text { American Sample }\end{array}$ & $\begin{array}{c}\% \text { of U.S. } \\
\text { Normative }\end{array}$ & $\begin{array}{c}\text { Chi-square for } \\
\text { the difference } \\
(\text { d.f. }=1)\end{array}$ \\
\hline ESFJ & 11.66 & 6.89 & $6.75,<.01$ \\
ESFP & 8.33 & 4.35 & $6.12,<.05$ \\
ISFP & 5.55 & 2.79 & $5.00,<.01$ \\
\hline
\end{tabular}

$\%$ of tota 1

accounted for

25.54

14.02 
that there is a real tendency in this Irish sample of college students towards introverted, intuitive, perceptive types.

The description of the INFP type given by the MBTI manual (1962) stresses the capacity of this type for depth and concentration, insight, ingenuity, grasp of the complicated, and capacity for devotion, sympathy, and adaptability. It mentions that this type may feel "a marked contrast between inner ideal and outer reality", making him/her "sensitive and vulnerable if no channel for expression can be found". In particular, the INFP types care about learning, ideas, Tanguage, and independent projects of their own. They tend to take on too much but somehow get it done, and are friendly but frequently too absorbed in what they are doing to be sociable. The INFP types are described as marked by insight and long range vision, curious about new ideas, interested in books and language, and likely to have a gift for expression, especially in writing. Such individuals are ingenious and persuasive on the subjects of their enthusiasms, which are quiet but deep-rooted.

INTP types were also significantly more frequent in the Irish sample than in the normative U.S. sample. This type shares many of the characteristics of the INFP - depth, concentration, ingenuity, etc. - but are apt to have a greater capactiy for analysis and logic due to the "T" dimension.

As was mentioned, there is also a significantly much smaller proportion in the Irish sample of ESTJ types. The ESTJ "type" is the practical, down-to-earth, realistic and matter-of-fact kind of person who is not interested in theoretical topics. The low incidence of the 
ESTJ type further highlights and makes even more consistent the finding of INFP as the "modal" type.

Italian Self-Perceptions

With respect to their AVA "self" profiles, $90 \%$ of the males and $79 \%$ of the females in the Italian sample fell into two fairly tight, somewhat overlapping clusters corresponding quite closely to the two clusters formed by their autostereotypes. The modal self-perception of both males and females was AVA PS 5717, and this is very similar to PS 5915, the mode for the autostereotype. ( $r$ between the two equals .87). Forty-seven percent of the females and sixty-eight percent of the males fell into the cluster around PS 5717. (The sex difference is significant at the .001 level.)

The second cluster of AVA "basic self" profiles formed around centroid 3539 and membership in this cluster accounted for $32 \%$ of the female sample and $22 \%$ of the males. (The sex difference is not significant.) Pattern shape 3539 is also very similar to PS 5519, the second autostereotype that emerged in the Italian data.

Only seven males fell outside of these two clusters and their profiles were, for the most part, rather widely dispersed. Thus, for Italian males, $90 \%$ of the sample was accounted for in two clusters.

For the females, a third weak cluster, accounting for $12.5 \%$ of the female sample, formed around AVA PS 1667. The cluster also included three males. Of the eight females not included in the three clusters just described, six fell just outside PS 5717 and their profiles correlated .67 with it. 
Thus, for Italian females, three clusters accounted for $91.5 \%$ of the sample, and the same three clusters for $94 \%$ of the males. (Refer to Table 18 for a summary of these data.)

AVA PS 5717 describes the active socially outgoing, basically optimistic person who is a "doer" and prefers action to inaction although beneath this facade of social poise this person is more deliberative than $s /$ he may appear to be. There is also an intellectual drive to probe for logical answers and a desire for perfection that may make this person somewhat slow in making decisions and prone to changing them. Significantly more males than females shared this self-perception.

AVA PS 3539 , with a much smaller proportion of Italian males and females clustered around it, describes the type of person who is highly dependent on others, finds it difficult to make independent decisions, and works best under supervision. This person tends to be an anxious worrier, to work with great conscientiousness and devotion to duty, and to be neat, organized, and accurate in approach to tasks.

This person appears to be the conservative type, approaching new situations with suspicion, and preferring traditional ways of doing things.

AVA PS 1667 drew a very small percentage of the total sample. This pattern is also described as a quiet and unassuming type, though one who lacks the anxiousness and tension of the preceding type. This individual exudes "peacefulness, tranquility, and serenity", is friendly, amiable, steady, patient, and empathic towards others. This individual also "resists change, preferring established systems and methods", as is 
the preceding type; and is good at carrying out routines with patience and dedication. This type is described as modest, cheerful, devoted and Toyal.

The distribution of the Italian sample on the MBTI is shown in Table 22. Inspection of this distribution makes it apparent that the extreme left hand column of the Type Table, the region of "ST" or sensing thinking" types was heavily weighted in the Italian sample. Clost to two-thirds of the entire Italian sample fell into the four "ST" types - whereas these four types account for only $24 \%$ of the U.S. normative sample. The differences between observed and expected frequencies of these types in the Italian sample were all significant at the .001 lever.

With respect to these four types (ISTJ, ISTP, ESTP, and ESTJ), the only significant sex difference in this distribution was for the ESTJ type, which has nearly three and one half times as many males $(n=24)$ as females $(n=7)$, a difference significant at the .01 level. Owing partly to this skewed distribution, 11 of the sixteen cells of the MBTI type table showed a significant difference in the Italian versuS U.S. normative, distributions. Outside of the "ST" cells mentioned, in which observed frequencies far exceeded expected frequencies, the significant differences in the other seven cells were in a negative direction - that is, contained far fewer-than-expected frequencies. That this is not simply a function of the extremely skewed "crowding" of the Italian sample into the four "ST" types is evident from inspection of the distribution throughout the table. Rather than being dispersed rather evenly throughout the other 12 cells, one finds a marked lack of cases in the "NF" region of the table: that is, the area which 
Table 22

Distribution of MBTI Types in the Italian Sample

$$
\begin{gathered}
\text { *(percent in U.S. normative sample) } \\
N=177
\end{gathered}
$$

SENSING TYPES

INTUITIVE TYPES

with THINKING with FEELING with FEELING with THINKING

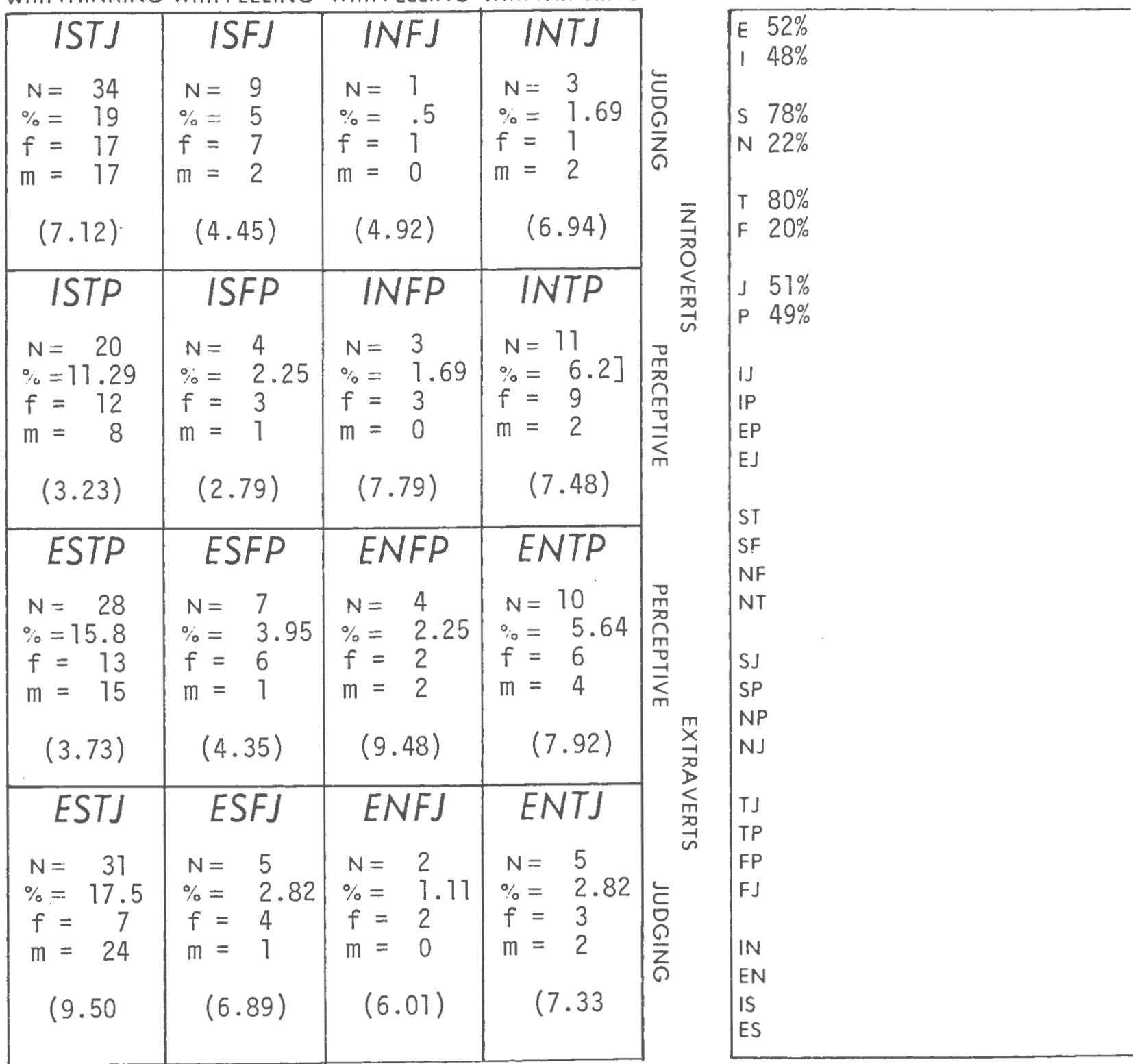

NOTES: 
represents the polar opposite of the "ST". In this column of the type table, eight females and two males are distributed across four cells, and the lowest frequency in the entire table is found in the INFJ cell, which claimed one female and no males. It was just this case which was found in the Irish data as well, but in the reverse direction. The Irish sample clustered in greater-than-expected proportions into the "NF" region, and in far-less-than-expected proportions in the "ST" region.

The ESTJ type was the most frequently occuring type in the Italian sample for males. The ESTJ is described as "an extraverted thinker...who has a great respect for impersonal truth, thought-out plans, and orderly efficiency. This type is at ease with the social environment, practical, observant, logical, decisive, critical, and organized. This kind of individual often makes a good executive.

The most frequently occuring personality types for the females were ISTJ and ISTP. The introversion of these two types adds depth and concentration to their capactiy for realism, observation, and logical analysis. The ISTJ type is better at organization while the ISTP type is better at adapting.

A11 of these types share a practical, orderly, matter-of-fact, realistic orientation to life and its problems. The introverted sensing types tend to remain more reserved, aloof, and detached from the environment, which may make them appear like "cool onlookers", or as serious and quiet, but which also give them an added capacity for concentration, depth, and impersonal analys is. 
The extraverted sensing types tend to manage the environment very effectively though sometimes in a rather blunt way.

There was, as noted, an extremely low incidence of "intuitive feeling types" in the Italian distribution, particularly INFJ. Only a single Italian (female) in the entire sample fell into this category. The low incidence of "NF" types appears to highlight a lack of a theoretical, as opposed to practical, orientation among these Italian students. "Sensing" types tend to "see the facts" whereas "intuitive types" tend to "see the possibilities". Thinking types tend to be good at impresonal analysis and organization and may make good administrators and executives. Feeling types, on the other hand, are good at persuasion and conciliation, and may be good at jobs which allow them to express their need to give sympathy and nurturance - though they often have a hard time taking a firm stand or "getting tough" when the situation calls for it.

"ST" types, according to correlations provided by the MBTI manual between the Strong Vocational Inventory Blank (SVIB) and the scales of the MBTI, are often good in practical or technical fields and tend to have a much lower rate of turnover in such fields, contrasted with "NF" types. Fields such as business, accounting, production, economics, law, surgery, etc. appear to draw their most successful practitioners from among the "ST" types. "NF" types, on the other hand, may excel in teaching, preaching, counselling, clinical psychology, psychiatry, writing, and most fields of research.

The highest correlations reported in the MBTI type manual between a given occupation and scale on the MBTI are as follows: 


$$
\begin{array}{ll}
\text { I - mathematics }-.37 & \text { E - Sales Manager }-.37 \\
\text { N - psychologist }-.55 & \mathrm{~S} \text { - banker }-.37 \\
\text { F - minister }-.27 & \mathrm{~T} \text { - purchasing agent }-.22 \\
\text { P - artist }-.20 & \mathrm{~J} \text { - accountant }-.24
\end{array}
$$

Correlations between the MBTI scales and the Allport-VernonLindzey Study of Values also sheds light on the interpretation of these "types". The "value" associated most strongly with each MBTI scale are as follows $(r=.20)$ :

$$
\begin{array}{ll}
I-\text { aesthetic }-.20 & \text { E - political }-.20 \\
\mathrm{~N}-\text { aesthetic }-.34 & \mathrm{~S} \text { - economic }-.46 \\
\mathrm{~F}-\text { social }-.34 & \mathrm{~T} \text { - theoretical }-.37 \\
\mathrm{P}-\text { Aesthetic }-.16 & \mathrm{~J} \text { - Economic }-.12
\end{array}
$$

Though numerous other correlations are reported between the MBTI scales or types and various other psychological tests, one last example should suffice to make clearer the meaning of these dimensions. Henry Murray's conceptualization of personality in terms of needs has been operationalized in the Edwards Personal Preference Scale, an attempt to measure these needs. Among these, the need most strongly associated with each of the preferences or dimensions of the MBTI are as follows:

$$
\begin{array}{ll}
I-\text { achievement }-.15 & E \text { - dominance }-.28 \\
\mathrm{~N} \text { - autonomy }-.31 & \mathrm{~S} \text { - order }-.34 \\
\mathrm{~F} \text { - nurturance }-.51 & \mathrm{~T} \text { - endurance }-.30 \\
\mathrm{P}-\text { autonomy }-.31 & \mathrm{~J} \text { - order }-.49
\end{array}
$$

American Self-Perceptions

Four clusters of scores were formed by the American sample on the AVA pattern universe, centering about group centroids PS 3539 , 
PS 6716, PS 1667, and PS 3944. Membership in these four clusters accounted for $80 \%$ of the total American sample, $87 \%$ of the females and $71 \%$ of the males. A fifth cluster, containing $15 \%$ of the male sample and no females, formed around PS 2594. Thus $87 \%$ of the females were accounted for by membership in four clusters, whereas five clusters were needed to account for a nearly equivalent (86\%) percentage of males. The four clusters, formed around group centroids 3539, 6716, 1667 , and 3944 also showed significant departures from the more heterogeneous normative U.S. sample. Chi-squares for these differences ranged from 8.47 to 36.00 , and were all significant at least at the .01 level, at least. The membership (of males only) in the loose cluster formed around PS 2594 does not show significant departure from the normative distribution. (Refer back to Table 18 for a summary of these data.) Two of these clusters, PS 3539, and PS 6716, accounted for the self-perceptions of $51 \%$ of the total sample, and showed a fairly high degree of similarity to two of the autostereotypes found earlier to account for $91 \%$ of the American autostereotypes. (Refer to Table 17).

The person typified by pattern 3539 has previously been described, then, as one of the American autostereotypes. This is the quiet, unassuming humble and dependent person who works best under direction from others. Such a person tends to be an anxious worrier, meticulous, fastidious, and puntilious, and takes great precautions not to deviate from established routines and guidelines. Clinically, this person may sometimes be described as "obssessive-compulsive" (Merenda and Berger, 1978). This was the self-perception held by $38 \%$ of the females and $31 \%$ of the males in the American sample. (The sex difference is not 
significant). It appears to describe a person rather low in selfconfidence.

AVA pattern 6716 , which described $16 \%$ of the total sample, $22.5 \%$ of the males and $11 \%$ of the females, was also previously described as one of the American autostereotypes. "This is a person who gives the appearance of being highly excitable, constantly irritable, and exceedingly impatient. $S /$ he is a rather high-strung person who approaches most demanding life situations with zeal but who invariably takes on much more than $s /$ he is capable of handling or accomplishing. $s / h e$ exudes nervous tension; is prone to impulsive actions and decisions; and is restless and uneasy in social situations - factors which often prevent him/her from being readily accepted by peers and other people toward whom personal contacts have been initiated." This pattern described a significantly greater proportion of males than females.

AVA pattern 1676, with $15 \%$ of the American sample clustering around it, $20 \%$ of the females and $9 \%$ of the males, described the "quiet and unassuming person whose presence among others exudes peacefulness, tranquility, and serenity. Being amiable and friendly, this person is we11-liked by others. Steady and patient, s/he likes to be sought out by others in time of need, is modest in manner, and cheerful in spirit. S/he resists change, performs duties with patience and dedication, and tends to be a loyal and devoted member of any group s/he belongs to." This pattern described a significantly greater proportion of females than males.

Fina11y, AVA pattern 3944, with $14 \%$ of the total American sample clustered around it, also described a significantly greater proportion 
of females than males ( $18 \%$ as opposed to $9 \%$ of the latter).

This person is described as always ready to help others promote ideas and projects, both their own and others. This is a person who is at ease in social situations and initiating contacts, is attracted to a wide variety of people, and is usually a joiner of clubs and social groups. This is the politically astute individual who has the charm and persuasiveness to influence others to go along with his/her point of view.

(The fifth cluster centering around AVA pattern 2594 and representing $15 \%$ of the males and no females, can be described as a group, as peaceful persons, modest, serene, calm, and relaxed - a pattern not unlike PS 1676 , described previously, with which it is correlated .79 . This was the only cluster in the American sample described thus far which did not show significant departure from the frequencies to be found in the U.S. normative sample. It is included here, however, because, taken together with the four clusters described above, it accounts for $84 \%$ of the male sample.

Turning now to the distribution of the American sample on the MBTI, three types were found in significantly greater proportions than would be expected on the basis of the normative reference sample. However, these three types together account for only about $25.54 \%$ of the American sample, whereas in the Irish sample three MBTI types accounted for $43 \%$ of that sample, and in the Italian sample, three types accounted for $63.59 \%$ of the Italian students. Thus, though the American sample shows a departure from the heterogeneity of the U.S. normative sample in its MBTI distribution, it is, nevertheless, more heterogeneous with 
respect to the distribution of types than either the Irish or Italian samples.

See Table 23 for the American distribution on the MBTI.

In the American sample, six cell frequencies differed significantly from expected frequencies. Three of these, ESFJ, ESFP, and ISFP, have significantly greater-than-expected frequencies, and three, INFJ, ENFJ, and INTJ, have significantly fewer frequencies. Thus, for the American students in this sample, the "SF" type appeared to be more frequent than in the general college student population, and the "NJ" types appeared to be less frequent.

The most frequent types for females in this sample were ESFJ and ENFP, both of which had nearly equal numbers of females, and taken together account for $35 \%$ of the female sample (versus $11 \%$ of the males).

The most frequent types for the males were ESTJ (13 males) and INFP (10 males) which, taken together, accounted for $29 \%$ of the male sample.

As was stated previously, however, only "SF" types showed a greater than expected frequency in the American sample, and only "NF" and "NJ" types less than expected frequencies.

"SF" types are described by the MBTI manual (1962) as mainly interested in facts they can gather directly through the senses, but they approach their decisions regarding these facts with personal warmth. Their personalities tend to be sociable and friendly, their most successful fields tend to be in elementary teaching, nursing (especially pediatrics), social work, etc. where they can exercise their personal warmth effectively in concrete situations. 
Table 23

Distribution of American Sample on the MBTI Types

$$
\begin{gathered}
\text { *(Percent in normative U.S. sample) } \\
N=180^{*}
\end{gathered}
$$

SENSING TYPES

INTUITIVE TYPES

\begin{tabular}{|c|c|c|c|c|c|}
\hline $\begin{array}{l}\text { ISTJ } \\
N=12 \\
\because=6.66 \\
f=4 \\
m=8 \\
(7.12)\end{array}$ & $\begin{array}{c}\text { ISFJ } \\
N=9 \\
\%=5.00 \\
f=7 \\
m=2 \\
(4.45)\end{array}$ & $\begin{array}{c}\text { INFJ } \\
N=2 \\
\%=1.11 \\
f=2 \\
m=0 \\
(9.92)\end{array}$ & $\begin{array}{l}\text { INTJ } \\
N=5 \\
\%=2.77 \\
f=0 \\
m=5 \\
(6.94)\end{array}$ & $\mid \begin{array}{l}\bar{c} \\
\frac{0}{0} \\
\frac{0}{z} \\
0 \\
\bar{z} \\
\bar{D} \\
0\end{array}$ & \begin{tabular}{|ll}
$E$ & $63 \%$ \\
1 & $37 \%$ \\
$S$ & $57 \%$ \\
$N$ & $43 \%$ \\
$T$ & $46 \%$ \\
$F$ & $54 \%$
\end{tabular} \\
\hline $\begin{array}{c}\text { ISTP } \\
N=6 \\
o_{i}=3.33 \\
f=1 \\
m=5 \\
(3.23)\end{array}$ & $\begin{array}{c}\text { ISFP } \\
N=10 \\
\%=5.55 \\
f=7 \\
m=3 \\
(2.79)\end{array}$ & $\begin{array}{l}\text { INFP } \\
N=16 \\
\%=8.88 \\
f=6 \\
m=10 \\
(7.79)\end{array}$ & $\begin{array}{l}\text { INTP } \\
N=6 \\
\%=3.33 \\
f=4 \\
m=2 \\
(7.48)\end{array}$ & 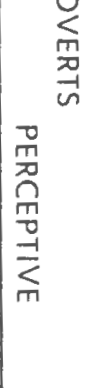 & $\begin{array}{ll}J & 42 \% \\
P & 58 \% \\
& \\
U \\
\text { IP } \\
\text { EP } \\
\text { EJ } \\
\text { ST }\end{array}$ \\
\hline $\begin{array}{c}\text { ESTP } \\
N=10 \\
\%=5.55 \\
f=6 \\
m=4 \\
(3.73)\end{array}$ & $\begin{array}{c}\text { ESFP } \\
N=15 \\
\%=8.33 \\
f=17 \\
m=4 \\
(4.35)\end{array}$ & 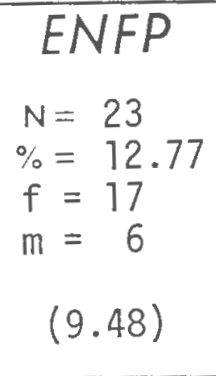 & $\begin{array}{c}\text { ENTP } \\
N=18 \\
\%=10.00 \\
f=6 \\
m=12 \\
(7.92)\end{array}$ & 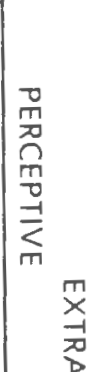 & $\begin{array}{l}\text { SF } \\
\text { NF } \\
\text { NT } \\
\text { SJ } \\
\text { SP } \\
\text { NP } \\
\text { NJ }\end{array}$ \\
\hline $\begin{array}{c}\text { ESTJ } \\
\mathrm{N}=20 \\
\%=9.50 \\
f=7 \\
\mathrm{~m}=13 \\
(9.50)\end{array}$ & $\begin{array}{c}\text { ESFJ } \\
N=21 \\
\%=11.66 \\
f=18 \\
m=3 \\
(6.89)\end{array}$ & 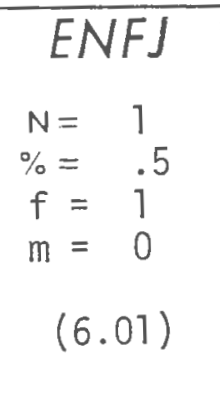 & $\begin{array}{c}\text { ENTJ } \\
N=6 \\
\%=3.33 \\
f=3 \\
m=3 \\
(7.33)\end{array}$ & $\mid \begin{array}{l}\vdots \\
0 \\
0 \\
\bar{o} \\
0\end{array}$ & $\begin{array}{l}\text { TJ } \\
T P \\
F P \\
F J \\
\text { FJ } \\
\text { IN } \\
E N \\
\text { IS } \\
\text { ES }\end{array}$ \\
\hline
\end{tabular}

with THINKING with FEELING with FEELING with THINKING

NOTES: *10 subjects did not complete MMPI 
"NF" types, which showed a low incidence in this sample, also possess the personal warmth of the "SF" types, but center their attention on possibilities and future projects rather than on concrete, here-and-now situations. Thus, it appears that the American sample, with its high incidence of SF types, has, on the whole, a greater-thanexpected proportion of subjects who are rather more practical and realistic than theoretical, though they combine this with personal warmth, rather than impersonal analysis due to the " $F$ " rather than " $T$ " dimension.

It has already been noted that modal autostereotypes and self-perceptions frequently coincided in this study. Table 24 presents the correlations, for the three samples, between their AVA autostereotypes and their AVA self-perception profiles. Inspection of this table reveals that the Italian sample showed the highest degree of agreement, overall, between their autostereotypes and their self-perceptions, with nearly three-fourths of the sample having correlations between the "role" profile and the "self" profile of from .60 to .99. Furthermore, inspection of the frequency column shows that the frequencies go down in a highly orderly and consistent manner as the correlation declines.

Irish students showed the next highest degree of agreement, with nearly half the sample showing correlation between .60 and .99 , of the autostereotype and the real self, though $27 \%$ of the Irish students had negative correlations.

American students had, overa 11, the least degree of agreement. of the total sample, $39 \%$ had correlations of between .60 and .99 , whereas $31.5 \%$ had negative correlations ranging from .00 to -.99 . 
Table 24

Correlations of AVA Autostereotypes with Basic Self-Perceptions for Irish, Italian and American Students

\begin{tabular}{|c|c|c|c|c|c|c|c|c|c|}
\hline \multirow[t]{2}{*}{ Correlation: } & \multicolumn{3}{|c|}{ IRISH } & \multicolumn{3}{|c|}{$\begin{array}{c}\text { percent of tota } 1 \\
\text { ITALIAN }\end{array}$} & \multicolumn{3}{|c|}{$\begin{array}{l}\text { sample } \\
\text { AMERICAN }\end{array}$} \\
\hline & $f$ & $\mathrm{~m}$ & tot. & $f$ & m & tot. & $f$ & m & tot. \\
\hline $\begin{array}{l}\text { positive } \\
.80-.99\end{array}$ & 34 & 30 & 32 & 48 & 56 & 52 & 20 & 29 & 24 \\
\hline $.60-.79$ & 12 & 19 & 15 & 19 & 24 & 22 & 15 & 15 & 15 \\
\hline $.40-.59$ & 25 & 6 & 15 & 14 & 5 & 10 & 12 & 7 & 20 \\
\hline $.20-.39$ & 6 & 7 & 6.5 & 7 & 1 & 4 & 16 & 6 & 12 \\
\hline $.00-.19$ & 4 & 4 & 4 & 4 & 4 & 4 & 6 & 10 & 8 \\
\hline $\begin{array}{l}\text { negative } \\
.00-.19\end{array}$ & 4 & 12 & 8 & 3 & 2 & 3 & 8 & 5 & 7 \\
\hline$-.20-.39$ & 2.5 & 5 & 4 & 2 & 1 & 1 & 9 & 4 & 7 \\
\hline$-.40-.59$ & 5 & 5 & 5 & 2 & 4 & 3 & 5 & 6 & 5 \\
\hline$-.60-.79$ & 8 & 8 & 8 & 0 & 1 & .5 & 6 & 12 & 9 \\
\hline$-.80-.99$ & 1 & 2 & 2 & 0 & 1 & .5 & 2 & 5 & 3 \\
\hline
\end{tabular}


This finding corresponds with the previously reported finding that the modal AVA self-perception often corresponded to the AVA autostereotype for a given group. For the Irish group, for example, the biomdal self-perceptions were AVA pattern 3449 and PS 5717, which accounted for exactly $26 \%$ each of the total Irish sample. The two modal AVA autostereotypes were PS 5717 (37\%) and PS 3539 (29\%). Thus the two modal autostereotypes and the two modal self-perceptions were nearly identical.

For the Italians, the modal self-perception was PS 5717 (56\%) and the modal autostereotype was PS 5915 (73\%). These two AVA patterns correlate $r=.87$ with each other.

For the Americans, however, the modal AVA self-perception for the group was PS 3539 (35\%) whereas the modal autostereotype was PS 7616 $(66 \%)$. These two correlate with each other .35 .

In terms of their AVA self-profiles, the Irish split into two equal groups, $26 \%$ in each, as follows: PS 5717 - the active "doer" who is optimistic, outgoing, and socially poised but has an inner drive for perfection and truth that makes this type more inwardly tense than he appears; and PS 3449 - quiet, fearfuT, dependent, unassertive, and lacking in confidence. The four scales of the MBTI, taken as separate dimensions, showed the Irish students to be, as a group, introverted $(65 \%)$, intuitive $(69 \%)$, feeling $(54 \%)$ and perceptive $(60 \%)$. The most frequentyy occuring feeling (54\%) and perceptive (60\%). The most frequently occuring "type" for the Irish was INFP (18\% of the sample), far more frequent than in the U.S. reference sample of American liberal arts college students. 
The Italian students as a group had distributions which were much more homogeneous than the other two samples. The modal AVA "self" profile for the group, agreed upon by ful1y $56 \%$ of the sample, was PS 5717 - the outwardly active "doer" described above who performs wel1 socially but is inwardly more tense, discontented, and driven than appears outwardly. On the scales of the MBTI, the group as a whole were extraverted (52\% - though more males than females), sensing (78\%), thinking (80\%) and judging (51\%). The most frequently occuring MBTI type for the sample as a whole was ISTJ (19\%). However, there was a significant sex difference here. The mode for females was ISTJ and for males it was ESTJ. Thus there was good agreement in the Italian sample on the " $\mathrm{S}$ " and " $T$ " scales, but females tended to be more introverted than males.

Thirty-five percent of the American students had an AVA self-perception represented by pattern 3539, which describes the "anxious, dependent, unassertive, individual who lacks confidence". This is in sharp contrast to the autostereotype, PS 7616 , held by $66 \%$ of the group, which described the "typical" American as excitable, irritable, impatient, and high-strung person always "on the go". This, taken together with the findings reported in Table 24, showed the group as a whole had the least correlation between self-perception and national identity, and suggests a real split in this sample. These students as a group seem to lack self-confidence and to perceive the typical member of the American culture as being quite different from them. On the MBTI scales taken individually, American students as a group were extraverted (63\%), sensing $(57 \%)$, feeling (54\%0, and perceptive (58). 
135.

The most frequently occuring "type" for the group reflects their preferences on these dimensions: The ESFP type was the most prevalent $(12 \%)$. 


\section{Chapter 4 \\ DISCUSSION}

In the light of these findings an attempt can now be made to address the questions posed at the outset of this study and to examine the degree to which the hypothesis of cultural differences, and the specific predictions flowing from this hypothesis, received empirical support. Each of these questions and predictions will be briefly recapitulated preliminary to commenting upon them.

\section{Heterostereotypes}

(1) Were clear-cut national stereotypes found to exist? If so, were there differences among the groups, either in their willingness to stereotype, or the content of the stereotypes themselves?

For the purposes of simplification, groups are discussed as groups - but it should be kept in mind that each group was made up of nearly 200 individuals, and there was a good deal of variability across the individuals within each group. Thus, though the discussion will focus on "central tendencies" or trends of the groups taken as a whole, the fact of individual variability should not be forgotten. As was pointed out previously, for example, some persons - particularly among the Italian students - did not respond to the question regarding heterostereotypes at a11. The researcher herself administered the test instruments to the American sample and found some students who were discomforted by the question and, in some cases, refused to respond to it. 
It was apparent from the data, however, that some members of each of the three groups studies held stereotypic pictures of the other two groups.

The Irish students appeared to have the greatest "enthusiasm" for the task of stereotyping, and they had the greatest degree of clarity and strength in describing these stereotypes. Their generally greater willingness to stereotype emerged in the larger number of total adjectives produced by the group as a whole, the overall greater mean number of adjectives used per subject, and the very low incidence (almost zero) of failure to answer the question. The clarity of the stereotypes produced by the Irish students was seen in the large number of synonyms occuring in the list of adjectives they generated. The strength of their consensus was shown by the fact that, especially in stereotyping Americans, many of the individual adjectives or their synonyms, were used with relatively high frequency. The word "loud" for example, was used by 79 Irish students in describing Americans. No other single word was used with a frequency even remotely approaching this in either of the other samples. Also Irish students stereotyped Americans more strongly and clearly than they did Italians. In the stereotype of the former, Americans were seen as loud, dominant, aggressive, competitive, and friendly. Italians, on the other hand, were seen by these Irish students as gregarious, friendly, warm, temperamental, and emotionally expressive.

The Italian students appeared almost diffident in their approach to the stereotyping task. As a group they produced the shortest 7 ist of adjectives and there were fewer synonyms in this list. They used, 
for the most part, a fewer mean number of adjectives per student and the frequency of use of any given word or its synonym was markediy lower than for the Irish sample. In addition, a substantial proportion of Italian students did not respond to the question. To the extent that they did produce stereotypes, Americans were perceived as happy, attractive, sociable, extravagant or spendthrift, selfaggrandizing, self-confident, and capricious. This stereotype emerged as much stronger (higher frequency of given words) than the stereotype produced by Italian students of the Irish. Here such consensus as existed in the group depicted the Irish as religious and/or Catholic, conservative, traditional, and irascible.

American students appeared to be intermediate between these two groups in the willingness to stereotype - again, in terms of total number of adjectives produced by the group, mean number of adjectives used per subject, and refusal to answer the question. The words they did use with any appreciable degree of frequency indicate moderate consensus about the "typical traits" of the Irish and Italians, respectivery, with emphasis on physical characteristics in describing both. Americans stereotyped the Irish as red-haired, freckled, fairskinned, drinkers, happy, friendly, stubborn, hot-tempered, and religious. They stereotyped the Italians as dark-skinned, dark-eyed, fat, loud, hard-working, family-oriented, aggressive, and romantic.

There does not appear to be a striking degree of agreement for the two stereotypes of any given group. Americans were seen as dominant, aggressive and competitive by the Irish but as "happy-goTucky", cheerful, capricious and spendthrift by the Italians. Both 
groups agreed, however, in perceiving Americans as sociable and selfinflated.

Italians were seen as warm, friendly, gregarious, emotionally expressive and romantic by the Irish students whereas American students saw them as - in addition to dark-eyed, dark-haired, etc. aggressive, loud, hard-working and family-oriented.

Irish were perceived quite differently by American than by Italian students. Italian students saw them as conservative, traditional, emotionally cold, introverted, and stingy (though it should be emphasized again that this picture was held by only a small percentage of students) whereas Americans saw them as boisterous, happy, jovial, friendly, and "good partyers" - in addition, of course, to physical characteristics such as freckled, red-haired, etc.

In summary, then, stereotyping was found to exist in the three groups, although the willingness to stereotype varied, as did the content of the stereotypes themselves, across the three groups.

The Meaning of Stereotypes

Certain factors and reservations, however, ought to be kept in mind in interpreting these results. First, it should be noted that the willingness to stereotype is not necessarily the same thing as holding that stereotype as a deep personal belief. The "demand characteristics" of experimental situations have previously been estab1ished. It has been shown that subjects in experimental situations often evince a remarkable degree of willingness to cooperate, even in performing tasks perceived as irrelevant or silly. In this study, 
the Irish students in general showed a very marked degree of cooperation in answering almost all of the questions and in following directions with great care. Even the test protocols themselves of the Irish students were remarkable for their overall neatness, correctness of spelling, legible handwriting, and precision in following directions. There were, in fact, quite noticeable differences in this respect across the three samples, with the Italian students often departing in rather creative ways from the directions in answering the questions. Thus, some part of the strength of the stereotype produced by the Irish students may possibly be assigned to the fact that they simply took the task more seriously, conscientiously producing all ten adjectives asked for. (Many of the subjects numbered the adjectives.)

Second, and related to this, the Irish students appeared to be the most fluent or literate of the three groups in terms of their language proficiency. Inspection of the list of adjectives generated by the Irish students is like looking at a lexicon of the English language. It would seem, in fact, that the Irish students took the task of producing ten adjectives almost as a personal challenge, and approached it with zest and zeal. This is especially interesting in light of the fact that the "INFP" type is described by the MBTI manual as having a "gift of language and expression". If richness of vocabulary is a valid measure of a facility for language, then it received some support in this research. It is entirely possible, however, that this finding is due, not to cultural, but to social class differences. It will be recalled that the socioeconomic status of 
the Irish students as a group was higher than that of either the Italian or the American students.

It was also previously noted that the nature or type of adjective used differed from group to group. The adjectives generated by the Irish students appeared to reveal, for the most part, a higher level of abstraction and depth of perceptiveness in their approach to personality trait description, a tendency also consonant with the higher prevalence of "introverted intuitive" types among the Irish students, a type characterized by their liking for the theoretical and abstract. Italian students, a higher proportion of whom were "ST" types, and American students, who tended to "SF" types, on the other hand, gave stereotypes in much more concrete and down-to-earth terms - physical characteristics, in the case of the American students, or specific and somewhat superficial social behaviors in the case of the Italian students (Catholic, "drinkers", "happy", "spendthrift", etc.)

Thus, in interpreting the differences among the groups on the strength and nature of stereotypes produced, it should be borne in mind that a stereotype may reveal much more about the person who produces it than about the person to whom it refers. In other words, it is possible that the open-ended question eliciting heterostereotypes functioned somewhat like a "projective technique", revealing what kinds of traits were salient for the stereotyper. In addition, it appears that both in approach to the task itself, and in the nature of the answers, cultural differences were revealed.

It should also be mentioned in passing that there were no controls built into this study to assure that subjects produced their own 
privately-held stereotype, rather than a stereotype - that is, the culturally held caricature of a given group. Although the intent of the question was to elicit the subject's own view of the target group, it appears that some students made the alternative interpretation and produced, instead, the "cultural stereotype". Thus some American students appeared to be free-associating to the stimulus words in an almost whimsical fashion, casting doubt about the degree to which the answer reflected personal views. One such student wrote about the Irish: "IRA, lucky, potatoes, Boston cop, politician, Irish pub, Catholic, temper, thick-headed", and about Italians, "Pasta, wine, Mafia, cities, crime, Catholic, emotional, good cooks, black suits". Future research should, it is feld, address more carefully the question of exactly what is being elicited from a subject when $s /$ he responds to a request to produce a stereotype.

In spite of these reservations, however, it is apparent that some clear stereotypes did emerge that represented the actual views of the subject.

(2) Were there sex-related differences in the nature of the stereotypes produced?

This question could not be definitively answered due to the relative small frequencies of subjects who used exactly the same of a highly synonymous word. Sex comparisons on the basis of such small numbers would not be very valid. However, in the cases where words or their synonyms were produced in sufficientiy large numbers to make legitimate comparisons possible, no sex differences were found in any of the groups. 
(3) (The question pertaining to ethnic differences in stereotyping or in self-perceptions - that is, in Irish-American students versus Italian-American students - was dropped from the study due to smal1 numbers and very uneven sex proportions of subjects who met the criterion for ethnicity.)

\section{Self-Perceptions}

In this study it was predicted that: (1) Irish and Italian students would show greater homogeneity in the distributions of their self-perceptions than would American students. It was also predicted that: (2a) Italian students would, as a group, show a greater frequency of "extraverted, sociable, sensing" types; (2b) Irish students would, as a group, show a greater frequency of "introverted, emotionally controlled, intuitive" types; and (2c) American students, as a group, would not depart significantly from the heterogeneous distributions of AVA and MBTI types found in the U.S. normative samples.

The prediction of homogeneity in the distributions of their selfperceptions was borne out to a striking degree in the case of the Italian sample, and to a much more limited extent in the case of the Irish sample. The American sample, though showing some clustering in their distributions on the AVA and MBTI measures, nevertheless approached more closely the heterogenetiy of the normative samples.

On the AVA measure, $84 \%$ of the Italian sample was accounted for in two tight clusters on the pattern universe. One of these clusters formed around PS 5717, and drew 56\% of the Italian sample (as opposed to $11 \%$ of the U.S. normative sample). AVA PS 5717 describes the active, socially outgoing person who, however, beneath a facade of 
social poise, may be more logical and deliberative than appears. On the MBTI measure, four of the 16 cells of the MBTI type table drew $64 \%$ of the Italian sample, as opposed to $24 \%$ for the normative sample of U.S. college students. These four cells all shared the "ST" or "sensing/thinking" dimensions. These dimensions describe the practical, down-to-earth, logical individual. Thus, with respect both to the prediction of greater homogeneity and the prediction that there would be more "extraverted, sociable, sensing" types in the Italian sample, confirmation was found in these data.

The Irish sample, on the other hand, showed a more complex pattern in the distributions of their self-perceptions. Exactly equal proportions $(26.48 \%$ each) were found in two clusters on the AVA pattern universe, one formed around PS 3449, and the second around PS 5717. Membership in these two clusters accounted for $53 \%$ of the total Irish sample as opposed to $28 \%$ in the U.S. normative sample. AVA PS 3449 describes the quiet, humble, unassuming, dependent type of person, whereas PS 5717, previously described as the modal AVA pattern for the Italian students, is the outgoing, active, socially confident individual.

On the MBTI measure, approximately $43 \%$ of the sample clustered into three cells of the MBTI type table, as opposed to the $25 \%$ of the U.S. normative sample who were represented in these three cells. All three cells share the "N" or intuitive and "P" or perceptive, dimensions of the Jungian typology. Thus, the Irish sample as a whole was more introverted, intuitive, and perceptive than the other samples, although it should be noted that introversion was a more 
prominent aspect of the self-perceptions of Irish males (74\%) than of Irish females (57\%). These data thus provide confirmation of the prediction that the Irish sample would be more homogeneous in the distribution of their self-perceptions, though clearly they were less so than the Italian sample. The prediction of a greater frequency of introverted, intuitive types was supported by their MBTI distribution, but the prediction of emotional control was not supported by the AVA distribution.

Final1y, the prediction with respect to the greater heterogeneity of the American sample distribution was only partially confirmed. On the AVA measure, four clusters were formed by the American sample which accounted for $80 \%$ of the sample, as opposed to $41 \%$ of the U.S. normative sample found in these four clusters. However, only one of these clusters, represented by PS 3539, drew an appreciable percentage $(35 \%)$ of the American sample. The other three clusters represented about $15 \%$ each of the total sample. AVA PS 3539 describes the quiet, humble, unassertive person previously discussed.

On the MBTI measure, the American sample showed a slight but significant tendency to cluster into the "SF" region of the type table, but this clustering was much less pronounced than in the cases of the Irish and Italian samples. Three MBTI cells ("NP" types) accounted for $43 \%$ of the Irish sample; four cells ("ST" types) accounted for $64 \%$ of the Italian sample; and three cells ("SF" types) accounted for $25.5 \%$ of the American sample.

Thus, about a quarter of the American sample showed a tendency toward "sensing/feeling" types on the MBTI and about $35 \%$ of the sample 
tended to describe themselves as the "quiet, unassuming type" of person on the AVA measure. To this extent, the prediction of heterogeneity in the American sample distributions was not supported.

The predictions with respect to within-group similarties in the self-perceptions of Irish and Italian students were made on the basis that the Irish and Italian cultures are more homogeneous with respect to nationality, and, to a lesser extent, socialization practices, than is the American culture. Since it is assumed that, in addition to other factors, there are strong cultural influences on the formation of an individual's self-perception, socialization into a fairly cohesive culture should be reflected in a greater degree of within-group similarity in the self-perceptions of members of that culture. To the extent that, in addition, the agents of socialization within a given culture (e.g. family, church) are strongly organized and in consensus about the values to be transmitted, there is further reason to expect greater homogeneity in self-perceptions of cultural group members.

The results obtained in this research were, of course, based on samples of college students and the question of how representative these samples are of the three cultural populations from which they were drawn constitutes a severe limitation on the interpretations which can be made of these data. If it is assumed that these results do, in fact, reflect population characteristics, the high degree of homogeneity in the self-perceptions of Italian students and the greater proportion of "extraverted, sensing/thinking types" come as no surprise to those familiar with the literature on Italian "familism" 
(Ban field, 1958; Gambino, 1974; et a1.). The conservative and highly structured nature of Italian family life or "l'ordine della famiglia" could never be maintained without a high degree of planning, foresight, orderliness, and committment to preordained values that characterize the "judging" and "thinking" types. Further, family socialization practices, with their high degree of consensus regarding the values to be transmitted tend, in themselves, to perpetuate similarities. One of the values stressed is that of loyalty and committment to the family as a group rather than acting in behalf of one's personal interests. This kind of socialization is not apt to encourage the development of individual differences or departure from group values. The strength and cohesiveness of family life, as Gambino, Banfield, and others have pointed out, has had historical survival value for the Italian people in a culture marked by a long struggle against poverty, foreign invasions, political oppression, etc.

The Irish students in this study, although not as homogeneous in the distributions of their self-perceptions as were the Italian students, did show, however, a decidedly greater degree of homogeneity than either the American sample or the U.S. normative sample, on the MBTI measure. The prediction that there would be a greater incidence of "introverted intuitive" types in the Irish sample was rather well supported in this study. The prevalence in the Irish sample of introverted, intuitive, feeling, and perceptive types also appears to be consonant with certain traits widely attributed to the Irish people e.g. their love of language and gift for expression, scholarship, and possibly, their celibacy and sexual repressiveness (cf. Scheper-Hugher, 1979). 
The greater homogeneity in the distribution of MBTI types for the Irish sample may possibly reflect, in part, the greater cohesiveness of the Irish culture as compared with the diverse, multiethnic culture of the United States. Although Irish family norms do not appear to be as strongly structured as are Italian family norms, they do appear to be a good deal more so than in the United States. Further, the strong identification of the Irish with Roman Catholicism probably provides another powerful agent of socialization within the culture which tends to promote a greater homogeneity in self-perceptions.

Finally, the American sample, while showing less homogeneity in distribution of self-perceptions than either the Italian or Irish samples, nevertheless departed significantly from the heterogeneity of the wider normative sample of U.S. college liberal arts college students.

It will be recalled that the modal AVA self-perception of the American sample depicted a rather quiet, unassuming, dependent, and non-assertive individual. The distribution of the sample on the MBTI measure showed a greater-than expected frequency of "SF" types. This suggests that the American sample may have been atypical of the population from which the normative sample was drawn. It is likely, in fact, that students at the Community College of Rhode Island have a more practical orientation and more interest in direct preparation for a career in human services or business fields rather than in more abstract and theoretical fields, likely to attract "ivy league" college students. 
Relationship of Heterostereotypes to Autostereotypes and Self-Perceptions

The final predictions made in this study concerned the relationship between national stereotypes and self-perceptions. It was specifically predicted that some elements in the heterostereotypes of these three groups would show correspondence with their autostereotypes; and that both would show some correspondence with self-perceptions.

Direct comparisons of heterostereotypes either with autostereotypes or self-perceptions was difficult because of the different ways in which the three variables were measured. In a general way, however, the specific content of the heterostereotypes produced showed a moderate to quite low degree of correspondence with either autostereotypes or self-perceptions.

The heterostereotypes of the Irish as "Catholic" and/or devout, drinkers, and hot-tempered were characteristics ascribed to the Irish by both the Italian and American samples. Data on religious preference and church attendance confirms this rather obvious perception of Irish Catholicism and/or devoutness. (As it happens, the stereotype of the Irish as drinkers is in agreement with what has been reported elsewhere - in the literature of the social sciences, for example - detailing the fact that though per capita consumption of alcohol is lower for this group than for other groups - e.g. Italians - the rate of alcoholism among the Irish is notably high.) The trait of "hot temper" was in agreement with the Irish autostereotype - $59 \%$ of both Irish males and Irish females described the typical member of their cultural group as 
"argumentative". A rather small percentage of Italian students held that the Irish were introverted, which, according to the MBTI scale measuring this dimension, as a group, these students tended to be.

The American students, on the one hand, and the Irish students on the other, produced stereotypes of the Italians which showed very little agreement either with each other, with the Italian autostereotype or with the self-perceptions of Italian students, with the possible exception of the word "romantic" which was used by all three groups in describing Italians.

In particular, the picture of the "typical" Italian as emotionally expressive, volatile, temperamental, etc. received scant support from MBTI scores for these students showing a high preponderance $(80 \%)$ of "thinking" and "judging" types in the Italian sample. The tendency to make judgments based on logic and facts, and to prefer an orderly and systematic life style is not consonant with the stereotype of an impulsive, spontaneous people. The trait of sociability was, however, reflected in the stereotype of the Italians and this is to be expected on the basis that stereotypes reflect more "public" and superficial behaviors.

Finally, the Irish heterostereotype of Americans as idominant aggressive, competitive, etc. was in fairly good agreement with the American students' autostereotype of themselves but in very poor agreement with their modal self-perception. The heterostereotypes of the Americans by the Italian students also showed fairly low agreement with either American autostereotypes or self-perceptions. There is very little in the data to suggest, for example, that these American 
students perceived themselves, either as a group or individually, as "happy" - the word used most frequently about them by Italian students.

In short, the heterostereotypes produced in this research by the three groups about each other do not appear to show much more than a very small degree of agreement either with group autostereotypes or self-perceptions of group members.

Three possible reasons for this lack of agreement suggest themselves. First and foremost, the stereotype elicited was of the "typical" or "average" member of the target group, whereas the autostereotypes and self-perceptions to which they were compared were those of young college students. In terms of age and educational status (and, in the case of the Irish students, socioeconomic class), these samples may well have been atypical of the larger populations from which they were drawn.

Second, Irish and Italian students apparently stereotyped each other and Americans on the basis of rather limited contacts with members of these cultures. In fact, in response to the open-ended question asking the subject to estimate the amoung of personal contact $s /$ he had had with members of the groups to be stereotyped, many Irish and Italian students mentioned tourists, television, and "foreign students" as the nature of this contact. Thus the stereotypes of the Irish and Italians produced about each other and about Americans may well have been based on atypical members of the stereotyped cultures. American students, on the other hand, may well have stereotyped Irish and Italians on the basis of contacts with Italo-Americans and IrishAmericans, rather than Italian and Irish nationals. 
Finally, as mentioned previously, heterostereotypes were measured with the use of open-ended questions whereas both autostereotypes and self-perceptions were measured with forced-choice instruments, and the differences in these formats created problems in direct comparison.

A11 of these limiting factors suggest the need for greater refinements in the measurement of stereotypes in future research.

In addition to the predictions just examined this study also examined the relationship between autostereotypes and self-perceptions. This was done in two ways: modal AVA autostereotypes were compared for each group with their modal self-perceptions, and the three groups were compared on the patterns which emerged when each subject's AVA stereotype was individually correlated with his/her self-perception.

The highest degree of correspondence between autostereotype and self-perception was found in the Italian sample. Seventy-three percent of the Italian sample selected AVA PS 5915 as their picture of the "typical Italian"; fifty-six percent of the Italian sample selected AVA PS 5717 as their self-perception. The correlation between these two patterns is $r=.87$. It is interesting to note that the Italian autostereotype (PS 5915) focuses on more superficial and public behaviors, whereas the modal self-perception (PS 5717) describes, in part, less visible or "inner traits". Both patterns describe the outgoing, extraverted person who is at ease with the social environment and well able to cope with it. The autostereotype, however, further stresses the ability to manipulate the environment in a forceful and effective way in furthering personal interests. The modal self-perception, 
though also describing a socially adept person, suggests the presence of less visible "traits" e.g. - the drive for perfection and for logical answers. This finding appears to support the validity of these measures since an autostereotype should, by definition, describe visible, public, superficial traits whereas the self-perception whould describe the "real inner person". Further, one would expect more group consensus on the autostereotype than on self-perceptions, and this was, indeed, found.

The high degree of agreement between the modal autostereotype and the modal self-perception of the Italian students is also of interest since it suggests that valid cultural differences were reflected in these measures. Italian culture is, by all accounts, cohesive and highly structured. One of its central values is the ideal of effectively dealing with the social environment in furthering one's personal interests (cf. Gambino, 1974). This high degree of consensus on the values transmitted, as well as the effectiveness of the socialization practices themselves, appears to be reflected in the correlations between the autostereotypes and the self-perceptions of these students. Eighty-four percent of the Italian sample had correlations between the two measures which ranged from .40 to 1.00 , and over half the group (52\%) had correlations of .80 or greater (refer back to Table 24 for a summary of these data). This is to be expected in a cultural group in which socialization practices stress conformity to a public image and loyalty to group rather than individual values (Gambino, 1974). A much more complicated pattern was found in the Irish sample. Whereas in both the American and Italian samples a clear majority agreed 
upon a modal stereotype, in the Irish sample three autostereotypes emerged which drew about equal percentages of the sample (25\% to 29\%). It thus appears that these Irish students could not agree on their picture of the "typical Irish person". AVA PS 3539 was chosen by $28.5 \%$ of the sample and describes the anxious, insecure, unassertive type of person. AVA PS 5717 chosen by $29.5 \%$ describes the socially adept, active, coping individual with an inner drive for perfection and truth. AVA PS 3944 , chosen by $25.8 \%$ as the autostereotype, describes the very extraverted and socially facile person who is active and competent in promoting his/her own interests and the interests of others. A similar diversity was seen in the Irish self-perceptions, with $28 \%$ selecting PS 3499 , 28\% selecting PS 5717 , and $12 \%$ selecting PS 5942 . Inspection of Table 25 shows that the correlations between the three most frequently occuring autostereotypes and the three most frequently ocuring self-perceptions for the Irish sample were extremely high. When, on the other hand, the pattern of individual correlations between autostereotype and self-perception was examined, the Irish students were found to be intermediate between the higher degree of congruence for Italian students and the lower degree of congruence for American students. Sixty-two percent of the Irish sample had correlations between .40 and 1.00, compared to $84 \%$ of the Italian students and $49 \%$ of the American students.

These data suggest that the majority of Irish students, as individuals, hold self-perceptions which are in moderate to strong accord with their picture of the "typical member" of their culture, but the 
Table 25

Comparison of Modal AVA Autostereotypes with Modal AVA Self-Perceptions for Irish, Italian and American Students

\begin{tabular}{|c|c|c|c|c|}
\hline $\begin{array}{c}\text { AVA } \\
\text { "Autostereotype" }\end{array}$ & $\begin{array}{c}\% \\
\text { of group }\end{array}$ & $\begin{array}{c}\text { AVA } \\
\text { "Self" }\end{array}$ & $\begin{array}{l}\% \text { of } \\
\text { group }\end{array}$ & $\begin{array}{l}r \text { between } \\
\text { auto and self } \\
\end{array}$ \\
\hline \multicolumn{5}{|c|}{ Irish Students } \\
\hline 3539 & 28.5 & 3449 & 28 & .96 \\
\hline 5717 & 29.5 & 5717 & 28 & 1.00 \\
\hline 3944 & 25.8 & 5942 & 12 & .84 \\
\hline
\end{tabular}

Italian Students

5915

73

5717

56

.87

5519

26

3539

28

.87

American Students

7616

66

3539

35

.35

4439

25

6716

16

.41 
students as a group are rather sharply split as to what this "typical member" is like.

It is possible, although of course strictly speculative, that the political history of the Irish people accounts for this finding of differing images. The political separation of Ireland from Great Britain occurred rather recently when the Republic of Ireland Act was passed in 1948 and "provided for Ireland's complete freedom from Great Britain." In practice, however, as Dr. Leo Carrol1 ${ }^{1}$ has suggested, Ireland's ties with Great Britain continue to be pervasive, complex, and ambivalent. It is possible, then, that a clear-cut and widelyheld sense of national identity has yet to emerge in this rather young Republic.

The lowers degree of agreement between autostereotypes and the self-perception was found in the American sample. This was true both for the modal patterns for the group as a whole, and for the pattern of correlations between individual profiles. Although American students as a group showed moderately strong consensus in their picture of the "typical American" (66\% chose AVA PS 7616 as the autostereotype), the modal self-perception for the group, PS 3539, correlates only $r=.35$ with this profile. AVA PS 7616 describes the "typical American" as a tense, highstrung, driven person - a picture somewhat congruent with the Irish stereotype of Americans as ambitious, aggressive, and hardhitting. AVA PS 3539, the modal American self-perception,

${ }^{1}$ Dr. Leo Carro17, Department of Sociology, University of Rhode Island in a personal communication. 
describes an unassertive, anxious, insecure and meek type of person qualities certainly at variance with the autostereotype. The sharp discrepancy between the "typical American" and the self-perceptions of these college students is further underscored by the pattern which emerged when individual correlations were examined. Forty-nine percent of the students had correlations ranging from .40 to 1.00 between the AVA "role" and the AVA "self" profiles, but nearly a third of the sample (31.5\%) had correlations ranging from .00 to -1.00 . Both the moderately high degree of consensus in the selection of the autostereotype and the diversity in self-perceptions is to be expected on theoretical grounds. The fact that sixty-six percent of the group agreed on an autostereotype as well as the content of the stereotype itself. suggests once again the validity of the measure. The diversity in self-perceptions is also to be expected in a multiethnic culture in which one of the few agreed-upon values is a stress on competitiveness and individualism.

Two alternative reasons suggest themselves in explaining the rather substantial proportion of students who saw themselves as quite different from the "typical American". One possibility is that these junior college students are, as a group, insecure and low in selfesteem. Community College of Rhode Island, from which the majority of the sample was obtained, was formerly known as Rhode Island Junior College or, more popularly, as "Reject" - and, unfortunately, this image of a "reject" is one which quite a few of the students appear to have internalized. Thus a majority of these students see the typical American as aggressive and competitive, but see themselves as meek 
and unassertive. A second, less likely, possibility is that the low correlations between the "typical American" and the "real self" represent a rejection of, or alienation from, "cultural mores" as they are perceived by these students.

In conclusion, this study found some support from the prediction of cultural differences in self-perceptions. It cannot be too strongly emphasized, however, that neither the similarities within groups nor the differences between groups, should be overstressed. In the face of the bewildering complexity of individual differences, psychology as a science attempts to simplify and generalize in order to provide useful explanatory and predictive constructs. In this kind of nomothetic approach, specific instances and exceptions in general rules are minimized. It is most certainly not the case that the richness, complexity, and uniqueness of human personality can be captured by classification into a few "types" or explained on the basis of a handful of traits.

Just as the similarities within groups in this study should not be overemphasized, neither should the differences that were found between groups. Although the results of this study indicate that the concept of "modal self-perception" within cultures may be a fruitful one in terms of future research, the deeply pervasive similarities shared by all human beings should not be overlooked. The point was, perhaps, best made by one of the subjects in this research who, when asked to describe the "typical member" of the other two groups wrote, simply, "human". 


\section{APPENDIX I}

Copy of Test Instruments:

forms for American Sample 
$\frac{\sqrt[5]{\circ}}{\frac{5}{5}}$

뭉

竞

ㅇํำ

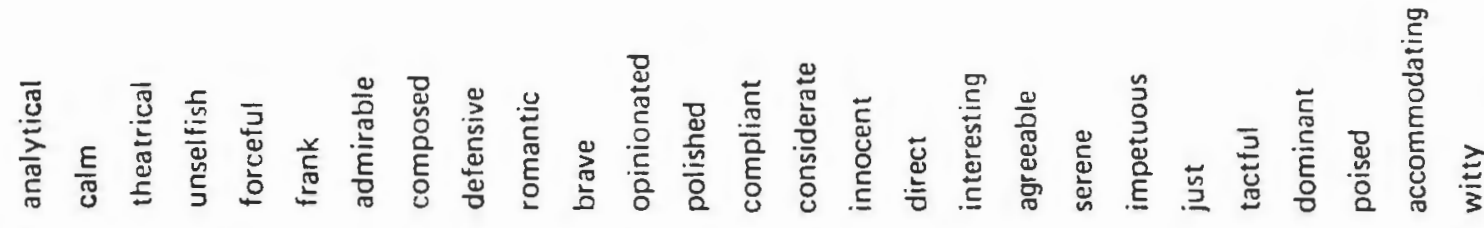
要客

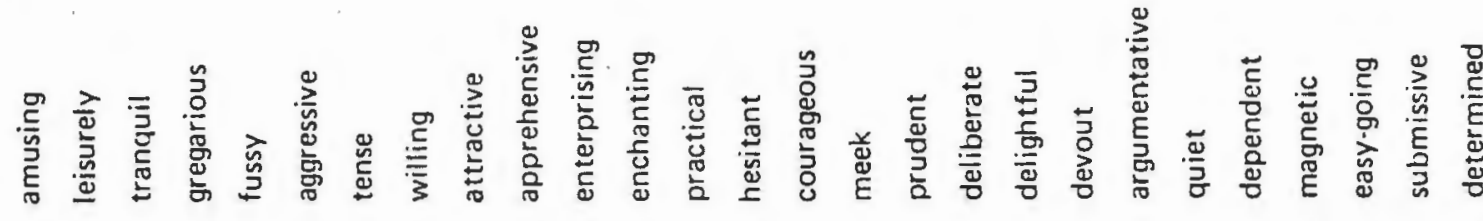
$\times \stackrel{2}{2}$

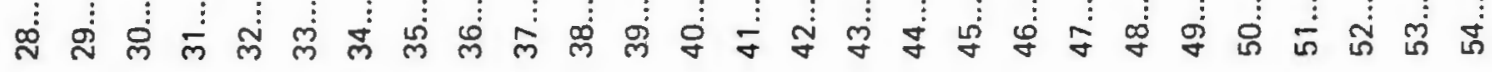

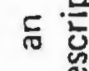
$\stackrel{8}{8}$

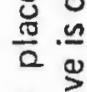
产章

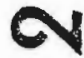

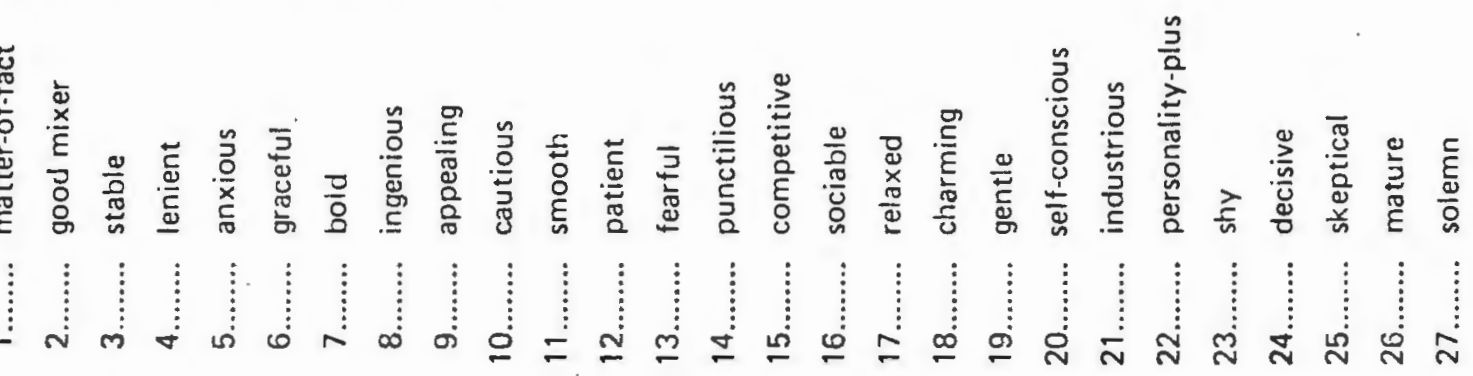

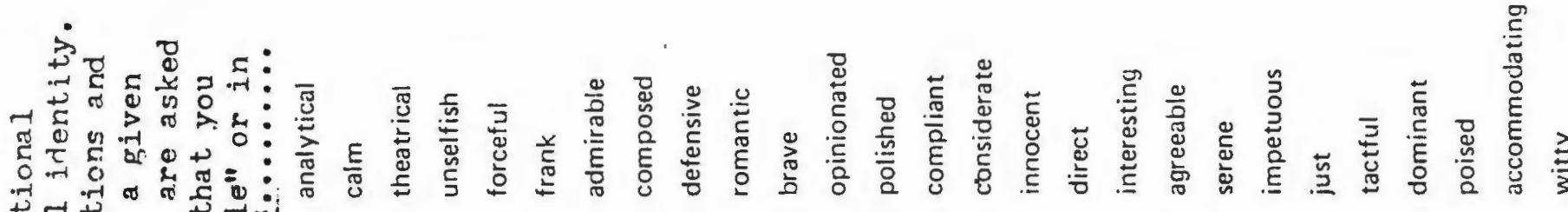

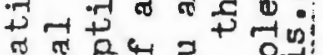
等

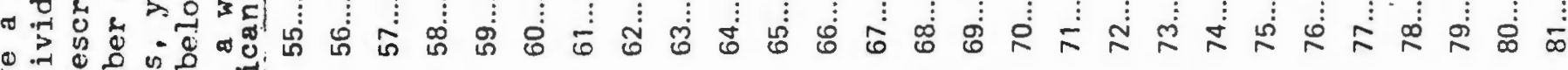

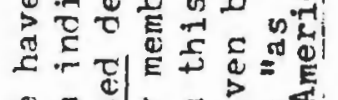

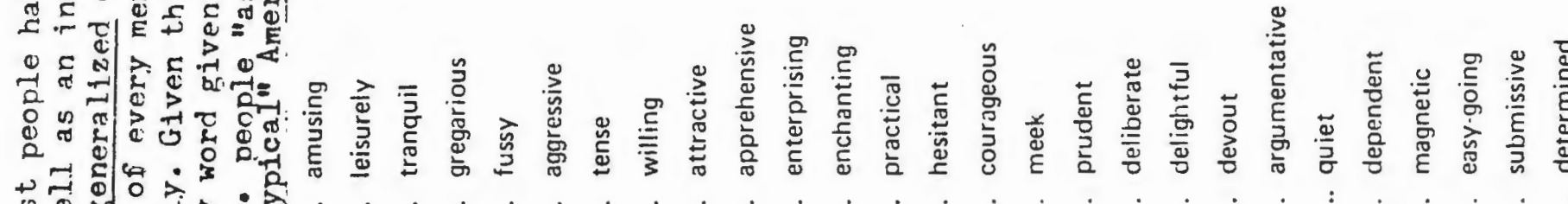

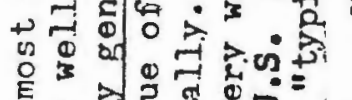

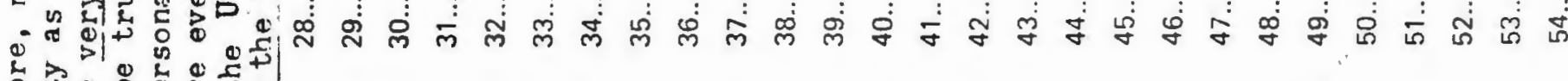

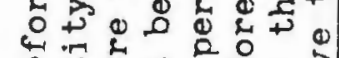

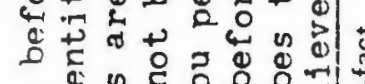

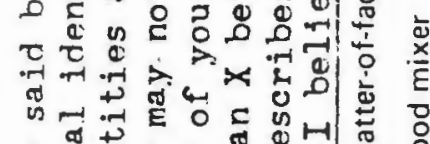

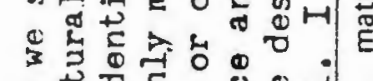

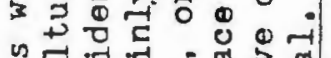
$<$ 政

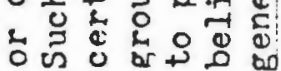



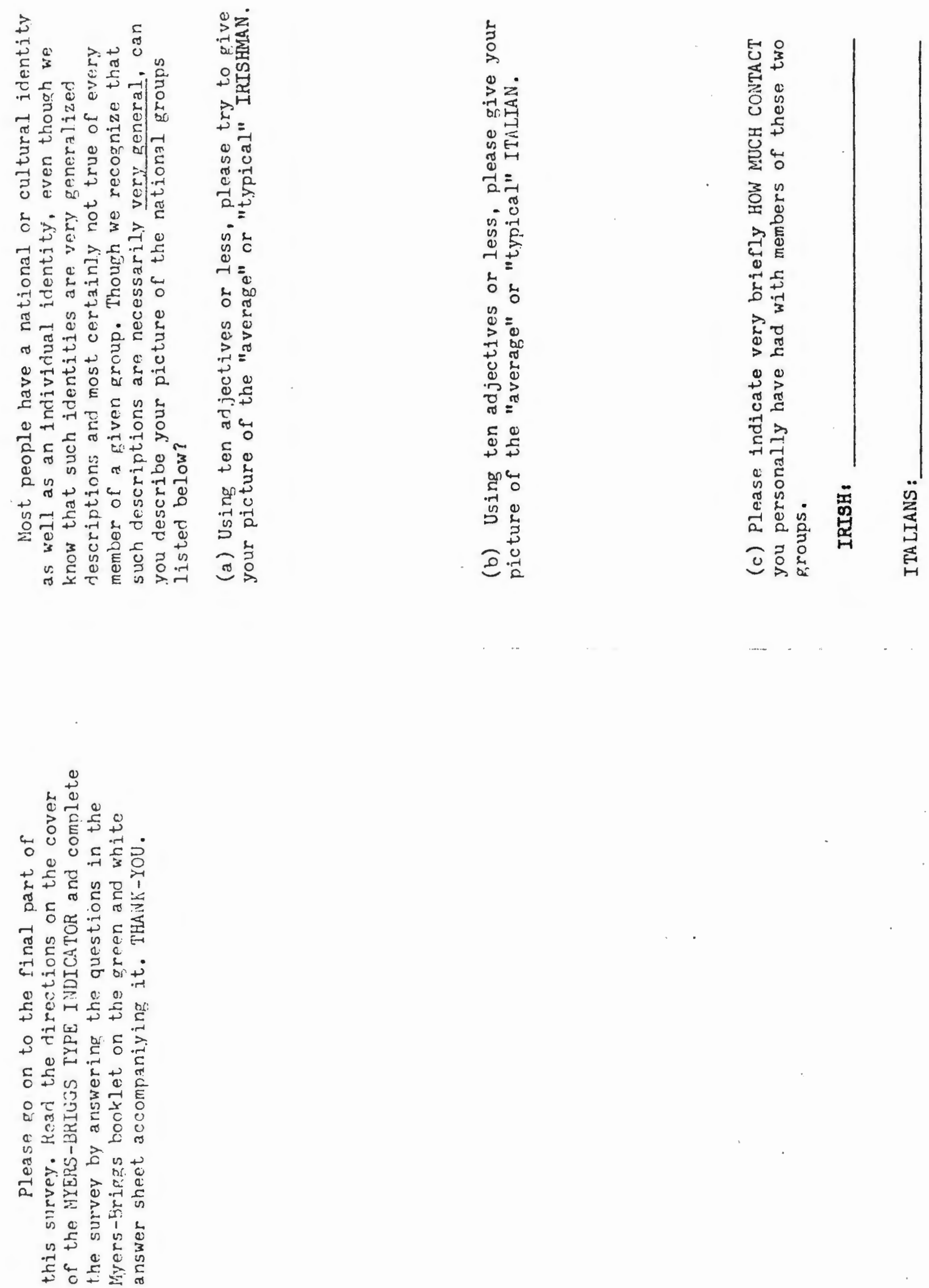
TO THE RESPCNDNNT:

Your particinztion in this cross-cultural study is helping to make a contribution of notentially ereat value to cur knnwledge of the world community to which we all belong. Your homest responses to the quastions contained in the hooklet you have just received aro vory imnortant to the success of this resaarch. The personal time and effort you aro ganerously contributing to the success of this study is zatiefully acknowledgot.

Please comolete the information requested below and on the back of this shert and then oroceed to follow the directions given.

$\underline{P A R} I_{2}$ THA NK-YOUI

AGE $\operatorname{SEX}$ COUNTRY OF BIET: CITIZEN CE:

Year of Undergraduate College You are PresentIy Comnloting: FRESHYAN: SCPHCRCRE : JUNTOR: SENIOR: OTHER:

Marital Status:

SINGLE:

MAR:IIED:

WIDCNED:

DIVCACED:

SEPARATED:

REIIGIOUS AFEIIIATICV:

Church Attendance:

DAIIY: WESTIY: yonThL: SEVERA ITMES A YEAR: NEVER:

PAKENT:S: CCUNTRY CE BIRTH: CCCUPATICN: IDUCAIICN: "umber of years of formal school completed:

GRANDPARENTS: CCINTIY CF EIATH:

NATIONALITY:

NOTHE:

'S FATHER:

NCTHE: :

S FATFE: 
MUCY SELSW AVEHAGE BELON A VEQMGE

AVERASE

A SOVE AVERAG VCE ABOVE AVERAGE

You have just completer Part I. Please go on to Part II. which is the small folded sheet markerNATICNhI GROUP PEKCPTIOAS. Complete the answers to the questions on the booklet cover and on the inside of the booklet. Then go on to answer the questjons in the large booklet titled: MYEAS BRIGSS TYPE INDICATOR. For this section only mark your arswers on the accomnanying answer sheet. THANH-YOUl 


\section{REFERENCES}

Abate, M. \& Berrien, F. K. Validation of stereotypes: Japanese versus American students. J. Persona1. \& Soc. Psy., 1967, ㄱ, 435-438

Adler, Leonare Loeb, editor Issues in Cross-Cultural Research. Annals of the New York Academy of Sciences, Vo1. 285, 1977

Adorno, T. W., Frenke1-Brunswik, E., Levinson, D. J., and Sanford, R. N. The Authoritarian Personality. New York: Harper and Brothers, 1950

Arensbert, Conrad The Irish Countryman. New York: The Natural History Press, 1937

Banfield, Edward C. The Moral Bas is of a Backward Society. New York: The Free Press, 1958.

Barnouw, Victor Culture and Personality. Illinois: The Dorsey Press, 1979.

Benedict, Ruth Patterns of Culture. Boston: Houghton-Mifflin, 1934.

Bourne \& Ekstrand, Psychology. New York: Holt, Rinehart, \& Winston, 1976.

Brigham, J. C. Ethnic Stereotypes. Psychological Bulletin, 1971, 76, 15-38.

Bryan, Walter The Improbable Irish. New York: Taplinger Publishing Company, 1969.

Buros, Oscar K. Eighth Mental Measurement Yearbook. Vo1. 1, New Jersey: The Gryphon Press, 1978.

Butcher, James and Pancheri, Paolo A Handbook of Cross-Cultural MMPI Research. Minneapolis: University of Minnesota Press, 1976.

Clarke, Walter V. Aids to Interpretation of AVA. Providence: Walter V. Clarke Associates, 1953.

Clarke, walter $V$. The construction of an industrial selection test. The Journal of Psychology, 1956, 41, 379-394.

Clarke, Walter $V$. Correlation Tables: AVA Pattern Universe. Providence: AVA Publications Inc., 1958.

Clarke, Walter V. Manual for Activity Vector Analysis. Providence: Walter V. Clarke Associates, Inc., 1973. 
Gal10, Patrick J. Ethnic Alienation: The Italian-Americans. New Jersey: Fairleigh Dickinson University Press, 1974.

Gambino, Richard Blood of My Blood. New York; Anchor Press, 1974.

Gilbert, G. M. Stereotypes, persistence, and change among college students. Journal of Abnormal and Social Psychology, 1951, 46, 245-254.

Glazer, N. Moynihan, D. P Beyond the Melting Pot. Cambridge, Mass.: The M.I.T. Press, 1970 .

Greeley, A. M. \& McCready, W. C. The Transmission of Cultural Heritages: The Case of the Irish and the Italians, in Ethnicity: Theory and Experience, edited by Glazer \& Moynihan, Cambridge, Mass: Harvard University Press, 1975.

Hasler, Kermit \& Merenda, Peter F. Sex correlates of Adjectives in the Current Activity Vector Analysis, Perceptual and Motor Ski17s, $1978,47,1115-11119$.

Heath, Douglas H. Maturity and Competence: A Transcultural View: New York: Gardner Press Inc., 1977

Hilgard, Atkinson, \& Atkinson Introduction to Psychology, 7th edition. New York: Harcourt, Brace \& Jovanovich, Inc., 1979.

Honigman, John J. Personality in Culture. New York: Harper \& Row, 1967.

Inkeles, A. \& Levinson, D. J. National Character: the study of modal personality and sociocultural systems. In Lindzey \& Aronson, E. editors, The Handbook of Social Psychology, Volume 4. Mass.: Addison-Wesley Publishing Co., 1969.

Kaplan, Bert. Illinois: Row, Peterson and Co., Studying Personality Cross-culturally, 1961.

Karlins, M., Coffman, T. L., \& Walters, G. On the fading of social stereotypes: Studies in three generations of college students. J. of Personality and Social Psychology, 1969, 13, 1-16.

Katz, D. \& Braly, K. Racial stereotypes in one hundred college students. Journal of Abnormal \& Social Psychology, 1933, 28, 280-290.

Levine, Robert A. Culture, Behavior and Personality. Chicago: Aldine Publishing Company, 1973.

Lippmann, W. Public Opinion. New York: Harcourt, Brace, 1922. 
Malinowski, Bronislaw Sex and Repression in Savage Societies. London: Routledge and Kegan Paul, 1953. (First published in 1927.)

Maraspini, A. L. The Study of an Italian Village. Paris: Mouton \& Company, 1968.

Mead, Margaret From the South Seas. Studies of Adolescence and Sex in Primitive Societies. New York: William Morrow, 1939.

Mead, M. The cross-cultural approach to the study of personality. In J. L. McCary (Ed.), Psychology of Personality. New York: Grove Press, 1956.

Merenda, Peter F. \& Berger, Stanley Further Evidence of the construct validity of the AVA. J.Clin. Psych., 1978, 34, 665-666.

Merenda, Peter F. \& Clarke, Walter V. Factor analysis of a measure of the social self. Psychol. Reports, 1959a, $\underline{5}, 597-605$.

Merenda, Peter \& Clarke, Walter $V$. The predictive efficiency of temperament characteristics and personal history variables in determining success of 1 ife insurance agents. J. of Applied Psychol., 43, No. 6, 1959b.

Merenda, Peter F. \& Clarke, Walter V. A further note on the selfperceptions of management personal and line workers. Engineering \& Industrial Psychol., vol 1, no. 1, 1959c.

Merenda, Peter F. \& Clarke, Walter V. Personality profiles of selfmade company presidents - a second look. Engineering \& Industrial Psychology, Vol. 1, No. 3, 1959d.

Merenda, Peter F. \& Clarke, Walter V. Self-description and personality measurement, $\mathrm{J}$. of Clinical Psychology, Vol XXV, No. 1, 52-56, January, 1965.

Merenda, Peter F. \& Migliorino, G. \& Clarke, Walter Self-perceptions of the Sicilian male youth. Perceptual and Motor Skills, 1972, 34, 75-78.

Middlebrook, Patricia N. Social Psychology and Modern Life. New York: Alfred A. Knopf, 1974 .

Mindel, Charles H. \& Habanstein, Robert W., editors. Ethnic Families in America. New York: Elvesier Scientific Publishing Co., 1977.

Myers, Isabel Briggs The Myers-Briggs Type Indicator, (Test Manual), Californis Consulting Psychologists Press, Inc., 1962.

01medo, Esteban, Acculturation: A psychometric perspective. American Psychologist, 1979, 34, No. 11, 1067-1070. 
Opler, M. K. and Singer, J. L. Ethnic differences in the behavior and psychopathology: Irish and Italians. International Journal of Social Psychiatry, VoT. II, No. 1, Summer 1956.

Osgood, C. E. Focus on Meaning. The Hague: Mouton, 1976.

Scheper-Hughes, Nancy Saints, Scholars, and Schizophrenics. Berkley: University of California Press, 1979.

Schuman, H. Social Change and the validity of regional stereotypes in East Pakistan. Sociometry, 1966, 29, 428-440.

Stodolsky, S. S. \& Lesser, G. Learning Patterns in the Disadvantaged. Harvard Educational Review, 37, No. 4, Fa17, 1967.

Sue, S. \& Kitano, H. L. Stereotypes as a measure of success. Journal of Social Issues, $1.973,29$, No. 2, 83-98.

Szalay, Lorand B. \& Deese, James Subjective Meaning and Culture. New Jersey: Lawrence Erlbaum Associates, Publishers, 1978.

Triandis, H. C. New York: Wiles \& Sons, 1972. The Analysis of Subjective Culture.

Triandis, Harry C. \& Lambert, W. W. (editors), Handbook of CrossCultural Psychology, (Perspectives, Vol. 1) Boston: Allyn \& Bacon Inc., 1980.

Traindis, H. C. \& Vassiliou, V. Frequency of contact and stereotyping. Journal of Personality and Social Psychology, 1967, $7,316-328$.

Vinacke, W. E. Stereotyping among national-racial groups in Hawai : A Study in ethnocentrism. Journa T of Social Psychology, 1949. 30, 265-291.

Wallace, Anthony F. C. Culture and Personality. New York: Random House, 1970. 